\title{
Phase Uncertainty in Digital Holographic Microscopy Measurements in the Presence of Solution Flow Conditions
}

\begin{abstract}
Alexander S. Brand
National Institute of Standards and Technology

Gaithersburg, MD 20899, USA

alexander.brand@nist.gov

Digital holographic microscopy (DHM) is a surface topography measurement technique with reported sub-nanometer vertical resolution. Although it has been made commercially available recently, few studies have evaluated the uncertainty or noise in the phase measurement by the DHM. As current research is using the DHM to monitor surface topography changes of dissolving materials under flowing water conditions, it is necessary to evaluate the effect of water and flow rate on the uncertainty in the measurement. Uncertainty in this study was concerned with the temporal standard deviation per pixel of the reconstructed phase. Considering the effects of solution flow rate, magnification, objective lens type (air or immersion), and experimental configuration, measurements under static conditions in air and in water with an immersion lens yielded the smallest amount of uncertainty (mean of $\leq 0.5 \mathrm{~nm}$ up to $40 \times$ magnification). Increasing the water flow rate resulted in an increase in mean uncertainty to $\leq 0.6 \mathrm{~nm}$ up to $40 \times$ with an immersion lens. Observations of a sample through a glass window at $20 \times$ magnification in flowing water also yielded increasing uncertainty, with mean values of $\leq 0.5 \mathrm{~nm}, \leq 0.8 \mathrm{~nm}$, and $\leq 1.1 \mathrm{~nm}$ for flow rates of $0 \mathrm{~mL} \mathrm{~min}{ }^{-1}, 15 \mathrm{~mL} \mathrm{~min}^{-1}$, and $33 \mathrm{~mL}$ $\mathrm{min}^{-1}$. Different hologram acquisition rates $\left(12.5 \mathrm{~s}^{-1}\right.$ and $\left.25 \mathrm{~s}^{-1}\right)$ did not significantly impact the uncertainty in the phase. Collecting holograms in single-wavelength versus dual-wavelength modes did impact the uncertainty, with the mean uncertainty at $10 \times$ magnification for the same wavelength being $\leq 0.5 \mathrm{~nm}$ from the single-wavelength mode compared to $\leq 1.5 \mathrm{~nm}$ from the dualwavelength mode. When the quantified uncertainty was applied to simulated dissolution data, lower limits of measured dissolution rates were found below which the measured data may not be distinguishable from the uncertainty in the measurement. The limiting surface-normal dissolution velocity is $-10^{-11.7} \mathrm{~m} \mathrm{~s}^{-1}$ for experiments with an immersion lens in flowing water conditions and $-10^{-11.7}$ $\mathrm{m} \mathrm{s}^{-1},-10^{-11.4} \mathrm{~m} \mathrm{~s}^{-1}$, and $-10^{-11.0} \mathrm{~m} \mathrm{~s}^{-1}$ for static $\left(0 \mathrm{~mL} \mathrm{~min}^{-1}\right)$, slow $\left(\leq 15 \mathrm{~mL} \mathrm{~min}^{-1}\right)$, and fast $\left(\leq 109 \mathrm{~mL} \mathrm{~min}^{-1}\right)$ flowing water conditions in experiments with a glass window, respectively. The data presented by this study will allow for better experimental design and methodology for future dissolution or precipitation studies using DHM and will provide confidence in the data produced in postprocessing.
\end{abstract}

Key words: digital holographic microscopy; dissolution; precipitation; quantitative phase microscopy; uncertainty.

Accepted: March 20, 2017

Published: March 27, 2017

https://doi.org/10.6028/jres.122.022

\section{Introduction}

Digital holographic microscopy (DHM) is a novel surface topography technique that has recently become commercially available. It is a quantitative phase microscopy technique capable of being configured for reflection or transmission microscopy, and it has been used for a variety of applications [1], including static and dynamic surface metrology [2-7], particle tracking [8,9], tracking and monitoring of live biological cells [3, 10-12], and monitoring surface dissolution [13, 14] or growth [15] kinetics. DHM and related quantitative phase imaging technologies have been extensively developed for the study of biological specimens [16-18]. The DHM operates by separating and recombining object and reference beams at a single wavelength to generate the interferometric data as a hologram, which is then numerically reconstructed to yield amplitude and phase information [19-21], examples of which are shown in Fig. 1. 
The primary advantage of DHM is that full-field two-dimensional (2D) holograms are collected at tens of frames per second and can be collected in situ.

The numerically reconstructed phase is directly proportional to height, therefore yielding threedimensional (3D) surface topography (see Fig. 1e), with sub-nanometer vertical accuracy being reported [22]. However, one complication of the technique is the presence of inherent (intrinsic and extrinsic) noise [23-29], which has not undergone a rigorous analysis to relate it to uncertainty in the measured phase (and therefore height) data. Furthermore, recent studies have utilized reflection DHM ${ }^{1}$ to track in situ surface topography changes of dissolving mineral phases in static and flowing water [13,14], but it is inconclusive from those studies how the presence of water (or any solution) or the use of flowing water conditions affects the noise and uncertainty in the measurement. Therefore, the objective of the present study is to further quantify the uncertainty in such measurements in order to better understand the limitations of the instrument, sampling statistics, and minimum measurable surface topography changes.

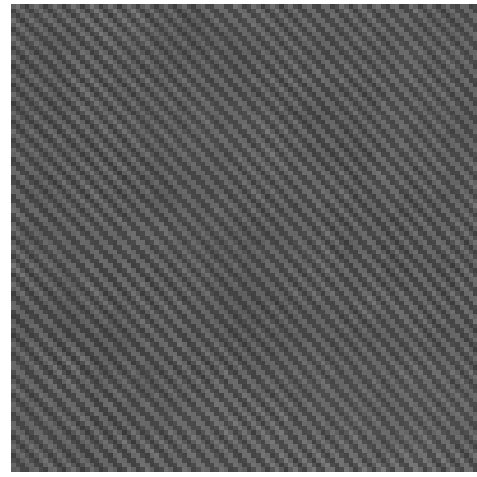

(a)

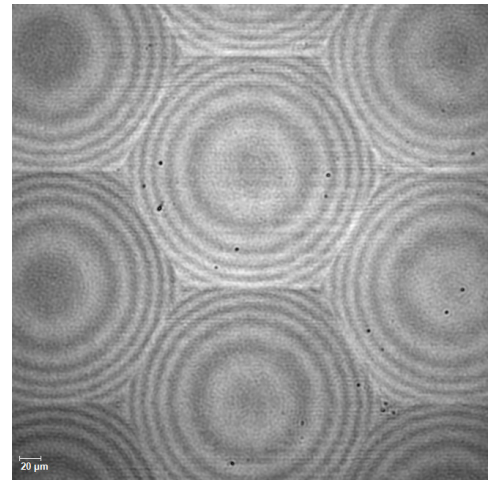

(b)

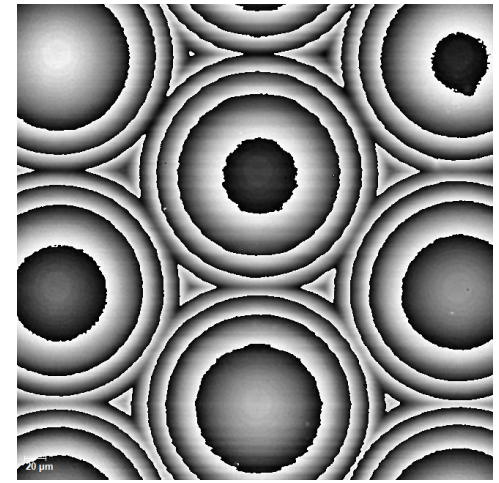

(c)

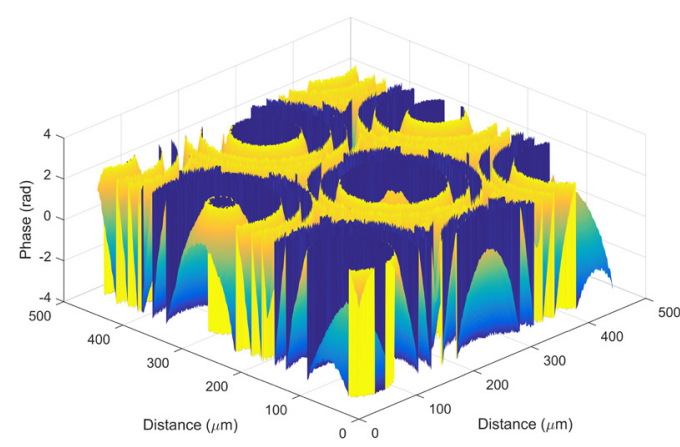

(d)

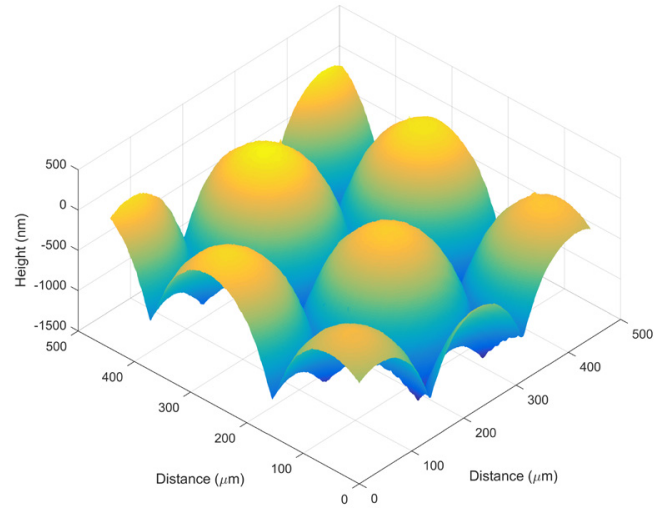

(e)

Fig. 1. DHM observations of microlenses, indicating (a) a zoomed-in view of the collected hologram showing the fringe interference pattern and the entire reconstructed (b) amplitude and (c) phase maps. The (b,c) images measure $443 \mu \mathrm{m}$ by $443 \mu \mathrm{m}$. The output phase data are "wrapped" (d) and confined to the interval $[-\pi, \pi]$, which can be numerically unwrapped and converted to height (e).

\footnotetext{
${ }^{1}$ Several studies have used DHM or related quantitative phase imaging techniques in a transmission configuration to study biological specimens under flowing conditions [60-64]. While one study assigned uncertainty to their measured and computed values [60], it is unclear how the effects of flow conditions, such as flow rate, influenced this uncertainty. Other studies demonstrated how flow rate influences image quality when particles (e.g., cells, colloids) are in solution [61, 62].
} 


\section{Principles of DHM}

Interferometric principles provide the basis for DHM. A coherent, monochromatic light source is split into object and reference beams. In a reflection mode DHM, the object beam passes through an objective lens, interacts with the sample surface, and is reflected back through the objective lens, where it is recombined with the reference beam (Fig. 2). The interferogram produced by the recombined object and reference beams is recorded as a $2 \mathrm{D}$ hologram on a charge coupled device (CCD) camera $[19,20]$. Numerical reconstruction of the hologram produces a reconstruction wavefront in an observation plane as a function of the recorded hologram intensity. This reconstruction wavefront consists of real and imaginary parts, from which a 2D amplitude image (similar to what would be observed in a conventional light microscope) and a 2D phase image are generated [19]. Additional processing accounts for aberrations and the shape (e.g., tilt) of the sample surface [30,31]. The phase, $\varphi$, at a given pixel location $(\xi, \eta)$ in the image can be converted to height, $h$, as a function of the known wavelength, $\lambda$, and the index of refraction, $n$ :

$$
h(\xi, \eta)=\frac{\lambda}{4 \pi n} \varphi(\xi, \eta) .
$$

The index of refraction used in Eq. (1) is that of the medium in which the sample surface is being measured, which in this study is air $(n=1.0)$ and water $(n=1.33)$.

The use of two wavelengths simultaneously is possible in DHM [32]. Assuming a dispersionless system and stable wavelengths $[32,33]$, at two wavelengths, $\lambda_{i}$ and $\lambda_{j}$, the difference in phase (i.e., $\varphi_{i}-\varphi_{j}$ ) yields a "synthetic" or "beat" wavelength, $\Lambda_{i j}[32,34]$ :

$$
\Lambda_{i j}=\left|\frac{\lambda_{i} \lambda_{j}}{\lambda_{i}-\lambda_{j}}\right| .
$$

This allows for greater height differences to be measured on a given surface, albeit with greater uncertainty. In addition, since the data are recorded simultaneously [32] at each of the two wavelengths, two data sets are generated for a given sample, so the noise contribution at each wavelength should be evaluated.

One type of intrinsic noise present in a DHM has been attributed to shot noise [23-26, 28, 29], which is related to the intrinsic variability in photons incident on the CCD camera [35]. Shot noise can be modelled by a Poisson distribution [35]. Temporal averaging of multiple reconstructed phase images can be used to reduce the effects of shot noise [22,24].

So-called "Gaussian noise" is also present in DHM measurements (i.e., in the reconstructed wavefront) and includes the combined effects of numerous noise sources, such as readout, thermal, and quantization noise, but it can also be attributable to extrinsic sources, such as dust or dirt on the lenses or spurious reflections [25]. Spatial averaging of phase images obtained at two different wavelengths in a dualwavelength DHM configuration has been shown to reduce noise in the measurement [22], and noise reduction has also been demonstrated by averaging holograms collected at multiple wavelengths [36] or with varying incident beam intensities [37].

The DHM utilized in this study was a Lyncée Tec Model R-2203 (Lausanne, Switzerland). ${ }^{2}$ The instrument is equipped to produce three different wavelengths $\left(\lambda_{1}=665.5651 \mathrm{~nm}, \lambda_{2}=793.2365 \mathrm{~nm}\right.$, or $\lambda_{3}$ $=681.0068 \mathrm{~nm})$ and can be operated in a single-wavelength $\left(\lambda_{1}\right.$ only) or dual-wavelength $\left(\lambda_{1}\right.$ and $\lambda_{2}$ or $\lambda_{1}$ and $\lambda_{3}$ ) mode. The resultant synthetic wavelengths in dual mode are $\Lambda_{12}=4135 \mathrm{~nm}$ and $\Lambda_{13}=29.35 \mu \mathrm{m}$. In manual collection mode, hologram acquisition can be started, paused, and stopped at will by the operator, and the CCD camera (Model ECO285MVGE, SVS-Vistek, Seefeld, Germany) can collect holograms at frame rates of up to $12.5 \mathrm{~s}^{-1}$, but a continuous collection "video" mode can collect holograms at a frame rate of $25 \mathrm{~s}^{-1}$. The objective lenses used in the DHM configuration for this study are summarized in Table 1 , including the pixel size and wavelength-dependent depth of field for each objective lens. The DHM is equipped with objective lenses for use in air as well as water immersion lenses. The DHM is configured for reflection only.

\footnotetext{
${ }^{2}$ Certain commercial equipment, instruments, or materials are identified in this paper to foster understanding. Such identification does not imply recommendation or endorsement by the National Institute of Standards and Technology, nor does it imply that the materials or equipment identified are necessarily the best available for the purpose.
} 
A reaction cell was constructed to contain a sample and allow continuous flow of water (or other solution). The cell was composed of polyether ether ketone (PEEK), which is chemically inert in most aqueous environments. Samples were affixed to a titanium stub, which was then screwed into the reaction cell, as shown in Fig. 3. The same cell was used in solution flow experiments and can be configured to use an immersion lens (Fig. 3a) or use a glass window with an objective lens in air (Fig. 3b). For each experimental configuration, the optical path length of the reference beam was adjusted to account for the object beam traveling through multiple media (e.g., air, glass, and water) to optimize coherence.

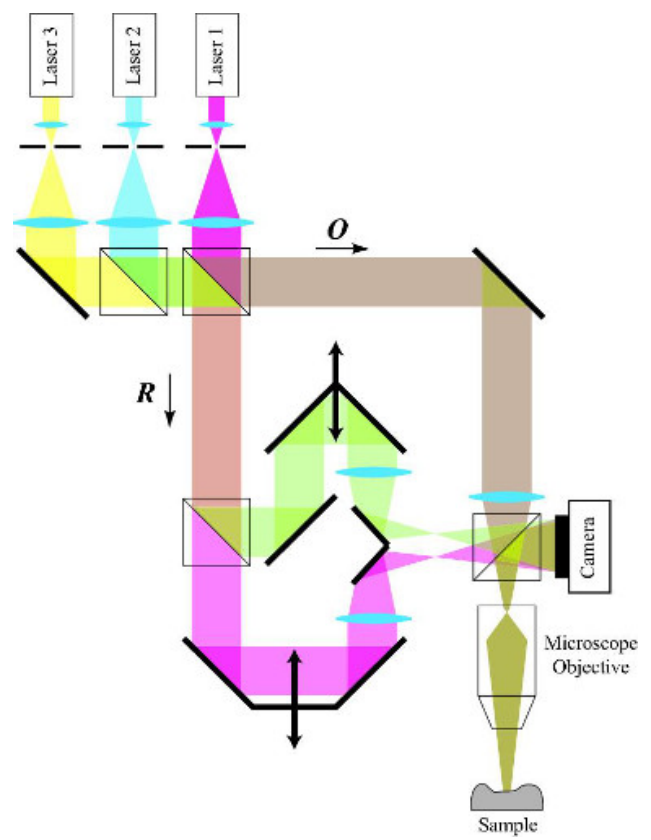

Fig. 2. Lyncée Tec R2200 Series reflection DHM, indicating the object $(\mathrm{O})$ and reference $(\mathrm{R})$ beams [38]. Reproduced with permission from Lyncée Tec SA.

Table 1. DHM objective lens details.

\begin{tabular}{|c|c|c|c|c|c|c|c|c|}
\hline \multirow{2}{*}{ Mag. } & \multirow{2}{*}{ Description } & \multirow{2}{*}{ Lens Type } & \multirow{2}{*}{$\begin{array}{c}\text { Numerical } \\
\text { Aperture }\end{array}$} & \multirow{2}{*}{ Pixel Size } & \multirow{2}{*}{$\begin{array}{l}\text { Free Working } \\
\text { Distance }(\mathrm{mm})\end{array}$} & \multicolumn{3}{|c|}{ Depth of Field $(\mu \mathrm{m})^{\mathrm{a}}$} \\
\hline & & & & & & $\lambda_{1}$ & $\lambda_{2}$ & $\lambda_{3}$ \\
\hline $2.5 \times$ & Leica N Plan $2.5 \times / 0.07$ & Air & 0.07 & $2.84 \mu \mathrm{m}$ & 11.2 & 140 & 160 & 140 \\
\hline $5 \times$ & $\begin{array}{l}\text { Leica N Plan EPI } \\
5 \times / 0.12\end{array}$ & Air & 0.12 & $1.39 \mu \mathrm{m}$ & 14.0 & 46 & 55 & 47 \\
\hline $10 \times$ & $\begin{array}{l}\text { Leica HC PL Fluotar } \\
10 \times / 0.30\end{array}$ & Air & 0.30 & $683 \mathrm{~nm}$ & 11.0 & 7.4 & 8.8 & 7.6 \\
\hline $20 \times$ & $\begin{array}{l}\text { Leica HC PL Fluotar } \\
20 \times / 0.40 \text { Corr }\end{array}$ & Air & 0.40 & $344 \mathrm{~nm}$ & 6.9 & 4.2 & 5.0 & 4.3 \\
\hline $20 \times$ & $\begin{array}{l}\text { Leica HCX APO } \\
\text { L20×/0.50 W U-V-I }\end{array}$ & Immersion & 0.50 & $343 \mathrm{~nm}$ & 3.5 & 3.5 & 4.2 & 3.6 \\
\hline $40 \times$ & $\begin{array}{l}\text { Leica HC PL Fluotar } \\
40 \times / 0.60 \text { Corr }\end{array}$ & Air & 0.60 & $171 \mathrm{~nm}$ & 3.3 & 1.8 & 2.2 & 1.9 \\
\hline $40 \times$ & $\begin{array}{l}\text { Leica HCX APO } \\
\text { L40×/0.80 W U-V-I }\end{array}$ & Immersion & 0.80 & $170 \mathrm{~nm}$ & 3.3 & 1.4 & 1.6 & 1.4 \\
\hline $100 \times$ & $\begin{array}{l}\text { Leica HC PL Fluotar } \\
100 \times / 0.90\end{array}$ & Air & 0.90 & $68.9 \mathrm{~nm}$ & 1.0 & 0.8 & 1.0 & 0.8 \\
\hline
\end{tabular}

${ }^{a}$ Varies as a function of wavelength: $\lambda_{1}=665.5651 \mathrm{~nm}, \lambda_{2}=793.2365 \mathrm{~nm}, \lambda_{3}=681.0068 \mathrm{~nm}$ 


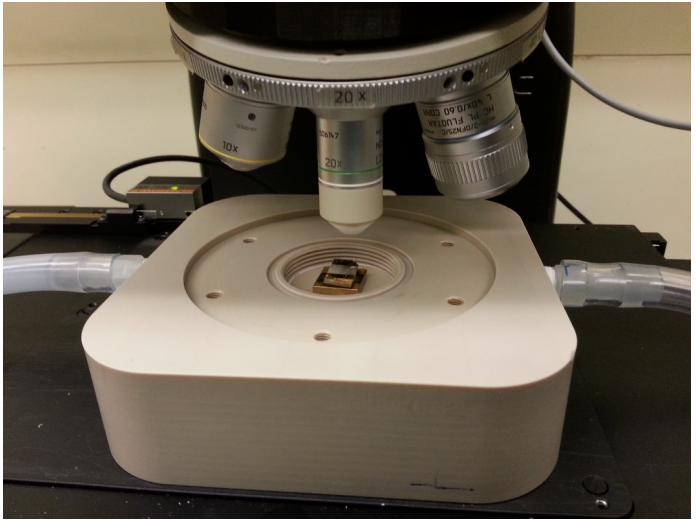

(a)

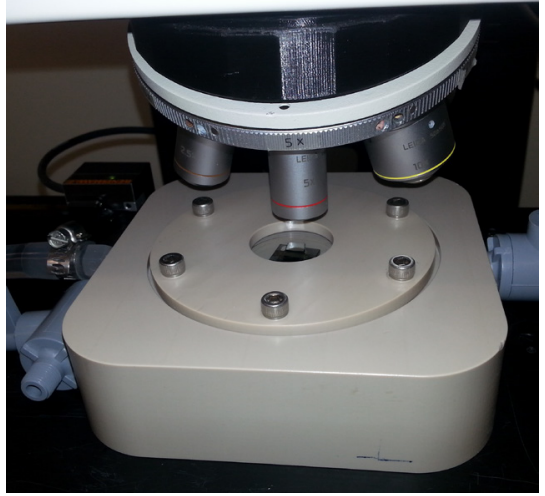

(b)

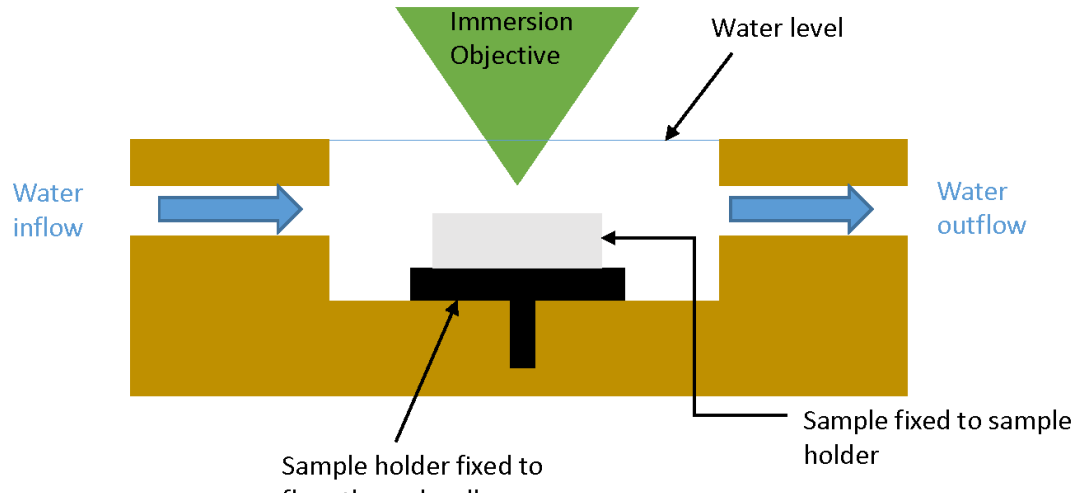

flow-through cell

(c)

Fig. 3. Fluid reaction cell constructed for the DHM experiments, indicating the configurations for (a) immersion lens use and (b) glass window use, as well as (c) a cross-section schematic. Note: The stage is lowered, and no water is present in $(\mathrm{a}, \mathrm{b})$ to more clearly show the sample and cell setup.

\section{Uncertainty in DHM Phase Measurements}

The uncertainty was quantified in the measured phase (and therefore height) of a nominally flat glass slide with a thin film of chromium. The thickness of the chromium was measured by DHM at various locations on the sample to be about $80 \mathrm{~nm}$ to $100 \mathrm{~nm}$; this was performed by examining sections of the surface that had been masked and did not have chromium. At this thickness, it is possible that the chromium layer is semitransparent, which would affect the results, because the reflected wavefront can be generated from both the top and the bottom of the chromium layer [39, 40]. Under the assumption that the chromium is transparent, the reflection, $R$, from the top of the chromium surface would be a function of the Fresnel reflection coefficients from the top (air-chromium interface) and bottom (chromium-glass interface) surfaces, $r_{01}$ and $r_{12}$, respectively, and the phase change, $\beta$,

$$
\mathrm{R}=\frac{r_{01}+r_{12} \exp (-i 2 \beta)}{1+r_{01} r_{12} \exp (-i 2 \beta)}
$$

where $\beta$ is a function of the cosine of the incident beam angle, wavelength, layer index of refraction, and layer thickness [40]. The Fresnel reflection coefficient, $r_{p q}$, at the interface of two media, $p$ and $q$, for perpendicularly incident light is a function of the refractive indices of the two media, $n_{p}$ and $n_{q}$ :

$$
r_{p q}=\left|\frac{n_{p}-n_{q}}{n_{p}+n_{q}}\right|^{2}
$$


At wavelength $\lambda_{1}$, the refractive indices of chromium and glass are around 3.5 [41] and 1.5, respectively, so $R$ is approximately $78 \%$, which suggests that even if the chromium is transparent, the reflectivity is relatively high. For very thin layers, it has been shown that chromium does demonstrate transparency (e.g., about $50 \%$ transmittance with a wavelength around $\lambda_{1}$ for an $18 \mathrm{~nm}$ chromium layer [42]), but thicker coatings of chromium have demonstrated zero transmittance. For instance, Rauf et al. [43] found zero transmittance in the wavelength range of $300 \mathrm{~nm}$ to $700 \mathrm{~nm}$ for a chromium layer thickness of $200 \mathrm{~nm}$, and Wang et al. [44] found zero transmittance at a wavelength of $550 \mathrm{~nm}$ for chromium layer thicknesses $\geq 100$ $\mathrm{nm}$. Therefore, it is assumed that the chromium layer thickness in the present study is thick enough to exhibit minimal effects, if any, of semitransparency.

Actual quantification of the uncertainty was performed by evaluating the temporal standard deviation per pixel. As each phase map consists of 650 pixels by 650 pixels, two nominally defect-free regions were selected: One region was selected as the reference offset height, while another was selected as the regionof-interest (ROI) from which the samples were collected (Fig. 4). The temporal standard deviation, $s$, was then defined per pixel along the time dimension for $N$ number of holograms, where $x_{i}$ is the phase at a given pixel location in the phase map from the $i$ th hologram, and $\bar{x}$ is the mean phase at a given pixel location across $N$ phase maps:

$$
\mathrm{s}=\sqrt{\frac{1}{N-1} \sum_{i=1}^{N}\left(x_{i}-\bar{x}\right)^{2}} .
$$

Type A uncertainty [45] is defined using the temporal standard deviation. The effects of three variables were considered: (1) magnification, which was changed using various objective lenses and which also influences the lateral resolution (see Table 1); (2) medium, which was air or water; and (3) water flow rate. Experiments under flowing conditions were separated into two categories: (1) measurements in flowing water using an immersion objective lens (see Fig. 3a configuration); and (2) measurements in flowing water using an objective lens in air and viewing through a glass window (see Fig. 3b configuration). All experiments were conducted at ambient laboratory conditions at $(23 \pm 1)^{\circ} \mathrm{C}$.

The uncertainty was quantified by determining the temporal standard deviation of a given pixel from a given number of reconstructed phase images. For each experiment, unless otherwise noted, 100 holograms were collected at a frame rate of $25 \mathrm{~s}^{-1}$, although the effects of sample size and hologram acquisition rate were also explored. The effect of sample size was investigated by randomly sampling a sequential subset of the 100-hologram data set. Subsets of 5, 10, 20, 30, and 50 holograms were taken.

As the uncertainty in the phase data was found to be a non-normal distribution, several metrics were used to describe the data set, including the mean, median, interquartile range (IQR), skewness, and kurtosis $[46,47]$. The IQR is the difference between the 75th and 25th percentiles of the data, which is the middle $50 \%$ of the data. The IQR is an indication of the data variability and provides a metric of the spread of the data and helps to identify outliers. Skewness is a representation of the symmetry (or asymmetry) of a distribution. A normal distribution has zero skewness. Positive skewness indicates that the distribution has more values to the right of the mean, while a negative skewness suggests the opposite. Kurtosis can be used to evaluate the normality of a distribution, where a kurtosis of 3 represents a normal distribution. Distributions with a kurtosis greater than 3 are more prone to outliers than a normal distribution or have heavy tails, while those with a kurtosis less than 3 are less prone to outliers than a normal distribution or have light tails.

Analysis and comparison of the uncertainty distributions across multiple configurations were performed using quantile-quantile plots and a two-sample Kolmogorov-Smirnov test. A quantile-quantile plot compares the quantiles from one data set to the quantiles of a second data set, which helps to assess if the two data sets are from a similar distribution. A reference line is shown in a quantile-quantile plot along with the data; if the two data sets are from a similar distribution, the plotted data points will fall along the reference line. The reference line represents a linear fit through the second and third quantiles of the two data sets (i.e., the middle $50 \%$ of the data), which is then extrapolated for the first and fourth quantiles. A one-sample quantile-quantile plot can also be generated, which is used to compare the sample distribution to a known distribution (e.g., normal, Poisson, etc.) by plotting the quantiles of the sample against quantiles of an ideal distribution. One-sample quantile-quantile plots will also have a reference line that represents the linear fit through the second and third quantiles of the data. The two-sample Kolmogorov-Smirnov test 
is a nonparametric test to evaluate if two data sets come from a common distribution. To make inferences between two distributions, multiple iterations of the Kolmogorov-Smirnov test were performed with random samplings of 100 data points from the large data set populations in this study.

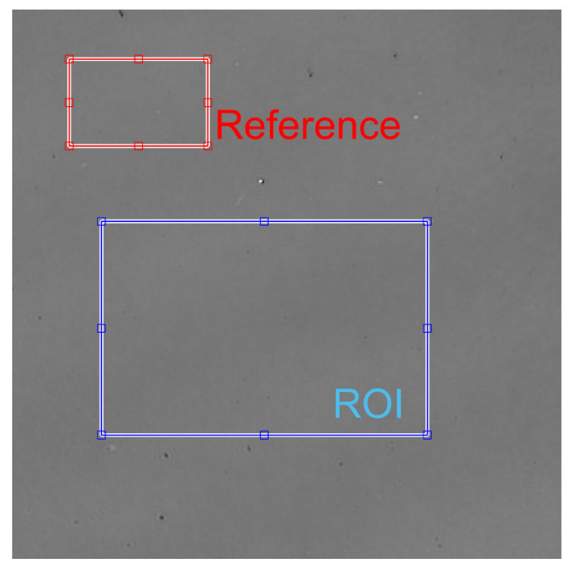

Fig. 4. The specified reference height offset (red box) and ROI (blue box) of the phase image for the $20 \times$ objective lens in air analyses. The image measures $223 \mu \mathrm{m}$ by $223 \mu \mathrm{m}$.

\subsection{Measurements in Air}

The uncertainty over 100 reconstructed phase maps collected at $25 \mathrm{~s}^{-1}$ was evaluated for each objective lens in air for $\lambda_{1}$, and the resulting histograms are shown in Fig. 5. The mean uncertainty and median uncertainty were less than $0.5 \mathrm{~nm}$ for all objective lenses (Table 2 and Table 3 ). These values are similar to the value of $0.4 \mathrm{~nm}$ reported by Charrière et al. [2] from phase data collected from 4500 holograms with a $20 \times$ objective lens and a wavelength of $635 \mathrm{~nm}$.

In Table 2 and Table 3, the uncertainty appears to decrease with increasing magnification, considering the 50- and 100-hologram data sets, with the exception of the data at $5 \times$ and at $40 \times$. In addition, the distribution, mean, and median uncertainty values at $100 \times$ appear to be significantly different from the other magnifications. However, when considering the resolution of the objective lens (i.e., $0.61 \lambda N A^{-1}$, where $N A$ is the numerical aperture) using $\lambda_{1}$, the ratio of the resolution to the pixel size (Table 1) at a given magnification is $2.0,2.4,2.0,3.0,4.0$, and 6.5 for the $2.5 \times, 5 \times, 10 \times, 20 \times, 40 \times$, and $100 \times$ objective lenses, respectively. The ratio is greatest at $100 \times$, which also yielded the lowest uncertainty. The uncertainty at $5 \times$ appears to be typically less than the uncertainty at $2.5 \times$ or $10 \times$, which also correlates to the ratio of the resolution to pixel size. The ratio for the $40 \times$ objective lens is greater than the $20 \times$ objective lens, and the uncertainty is less for $40 \times$ compared to $20 \times$ magnification when considering 30 holograms or fewer. The resolving power and numerical aperture can be considered intrinsic factors affecting the uncertainty, although the data collected also include extrinsic factors, which influence the variability in uncertainty in Table 2 and Table 3.

The effect of sample size on the standard deviation histogram is shown in Fig. 6, and, as expected, the histogram shape was altered as a function of sample size. As can be seen in Table 2, the sample size of holograms minimally affected the mean uncertainty for the majority of objective lenses. As a function of sample size, the uncertainty IQR shows that the middle $50 \%$ of the uncertainty lies within $0.1 \mathrm{~nm}$ for sample sizes of 10 holograms or more and within $0.2 \mathrm{~nm}$ for sample sizes of 5 holograms (Table 4).

The general shapes of these histograms are right-skewed and non-normal. For data collected from 100 holograms, the uncertainty is less skewed and more normal at higher magnifications $(40 \times$ and $100 \times)$, as shown in Table 5. The uncertainty distribution approaches normality at smaller sample sizes (e.g., phase data from 20 holograms or fewer), as shown in Table 6. The skewness of the data is also evident in a quantile-quantile plot of the data (Fig. 7), which shows that, relative to a normal distribution, the standard deviation data are skewed at the tails, particularly the right tail, which agrees with the findings from the analysis of the skewness value (Table 5 and Table 6). 
Table 2. Mean uncertainty in the phase measurement per objective lens in air.

\begin{tabular}{|c|c|c|c|c|c|c|c|}
\hline & \multirow{2}{*}{ Uncertainty } & \multicolumn{6}{|c|}{ Objective Lens } \\
\hline & & $2.5 \times$ & $5 \times$ & $10 \times$ & $20 \times$ & $40 \times$ & $100 \times$ \\
\hline \multirow{2}{*}{$\begin{array}{c}\text { Collected from } 100 \\
\text { Holograms }\end{array}$} & $\mathrm{rad}$ & 0.0089 & 0.0080 & 0.0086 & 0.0086 & 0.0093 & 0.0049 \\
\hline & $\mathrm{nm}$ & 0.47 & 0.42 & 0.46 & 0.46 & 0.49 & 0.26 \\
\hline \multirow{2}{*}{$\begin{array}{c}\text { Collected from } 50 \\
\text { Holograms }\end{array}$} & $\mathrm{rad}$ & 0.0089 & 0.0080 & 0.0085 & 0.0087 & 0.0088 & 0.005 \\
\hline & $\mathrm{nm}$ & 0.47 & 0.42 & 0.45 & 0.46 & 0.47 & 0.26 \\
\hline \multirow{2}{*}{$\begin{array}{c}\text { Collected from } 30 \\
\text { Holograms }\end{array}$} & $\mathrm{rad}$ & 0.0089 & 0.0080 & 0.0085 & 0.0086 & 0.0083 & 0.0049 \\
\hline & $\mathrm{nm}$ & 0.47 & 0.42 & 0.45 & 0.46 & 0.44 & 0.26 \\
\hline \multirow{2}{*}{$\begin{array}{c}\text { Collected from } 20 \\
\text { Holograms }\end{array}$} & $\mathrm{rad}$ & 0.0087 & 0.0079 & 0.0087 & 0.0084 & 0.0080 & 0.005 \\
\hline & $\mathrm{nm}$ & 0.46 & 0.42 & 0.46 & 0.44 & 0.42 & 0.26 \\
\hline \multirow{2}{*}{$\begin{array}{c}\text { Collected from } 10 \\
\text { Holograms }\end{array}$} & $\mathrm{rad}$ & 0.0089 & 0.0078 & 0.0086 & 0.0082 & 0.0075 & 0.0047 \\
\hline & $\mathrm{nm}$ & 0.47 & 0.41 & 0.46 & 0.43 & 0.40 & 0.25 \\
\hline \multirow{2}{*}{$\begin{array}{c}\text { Collected from } 5 \\
\text { Holograms }\end{array}$} & $\mathrm{rad}$ & 0.0083 & 0.0077 & 0.0078 & 0.0084 & 0.0075 & 0.0048 \\
\hline & $\mathrm{nm}$ & 0.44 & 0.41 & 0.41 & 0.44 & 0.40 & 0.25 \\
\hline
\end{tabular}

Table 3. Median uncertainty in the phase measurement per objective lens in air.

\begin{tabular}{|c|c|c|c|c|c|c|c|}
\hline & \multirow{2}{*}{ Uncertainty } & \multicolumn{6}{|c|}{ Objective Lens } \\
\hline & & $2.5 \times$ & $5 \times$ & $10 \times$ & $20 \times$ & $40 \times$ & $100 \times$ \\
\hline \multirow{2}{*}{$\begin{array}{c}\text { Collected from } 100 \\
\text { Holograms }\end{array}$} & $\mathrm{rad}$ & 0.0086 & 0.0079 & 0.0085 & 0.0085 & 0.0090 & 0.0049 \\
\hline & $\mathrm{nm}$ & 0.46 & 0.42 & 0.45 & 0.45 & 0.48 & 0.26 \\
\hline \multirow{2}{*}{$\begin{array}{c}\text { Collected from } 50 \\
\text { Holograms }\end{array}$} & $\mathrm{rad}$ & 0.0086 & 0.0079 & 0.0084 & 0.0086 & 0.0086 & 0.0049 \\
\hline & $\mathrm{nm}$ & 0.46 & 0.42 & 0.44 & 0.46 & 0.46 & 0.26 \\
\hline \multirow{2}{*}{$\begin{array}{c}\text { Collected from } 30 \\
\text { Holograms }\end{array}$} & $\mathrm{rad}$ & 0.0086 & 0.0079 & 0.0083 & 0.0085 & 0.0081 & 0.0048 \\
\hline & $\mathrm{nm}$ & 0.46 & 0.42 & 0.44 & 0.45 & 0.43 & 0.25 \\
\hline \multirow{2}{*}{$\begin{array}{c}\text { Collected from } 20 \\
\text { Holograms }\end{array}$} & $\mathrm{rad}$ & 0.0085 & 0.0078 & 0.0085 & 0.0083 & 0.0079 & 0.0049 \\
\hline & $\mathrm{nm}$ & 0.45 & 0.41 & 0.45 & 0.44 & 0.42 & 0.26 \\
\hline \multirow{2}{*}{$\begin{array}{c}\text { Collected from } 10 \\
\text { Holograms }\end{array}$} & $\mathrm{rad}$ & 0.0087 & 0.0076 & 0.0084 & 0.0081 & 0.0074 & 0.0046 \\
\hline & $\mathrm{nm}$ & 0.46 & 0.40 & 0.44 & 0.43 & 0.39 & 0.24 \\
\hline \multirow{2}{*}{$\begin{array}{c}\text { Collected from } 5 \\
\text { Holograms }\end{array}$} & $\mathrm{rad}$ & 0.0080 & 0.0074 & 0.0076 & 0.0081 & 0.0073 & 0.0047 \\
\hline & $\mathrm{nm}$ & 0.42 & 0.39 & 0.40 & 0.43 & 0.39 & 0.25 \\
\hline
\end{tabular}

Table 4. Uncertainty IQR in the phase measurement per objective lens in air.

\begin{tabular}{|c|c|c|c|c|c|c|c|}
\hline & \multirow{2}{*}{ Uncertainty } & \multicolumn{6}{|c|}{ Objective Lens } \\
\hline & & $2.5 \times$ & $5 \times$ & $10 \times$ & $20 \times$ & $40 \times$ & $100 \times$ \\
\hline \multirow{2}{*}{$\begin{array}{c}\text { Collected from } 100 \\
\text { Holograms }\end{array}$} & $\mathrm{rad}$ & 0.0017 & 0.0012 & 0.0014 & 0.0011 & 0.0020 & 0.0007 \\
\hline & $\mathrm{nm}$ & 0.07 & 0.05 & 0.06 & 0.04 & 0.08 & 0.03 \\
\hline \multirow{2}{*}{$\begin{array}{c}\text { Collected from } 50 \\
\text { Holograms }\end{array}$} & $\mathrm{rad}$ & 0.0020 & 0.0015 & 0.0015 & 0.0014 & 0.0019 & 0.0009 \\
\hline & $\mathrm{nm}$ & 0.08 & 0.06 & 0.06 & 0.06 & 0.08 & 0.04 \\
\hline \multirow{2}{*}{$\begin{array}{c}\text { Collected from } 30 \\
\text { Holograms }\end{array}$} & $\mathrm{rad}$ & 0.0023 & 0.0017 & 0.0018 & 0.0017 & 0.0019 & 0.0010 \\
\hline & $\mathrm{nm}$ & 0.09 & 0.07 & 0.07 & 0.07 & 0.08 & 0.04 \\
\hline \multirow{2}{*}{$\begin{array}{c}\text { Collected from } 20 \\
\text { Holograms }\end{array}$} & $\mathrm{rad}$ & 0.0023 & 0.0020 & 0.0022 & 0.0019 & 0.0020 & 0.0012 \\
\hline & $\mathrm{nm}$ & 0.09 & 0.08 & 0.09 & 0.08 & 0.08 & 0.05 \\
\hline \multirow{2}{*}{$\begin{array}{c}\text { Collected from } 10 \\
\text { Holograms }\end{array}$} & $\mathrm{rad}$ & 0.0033 & 0.0027 & 0.0030 & 0.0027 & 0.0026 & 0.0016 \\
\hline & $\mathrm{nm}$ & 0.13 & 0.11 & 0.12 & 0.11 & 0.10 & 0.06 \\
\hline \multirow{2}{*}{$\begin{array}{c}\text { Collected from } 5 \\
\text { Holograms }\end{array}$} & $\mathrm{rad}$ & 0.0043 & 0.0039 & 0.0039 & 0.0042 & 0.0038 & 0.0025 \\
\hline & $\mathrm{nm}$ & 0.17 & 0.16 & 0.16 & 0.17 & 0.15 & 0.10 \\
\hline
\end{tabular}




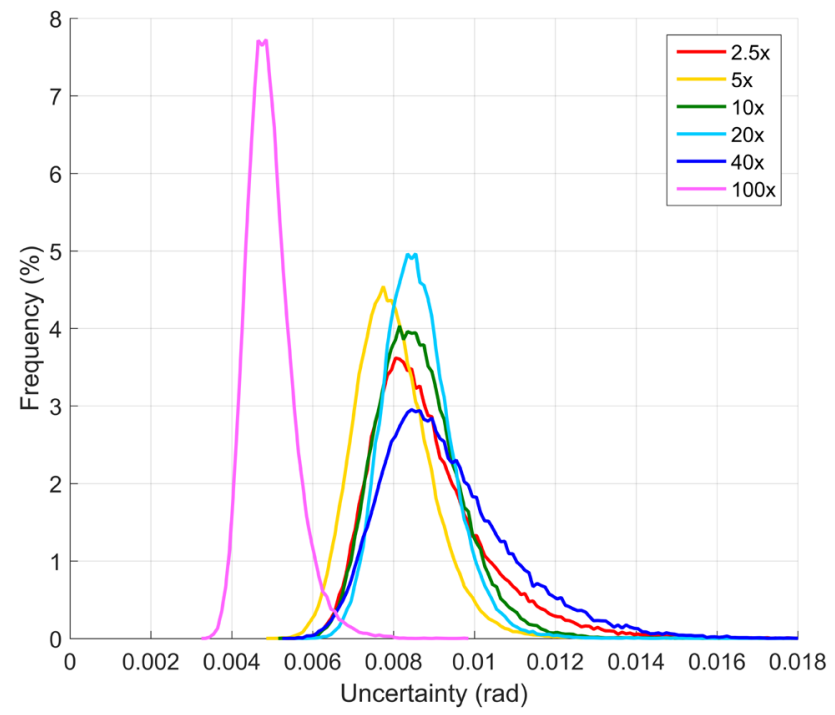

Fig. 5. Uncertainty over 100 reconstructed phase maps for a glass sample in air with a hologram acquisition rate of $25 \mathrm{~s}^{-1}$.

Table 5. Skewness and kurtosis of data in Fig. 5.

\begin{tabular}{|l|c|c|c|c|c|c|}
\hline Objective Lens & $2.5 \times$ & $5 \times$ & $10 \times$ & $20 \times$ & $40 \times$ & $100 \times$ \\
\hline Skewness & 2.1 & 2.3 & 3.6 & 2.4 & 1.0 & 1.0 \\
\hline Kurtosis & 17.2 & 30.1 & 59.3 & 35.8 & 4.5 & 5.2 \\
\hline
\end{tabular}

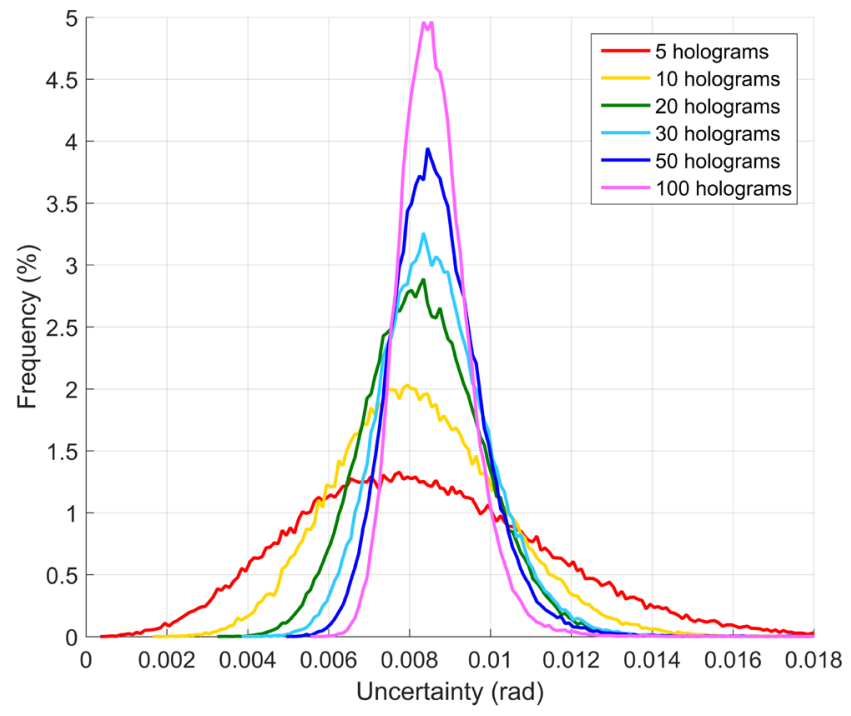

Fig. 6. Histograms of the standard deviation per pixel over 5, 10, 20, 30, 50, and 100 reconstructed phase maps for a glass sample in air with the $20 \times$ objective lens and a hologram acquisition rate of $25 \mathrm{~s}^{-1}$. 
Table 6. Skewness and kurtosis of data in Fig. 6.

\begin{tabular}{|l|c|c|c|c|c|c|}
\hline No. of Holograms & 5 & 10 & 20 & 30 & 50 & 100 \\
\hline Skewness & 0.5 & 0.3 & 0.4 & 0.8 & 1.7 & 2.4 \\
\hline Kurtosis & 3.3 & 3.2 & 4.9 & 7.6 & 21.7 & 35.8 \\
\hline
\end{tabular}

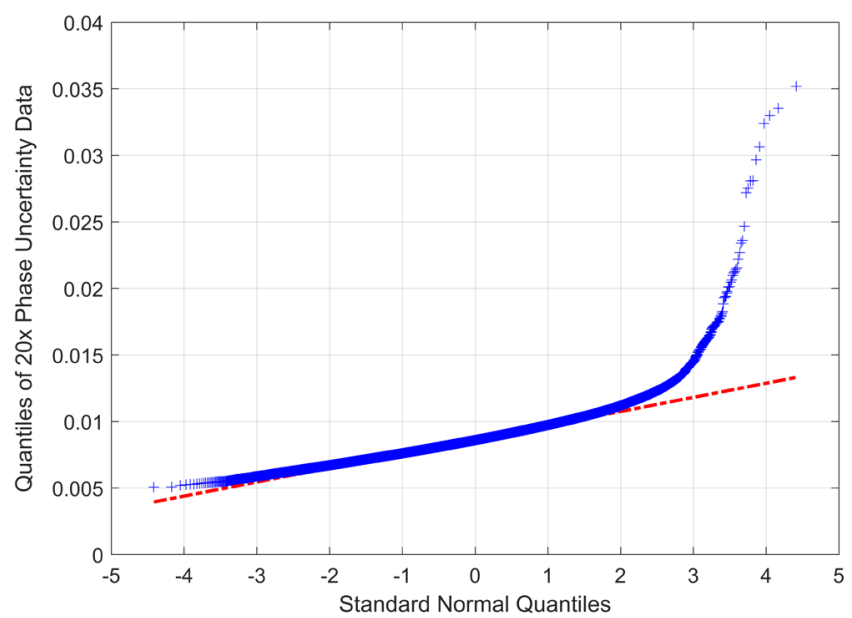

Fig. 7. Quantile-quantile plot of the uncertainty over 30 reconstructed phase maps for a glass sample in air with the $20 \times$ objective lens compared to quantiles for a normal distribution. A reference line (linear fit of the second and third quantiles) is shown in red. The plot indicates that the body of the distribution is normal, and the tails (particularly the right tail) are non-normal, as they deviate from the red line.

\subsubsection{Measurements at Different Acquisition Rates}

Using the $10 \times$ objective lens in air with $\lambda_{1}, 100$ holograms were collected at two different acquisition rates of $25 \mathrm{~s}^{-1}$ and $12.5 \mathrm{~s}^{-1}$. The same area of the sample was examined as the acquisition rate was changed. The uncertainties based on mean and median values were comparable between the two acquisition rates, being on the order of $0.4 \mathrm{~nm}$ to $0.5 \mathrm{~nm}$, depending on the number of holograms (see Table 7 and Fig. 8). In general, the skewness and kurtosis values were slightly greater for data acquired at $12.5 \mathrm{~s}^{-1}$ relative to the $25 \mathrm{~s}^{-1}$ acquisition rate, but the IQR values were relatively unaffected.

Quantile-quantile plots comparing the phase uncertainty at the two acquisition rates are shown in Fig. 9, which suggest that the uncertainty distributions of the two acquisition rates may be similar. Therefore, a two-sample Kolmogorov-Smirnov test was used. To evaluate, 1000 iterations of the Kolmogorov-Smirnov test were conducted by randomly sampling 100 data points from the two data sets with different acquisition rates. The results suggest that the data sets are likely from similar continuous distributions, since, of the 1000 iterations, with $95 \%$ confidence, $89 \%$ of the Kolmogorov-Smirnov test results indicated that the distributions were the same between the $25 \mathrm{~s}^{-1}$ and $12.5 \mathrm{~s}^{-1}$ acquisition rates for the 100-hologram data sets. Similarly, for the 50-, 30-, 20-, 10-, and 5-hologram data sets, $77 \%, 84 \%, 94 \%, 88 \%$, and $84 \%$, respectively, of the Kolmogorov-Smirnov test results indicated that the distributions were the same between the $25 \mathrm{~s}^{-1}$ and $12.5 \mathrm{~s}^{-1}$ acquisition rates. 
Table 7. Effect of acquisition rate on the uncertainty characteristics.

\begin{tabular}{|c|c|c|c|c|c|c|c|}
\hline \multirow{2}{*}{$\begin{array}{c}\text { Acquisition } \\
\text { Rate }\end{array}$} & \multirow{2}{*}{ Data Value } & \multicolumn{6}{|c|}{ No. of Holograms } \\
\hline & & 5 & 10 & 20 & 30 & 50 & 100 \\
\hline \multirow{8}{*}{$25 \mathrm{~s}^{-1}$} & Mean (rad) & 0.0078 & 0.0086 & 0.0087 & 0.0085 & 0.0085 & 0.0086 \\
\hline & Mean (nm) & 0.41 & 0.46 & 0.46 & 0.45 & 0.45 & 0.46 \\
\hline & Median (rad) & 0.0076 & 0.0084 & 0.0085 & 0.0083 & 0.0084 & 0.0085 \\
\hline & Median (nm) & 0.40 & 0.44 & 0.45 & 0.44 & 0.44 & 0.45 \\
\hline & IQR (rad) & 0.0039 & 0.0030 & 0.0022 & 0.0018 & 0.0015 & 0.0014 \\
\hline & IQR (nm) & 0.16 & 0.12 & 0.09 & 0.07 & 0.06 & 0.06 \\
\hline & Skewness & 0.5 & 1.2 & 2.1 & 1.4 & 1.7 & 3.6 \\
\hline & Kurtosis & 3.1 & 11.5 & 27.0 & 16.0 & 20.6 & 59.3 \\
\hline \multirow{8}{*}{$12.5 \mathrm{~s}^{-1}$} & Mean (rad) & 0.0083 & 0.0083 & 0.0085 & 0.0087 & 0.0087 & 0.0088 \\
\hline & Mean (nm) & 0.44 & 0.44 & 0.45 & 0.46 & 0.46 & 0.47 \\
\hline & Median (rad) & 0.0080 & 0.0081 & 0.0084 & 0.0086 & 0.0086 & 0.0086 \\
\hline & Median (nm) & 0.42 & 0.43 & 0.44 & 0.46 & 0.46 & 0.46 \\
\hline & IQR (rad) & 0.0042 & 0.0028 & 0.0022 & 0.0019 & 0.0016 & 0.0014 \\
\hline & IQR (nm) & 0.17 & 0.11 & 0.09 & 0.08 & 0.06 & 0.06 \\
\hline & Skewness & 0.8 & 0.6 & 1.3 & 2.5 & 3.5 & 4.8 \\
\hline & Kurtosis & 5.5 & 4.8 & 15.6 & 38.0 & 58.0 & 91.3 \\
\hline
\end{tabular}

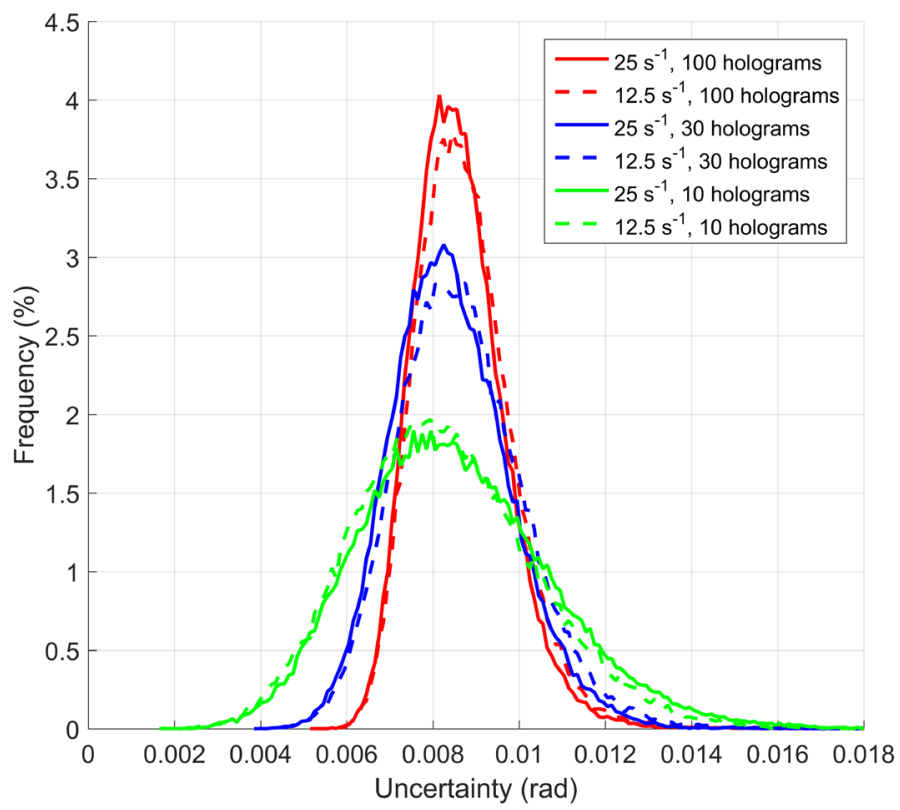

Fig. 8. Uncertainty over 10,30, and 100 reconstructed phase maps for a glass sample in air with the $10 \times$ objective lens comparing the effect of hologram acquisition rates at $25 \mathrm{~s}^{-1}$ and $12.5 \mathrm{~s}^{-1}$. 


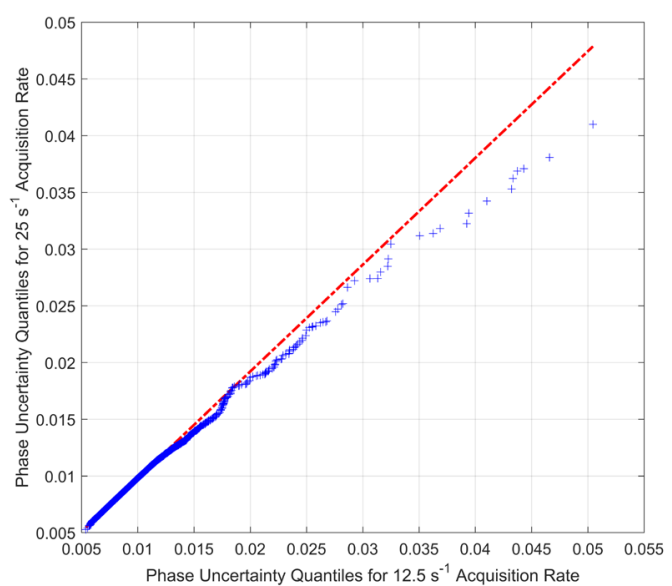

(a)

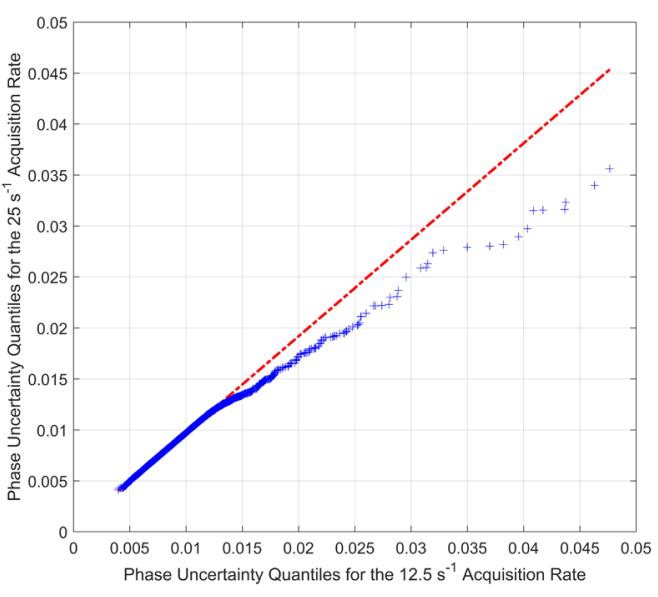

(b)

Fig. 9. Quantile-quantile plots of the phase uncertainty (blue data) over (a) 100 and (b) 30 reconstructed phase maps for a glass sample in air with the $10 \times$ objective lens comparing the hologram acquisition rates at $25 \mathrm{~s}^{-1}$ and $12.5 \mathrm{~s}^{-1}$. A reference line (linear fit of the second and third quantiles) is shown in red.

\subsubsection{Measurements in Dual-Wavelength Mode}

Using the $10 \times$ objective lens in air in dual-wavelength mode, 100 holograms were collected at an acquisition rate of $25 \mathrm{~s}^{-1}$. The holograms were collected using the $\lambda_{1}-\lambda_{2}$ and $\lambda_{1}-\lambda_{3}$ configurations. The uncertainty at each individual wavelength and the combined synthetic wavelength are summarized in Table 8 and Table 9. For direct comparability, the same area of the sample was examined as the single $\lambda_{1}$ experiment in Sec. 3.1. As seen in Fig. 10, the synthetic wavelength increases the uncertainty, which is expected since the noise is additive [32, 34, 48-50]. Kühn et al. [32] reported an amplification of $\sqrt{2}$ in the synthetic-wavelength phase noise. Since the noise is additive, the sum of the standard deviations of the individual wavelengths multiplied by $1 / \sqrt{2}$ should yield the standard deviation of the synthetic-wavelength phase; the mean and median uncertainty values in Table 8 and Table 9 agree very well with this amplification value of $\sqrt{2} .^{3}$

For phase data collected from the $\lambda_{1}-\lambda_{2}$ dual-wavelength mode, the phase uncertainty is on the order of $0.9 \mathrm{~nm}$ for the $\lambda_{1}$ data, $1.3 \mathrm{~nm}$ for the $\lambda_{2}$ data, and as high as $8.7 \mathrm{~nm}$ for the $\Lambda_{12}$ data (Table 8). The distributions are still non-normal and skewed right, but the $\lambda_{2}$ and $\Lambda_{12}$ data tend towards normality, particularly at smaller sample sizes, at least when compared to the phase data from Sec. 3.1. The IQR values for the single wavelengths are larger in dual-wavelength mode than in single-wavelength mode, with the $\Lambda_{12}$ synthetic-wavelength phase uncertainty IQR being an order of magnitude greater than the singlewavelength phase uncertainty.

For phase data collected from the $\lambda_{1}-\lambda_{3}$ dual-wavelength mode, the phase uncertainty is on the order of $1.7 \mathrm{~nm}$ for the $\lambda_{1}$ data, $1.1 \mathrm{~nm}$ for the $\lambda_{3}$ data, and as high as $91 \mathrm{~nm}$ for the $\Lambda_{13}$ data (Table 9). The distribution characteristics are similar to the $\lambda_{1}-\lambda_{2}$ data in that the $\lambda_{1}-\lambda_{3}$ data are non-normal and skewed right, but they tend toward normality more so than the single-wavelength data in Sec. 3.1. For a similar dual-wavelength configuration as $\lambda_{1}-\lambda_{3}$ in this study, Kühn et al. [22] reported the temporal standard deviation of one pixel over a $15 \mathrm{~s}$ acquisition time (the number of holograms, though, was not reported) as $1.3 \mathrm{~nm}(\lambda=657 \mathrm{~nm})$ and $1.0 \mathrm{~nm}(\lambda=680 \mathrm{~nm})$, which agrees very well with the findings shown in Table 9. The $\Lambda_{13}$ synthetic-wavelength phase uncertainty IQR can be upwards of two orders of magnitude greater than the individual wavelength phase uncertainty IQR obtained in dual-wavelength mode.

\footnotetext{
${ }^{3}$ Though not investigated in the present study, it is worth noting that techniques have been developed [34, 48] to reduce phase ambiguities by combining the synthetic-wavelength and single-wavelength data, which may reduce the effects of noise and uncertainty.
} 
For comparison of phase data from single- and dual-wavelength modes, Fig. 11 shows the distributions for $\lambda_{1}$ obtained from both single- and dual-wavelength modes, which clearly demonstrate that the uncertainty is greater in phase data from dual-wavelength mode compared to single-wavelength mode. Table 10 indicates that the uncertainty in the $\lambda_{1}$ phase is increased by a factor of 2.0 to 3.3 when dualwavelength mode is used compared to single-wavelength mode. Quantile-quantile plots comparing the $\lambda_{1}$ phase uncertainty from single- and dual-wavelength modes (Fig. 12) show that the plots deviate, suggesting that they likely do not come from the same distribution. The two-sample Kolmogorov-Smirnov test using 1000 iterations indicated, with $95 \%$ confidence, that the $\lambda_{1}$ phase uncertainty from the single-wavelength mode is not from the same distribution as either of the $\lambda_{1}$ phase uncertainty data sets collected in dualwavelength mode.

Table 8. Uncertainty characteristics for phase data from $\lambda_{1}-\lambda_{2}$ dual-wavelength mode.

\begin{tabular}{|c|c|c|c|c|c|c|c|}
\hline \multirow{2}{*}{ Wavelength } & \multirow{2}{*}{ Data Value } & \multicolumn{6}{|c|}{ No. of Holograms } \\
\hline & & 5 & 10 & 20 & 30 & 50 & 100 \\
\hline \multirow{8}{*}{$\lambda_{1}$} & Mean (rad) & 0.0162 & 0.0169 & 0.0169 & 0.0171 & 0.0172 & 0.0171 \\
\hline & Mean (nm) & 0.86 & 0.90 & 0.90 & 0.91 & 0.91 & 0.91 \\
\hline & Median (rad) & 0.0156 & 0.0165 & 0.0166 & 0.0168 & 0.0169 & 0.0169 \\
\hline & Median (nm) & 0.83 & 0.87 & 0.88 & 0.89 & 0.90 & 0.90 \\
\hline & IQR (rad) & 0.0083 & 0.0060 & 0.0044 & 0.0040 & 0.0035 & 0.0031 \\
\hline & IQR (nm) & 0.44 & 0.32 & 0.23 & 0.21 & 0.19 & 0.16 \\
\hline & Skewness & 0.6 & 0.7 & 0.7 & 1.0 & 1.4 & 1.5 \\
\hline & Kurtosis & 3.7 & 5.8 & 6.0 & 10.1 & 15.3 & 19.0 \\
\hline \multirow{8}{*}{$\lambda_{2}$} & Mean (rad) & 0.0188 & 0.0197 & 0.0197 & 0.0199 & 0.0200 & 0.0200 \\
\hline & Mean (nm) & 1.19 & 1.24 & 1.24 & 1.26 & 1.26 & 1.26 \\
\hline & Median (rad) & 0.0182 & 0.0194 & 0.0195 & 0.0197 & 0.0198 & 0.0198 \\
\hline & Median (nm) & 1.15 & 1.22 & 1.23 & 1.24 & 1.25 & 1.25 \\
\hline & IQR (rad) & 0.0095 & 0.0067 & 0.0049 & 0.0042 & 0.0036 & 0.0030 \\
\hline & IQR (nm) & 0.60 & 0.42 & 0.31 & 0.27 & 0.23 & 0.19 \\
\hline & Skewness & 0.5 & 0.4 & 0.4 & 0.4 & 0.6 & 0.6 \\
\hline & Kurtosis & 3.3 & 3.3 & 3.3 & 3.5 & 3.9 & 4.3 \\
\hline \multirow{8}{*}{$\Lambda_{12}$} & Mean (rad) & 0.0247 & 0.0259 & 0.0259 & 0.0262 & 0.0264 & 0.0263 \\
\hline & Mean (nm) & 8.13 & 8.52 & 8.52 & 8.62 & 8.69 & 8.65 \\
\hline & Median (rad) & 0.0240 & 0.0255 & 0.0256 & 0.0260 & 0.0261 & 0.0261 \\
\hline & Median (nm) & 7.90 & 8.39 & 8.42 & 8.56 & 8.59 & 8.59 \\
\hline & IQR (rad) & 0.0125 & 0.0087 & 0.0062 & 0.0054 & 0.0046 & 0.0037 \\
\hline & IQR (nm) & 4.1 & 2.9 & 2.0 & 1.8 & 1.5 & 1.2 \\
\hline & Skewness & 0.5 & 0.4 & 0.4 & 0.5 & 0.6 & 0.8 \\
\hline & Kurtosis & 3.2 & 3.5 & 3.5 & 4.3 & 5.4 & 6.7 \\
\hline
\end{tabular}




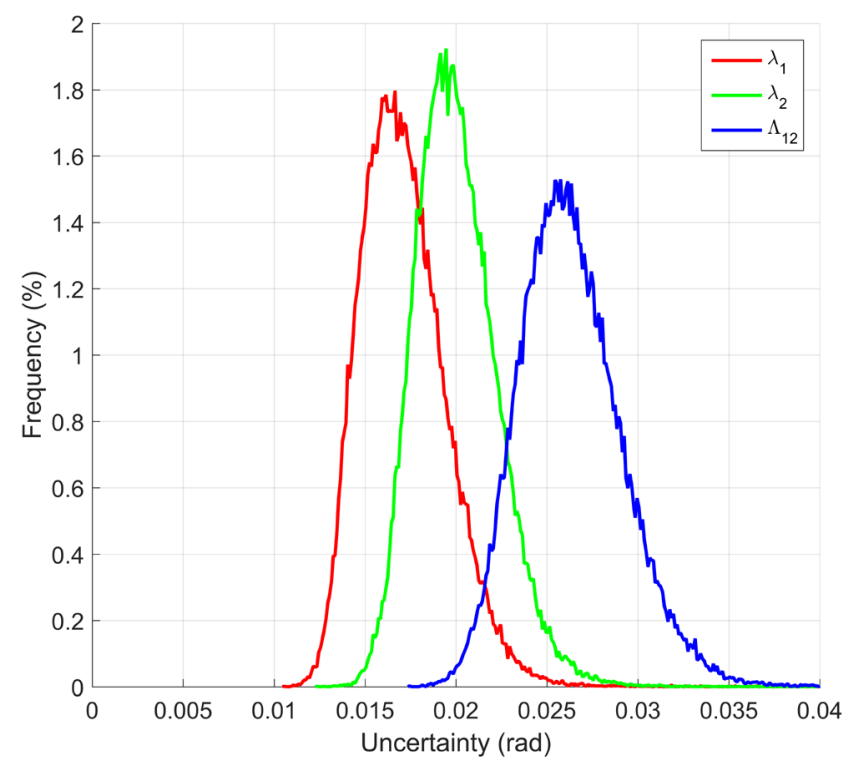

Fig. 10. Uncertainty over 100 reconstructed phase maps for a glass sample in air with the $10 \times$ objective lens comparing the data from $\lambda_{1}-\lambda_{2}$ dual-wavelength mode with the phase data obtained from the individual $\lambda_{1}$ and $\lambda_{2}$ wavelengths and the synthetic $\Lambda_{12}$ wavelength.

Table 9. Uncertainty characteristics for phase data from $\lambda_{1}-\lambda_{3}$ dual-wavelength mode.

\begin{tabular}{|c|c|c|c|c|c|c|c|}
\hline \multirow{2}{*}{ Wavelength } & \multirow{2}{*}{ Data Value } & \multicolumn{6}{|c|}{ No. of Holograms } \\
\hline & & 5 & 10 & 20 & 30 & 50 & 100 \\
\hline \multirow{8}{*}{$\lambda_{1}$} & Mean (rad) & 0.0227 & 0.0232 & 0.0257 & 0.0284 & 0.0316 & 0.0329 \\
\hline & Mean (nm) & 1.20 & 1.23 & 1.36 & 1.50 & 1.67 & 1.74 \\
\hline & Median (rad) & 0.0219 & 0.0227 & 0.0249 & 0.0271 & 0.0297 & 0.0309 \\
\hline & Median (nm) & 1.16 & 1.20 & 1.32 & 1.44 & 1.57 & 1.64 \\
\hline & IQR (rad) & 0.0117 & 0.0082 & 0.0075 & 0.0083 & 0.0103 & 0.0112 \\
\hline & IQR (nm) & 0.62 & 0.43 & 0.40 & 0.44 & 0.55 & 0.59 \\
\hline & Skewness & 0.6 & 0.5 & 1.1 & 1.6 & 1.7 & 1.6 \\
\hline & Kurtosis & 3.4 & 3.4 & 6.8 & 9.8 & 9.2 & 8.4 \\
\hline \multirow{8}{*}{$\lambda_{3}$} & Mean (rad) & 0.0187 & 0.0190 & 0.0199 & 0.0201 & 0.0203 & 0.0202 \\
\hline & Mean (nm) & 1.01 & 1.03 & 1.08 & 1.09 & 1.10 & 1.09 \\
\hline & Median (rad) & 0.0181 & 0.0187 & 0.0196 & 0.0199 & 0.0200 & 0.0200 \\
\hline & Median (nm) & 0.98 & 1.01 & 1.06 & 1.08 & 1.08 & 1.08 \\
\hline & IQR (rad) & 0.0093 & 0.0065 & 0.0050 & 0.0043 & 0.0037 & 0.0031 \\
\hline & IQR (nm) & 0.50 & 0.35 & 0.27 & 0.23 & 0.20 & 0.17 \\
\hline & Skewness & 0.5 & 0.4 & 0.4 & 0.5 & 0.5 & 0.6 \\
\hline & Kurtosis & 3.4 & 3.2 & 3.5 & 3.6 & 3.7 & 3.9 \\
\hline \multirow{8}{*}{$\Lambda_{13}$} & Mean (rad) & 0.0294 & 0.0299 & 0.0325 & 0.0349 & 0.0376 & 0.0388 \\
\hline & Mean (nm) & 68.7 & 69.8 & 75.9 & 81.5 & 87.8 & 90.6 \\
\hline & Median (rad) & 0.0285 & 0.0294 & 0.0318 & 0.0339 & 0.0361 & 0.0370 \\
\hline & Median (nm) & 66.6 & 68.7 & 74.3 & 79.2 & 84.3 & 86.4 \\
\hline & IQR (rad) & 0.0149 & 0.0103 & 0.0087 & 0.0089 & 0.0098 & 0.0102 \\
\hline & IQR (nm) & 34.8 & 24.1 & 20.3 & 20.8 & 22.9 & 23.8 \\
\hline & Skewness & 0.5 & 0.4 & 0.7 & 1.2 & 1.6 & 1.6 \\
\hline & Kurtosis & 3.3 & 3.3 & 4.4 & 7.8 & 9.8 & 9.0 \\
\hline
\end{tabular}




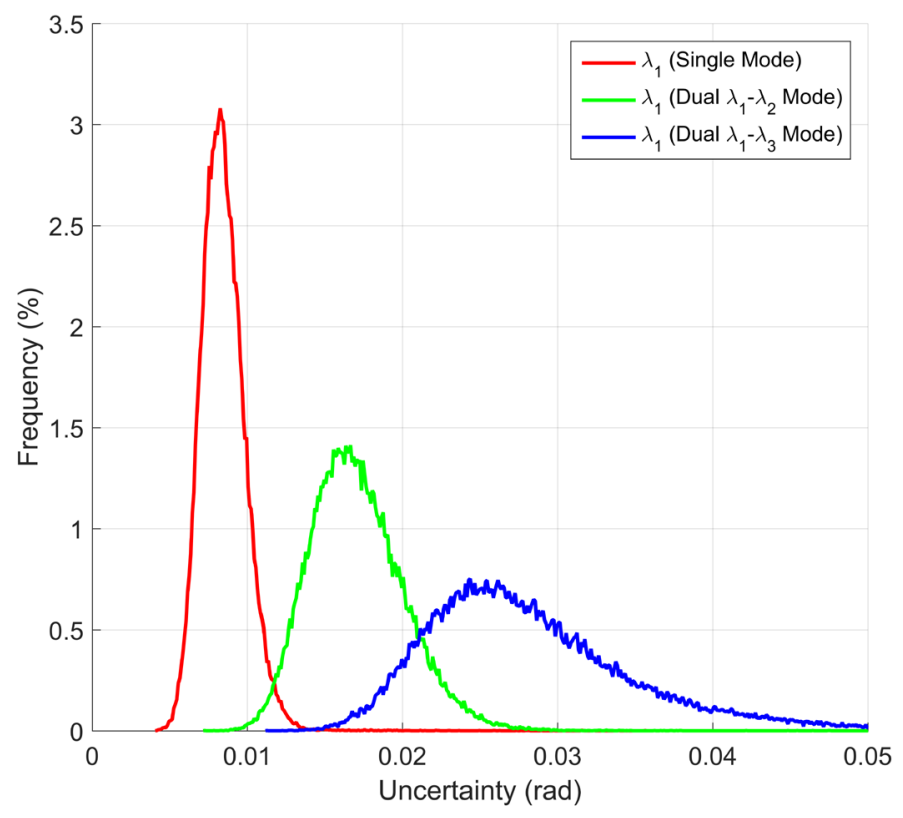

Fig. 11. Uncertainty over 30 reconstructed phase maps for a glass sample in air with the $10 \times$ objective lens comparing phase data for $\lambda_{1}$ obtained from single-wavelength mode, $\lambda_{1}-\lambda_{2}$ dual-wavelength mode, and $\lambda_{1}-\lambda_{3}$ dual-wavelength mode.

Table 10. Uncertainty characteristics for phase data in Fig. 11.

\begin{tabular}{|l|c|c|c|}
\hline & $\lambda_{1}$ (Single Mode) & $\begin{array}{c}\lambda_{1}\left(\text { Dual } \lambda_{1}-\lambda_{2}\right. \\
\text { Mode) }\end{array}$ & $\begin{array}{c}\lambda_{1} \text { (Dual } \lambda_{1}-\lambda_{3} \\
\text { Mode) }\end{array}$ \\
\hline Mean (rad) & 0.0085 & 0.0171 & 0.0284 \\
\hline Mean (nm) & 0.45 & 0.91 & 1.50 \\
\hline Median (rad) & 0.0083 & 0.0168 & 0.0271 \\
\hline Median (nm) & 0.44 & 0.89 & 1.44 \\
\hline IQR (rad) & 0.0018 & 0.0040 & 0.0083 \\
\hline IQR (nm) & 0.07 & 0.21 & 0.44 \\
\hline Skewness & 1.4 & 1.0 & 1.6 \\
\hline Kurtosis & 16.0 & 10.1 & 9.8 \\
\hline
\end{tabular}

\subsection{Measurements in Flowing Water (with an Immersion Objective)}

Using the $20 \times$ and $40 \times$ immersion lenses in distilled water, the uncertainty was determined over 100 reconstructed phase maps collected at $25 \mathrm{~s}^{-1}$. The uncertainty was evaluated at water flow rates of $0 \mathrm{~mL}$

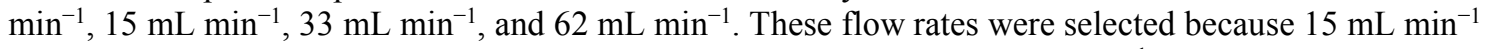
was the slowest repeatable flow rate that the pump could output, and $62 \mathrm{~mL} \mathrm{~min}^{-1}$ was the fastest flow rate that the reaction cell could handle with the immersion lens. The same area of the sample was examined as the flow rate was changed. For the $20 \times$ (Table 11 and Table 12) and $40 \times$ (Table 13 and Table 14) immersion lenses, the mean and median uncertainty increased with flow rate (Fig. 13), although the uncertainty was similar between flow rates of $15 \mathrm{~mL} \mathrm{~min}^{-1}$ and $33 \mathrm{~mL} \mathrm{~min}^{-1}$. With static water $(0 \mathrm{~mL}$ $\min ^{-1}$ ), the uncertainty was around $0.4 \mathrm{~nm}$ at both $20 \times$ and $40 \times$. At flow rates of $15 \mathrm{~mL} \mathrm{~min}^{-1}$ and $33 \mathrm{~mL}$ $\mathrm{min}^{-1}$, the uncertainty was less than $0.5 \mathrm{~nm}$ at both $20 \times$ and $40 \times$, while at a flow rate of $62 \mathrm{~mL} \mathrm{~min}^{-1}$, the uncertainty was at most $0.6 \mathrm{~nm}$ at $20 \times$ and $0.5 \mathrm{~nm}$ at $40 \times$. Figure 14 demonstrates the shift in the uncertainty distribution as a function of flow rate, while Fig. 15 compares the $0 \mathrm{~mL} \mathrm{~min}^{-1}$ and $62 \mathrm{~mL} \mathrm{~min}^{-1}$ uncertainty distributions. 


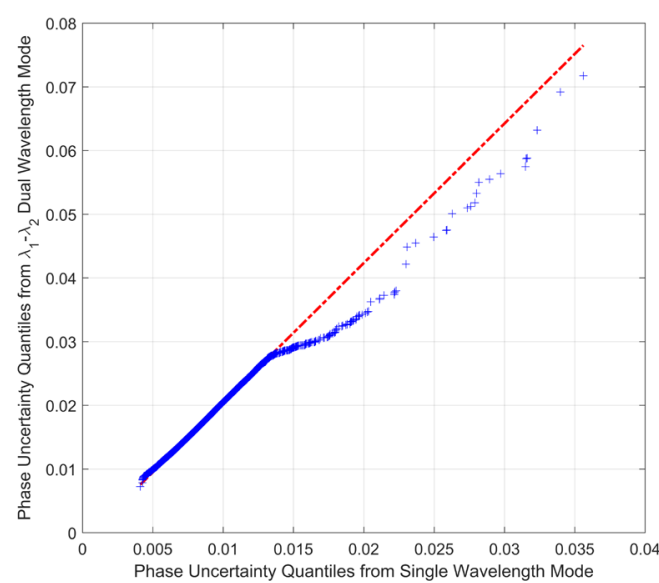

(a)

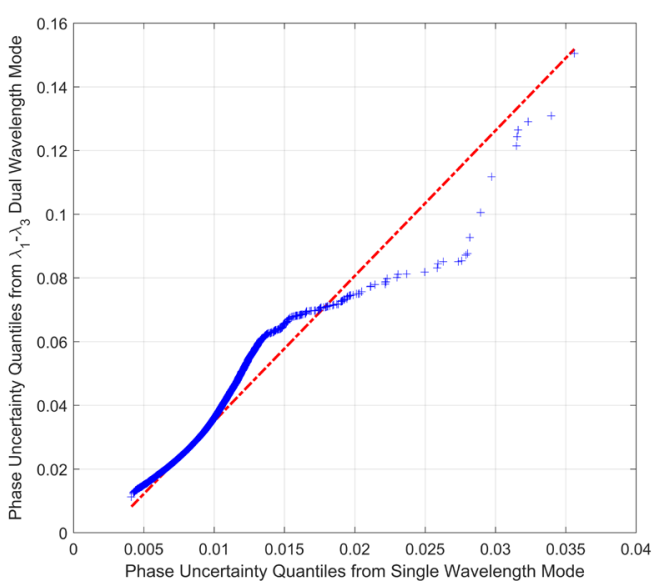

(b)

Fig. 12. Quantile-quantile plot of the phase uncertainty over 30 reconstructed phase maps for a glass sample in air with the $10 \times$ objective lens comparing (a) phase data for $\lambda_{1}$ obtained from single-wavelength mode to $\lambda_{1}$ obtained from $\lambda_{1}-\lambda_{2}$ dual-wavelength mode and (b) phase data for $\lambda_{1}$ obtained from single-wavelength mode to $\lambda_{1}$ obtained from $\lambda_{1}-\lambda_{3}$ dual-wavelength mode. A reference line (linear fit of the second and third quantiles) is shown in red.

Table 11. Mean uncertainty in the phase measurement with the $20 \times$ immersion lens in water.

\begin{tabular}{|c|l|c|c|c|c|}
\hline \multirow{2}{*}{} & \multirow{2}{*}{ Uncertainty } & \multicolumn{4}{|c|}{ Water Flow Rate $\left(\mathrm{mL} \mathrm{min}^{-1}\right)$} \\
\cline { 3 - 6 } & & 0 & 15 & 33 & 62 \\
\hline \multirow{2}{*}{$\begin{array}{c}\text { Collected from } 100 \\
\text { Holograms }\end{array}$} & $\mathrm{rad}$ & 0.0104 & 0.0116 & 0.0115 & 0.0150 \\
\cline { 2 - 6 } & $\mathrm{nm}$ & 0.41 & 0.46 & 0.46 & 0.60 \\
\hline $\begin{array}{c}\text { Collected from 50 } \\
\text { Holograms }\end{array}$ & $\mathrm{rad}$ & 0.0100 & 0.0117 & 0.0116 & 0.0153 \\
\cline { 2 - 6 } & $\mathrm{nm}$ & 0.40 & 0.47 & 0.46 & 0.61 \\
\hline $\begin{array}{c}\text { Collected from } 30 \\
\text { Holograms }\end{array}$ & $\mathrm{rad}$ & 0.0099 & 0.0116 & 0.0111 & 0.0125 \\
\cline { 2 - 6 } & $\mathrm{nm}$ & 0.39 & 0.46 & 0.44 & 0.50 \\
\hline $\begin{array}{c}\text { Collected from } 20 \\
\text { Holograms }\end{array}$ & $\mathrm{rad}$ & 0.0106 & 0.0115 & 0.0102 & 0.0146 \\
\cline { 2 - 6 } & $\mathrm{nm}$ & 0.42 & 0.46 & 0.41 & 0.58 \\
\hline $\begin{array}{c}\text { Collected from } 10 \\
\text { Holograms }\end{array}$ & $\mathrm{rad}$ & 0.0105 & 0.0123 & 0.0099 & 0.0124 \\
\cline { 2 - 6 } & $\mathrm{nm}$ & 0.42 & 0.49 & 0.39 & 0.49 \\
\hline $\begin{array}{c}\text { Collected from 5 } \\
\text { Holograms }\end{array}$ & $\mathrm{rad}$ & 0.4102 & 0.0114 & 0.0093 & 0.0118 \\
\cline { 2 - 6 } & $\mathrm{nm}$ & 0.45 & 0.37 & 0.47 \\
\hline
\end{tabular}

Table 12. Median uncertainty in the phase measurement with the $20 \times$ immersion lens in water.

\begin{tabular}{|c|l|c|c|c|c|}
\hline \multirow{2}{*}{} & \multirow{2}{*}{ Uncertainty } & \multicolumn{4}{|c|}{ Water Flow Rate $\left(\mathrm{mL} \mathrm{min}^{-1}\right)$} \\
\cline { 3 - 6 } & & 0 & 15 & 33 & 62 \\
\hline \multirow{2}{*}{$\begin{array}{c}\text { Collected from 100 } \\
\text { Holograms }\end{array}$} & $\mathrm{rad}$ & 0.0101 & 0.0112 & 0.0111 & 0.0143 \\
\cline { 2 - 6 } & $\mathrm{nm}$ & 0.40 & 0.45 & 0.44 & 0.57 \\
\hline $\begin{array}{c}\text { Collected from 50 } \\
\text { Holograms }\end{array}$ & $\mathrm{rad}$ & 0.0098 & 0.0113 & 0.0111 & 0.0142 \\
\cline { 2 - 6 } & $\mathrm{nm}$ & 0.39 & 0.45 & 0.44 & 0.57 \\
\hline $\begin{array}{c}\text { Collected from } 30 \\
\text { Holograms }\end{array}$ & $\mathrm{rad}$ & 0.0098 & 0.0112 & 0.0107 & 0.0121 \\
\cline { 2 - 6 } & $\mathrm{nm}$ & 0.39 & 0.45 & 0.43 & 0.48 \\
\hline $\begin{array}{c}\text { Collected from 20 } \\
\text { Holograms }\end{array}$ & $\mathrm{rad}$ & 0.0103 & 0.0112 & 0.0099 & 0.0140 \\
\cline { 2 - 6 } & $\mathrm{nm}$ & 0.0102 & 0.45 & 0.39 & 0.56 \\
\hline $\begin{array}{c}\text { Collected from 10 } \\
\text { Holograms }\end{array}$ & $\mathrm{rad}$ & 0.41 & 0.012 & 0.0096 & 0.0119 \\
\cline { 2 - 6 } & $\mathrm{nm}$ & 0.0098 & 0.010 & 0.38 & 0.47 \\
\hline $\begin{array}{c}\text { Collected from 5 } \\
\text { Holograms }\end{array}$ & $\mathrm{rad}$ & 0.39 & 0.43 & 0.0090 & 0.0113 \\
\cline { 2 - 6 } & $\mathrm{nm}$ & & & & 0.45 \\
\hline
\end{tabular}


Table 13. Mean uncertainty in the phase measurement with the $40 \times$ immersion lens in water.

\begin{tabular}{|c|l|c|c|c|c|}
\hline \multirow{2}{*}{} & \multirow{2}{*}{ Uncertainty } & \multicolumn{4}{|c|}{ Water Flow Rate $\left(\mathrm{mL} \mathrm{min}^{-1}\right)$} \\
\cline { 3 - 6 } & & 0 & 15 & 33 & 62 \\
\hline Collected from 100 & $\mathrm{rad}$ & 0.0102 & 0.0112 & 0.0112 & 0.0134 \\
\cline { 2 - 6 } Holograms & $\mathrm{nm}$ & 0.41 & 0.45 & 0.45 & 0.53 \\
\hline Collected from 50 & $\mathrm{rad}$ & 0.0104 & 0.0109 & 0.0107 & 0.0133 \\
\cline { 2 - 6 } Holograms & $\mathrm{nm}$ & 0.41 & 0.43 & 0.43 & 0.53 \\
\hline $\begin{array}{c}\text { Collected from } 30 \\
\text { Holograms }\end{array}$ & $\mathrm{rad}$ & 0.0107 & 0.0113 & 0.0106 & 0.0127 \\
\cline { 2 - 6 } & $\mathrm{nm}$ & 0.43 & 0.45 & 0.42 & 0.51 \\
\hline $\begin{array}{c}\text { Collected from 20 } \\
\text { Holograms }\end{array}$ & $\mathrm{rad}$ & 0.0103 & 0.0106 & 0.0106 & 0.0135 \\
\cline { 2 - 6 } & $\mathrm{nm}$ & 0.41 & 0.42 & 0.42 & 0.54 \\
\hline $\begin{array}{c}\text { Collected from 10 } \\
\text { Holograms }\end{array}$ & $\mathrm{rad}$ & 0.0099 & 0.0109 & 0.0103 & 0.0119 \\
\cline { 2 - 6 } & $\mathrm{nm}$ & 0.0106 & 0.43 & 0.41 & 0.47 \\
\hline Collected from 5 & $\mathrm{rad}$ & 0.42 & 0.45 & 0.0105 & 0.0118 \\
\cline { 2 - 6 } Holograms & $\mathrm{nm}$ & & & 0.42 & 0.47 \\
\hline
\end{tabular}

Table 14. Median uncertainty in the phase measurement with the $40 \times$ immersion lens in water.

\begin{tabular}{|c|l|c|c|c|c|}
\hline \multirow{2}{*}{} & \multirow{2}{*}{ Uncertainty } & \multicolumn{4}{|c|}{ Water Flow Rate $\left(\mathrm{mL} \mathrm{min}^{-1}\right)$} \\
\cline { 3 - 6 } & & 0 & 15 & 33 & 62 \\
\hline Collected from 100 & $\mathrm{rad}$ & 0.0106 & 0.011 & 0.0109 & 0.0129 \\
\cline { 2 - 6 } Holograms & $\mathrm{nm}$ & 0.42 & 0.44 & 0.43 & 0.51 \\
\hline Collected from 50 & $\mathrm{rad}$ & 0.0102 & 0.0108 & 0.0105 & 0.0127 \\
\cline { 2 - 6 } Holograms & $\mathrm{nm}$ & 0.41 & 0.43 & 0.42 & 0.51 \\
\hline $\begin{array}{c}\text { Collected from } 30 \\
\text { Holograms }\end{array}$ & $\mathrm{rad}$ & 0.0105 & 0.0111 & 0.0104 & 0.0123 \\
\cline { 2 - 6 } & $\mathrm{nm}$ & 0.42 & 0.44 & 0.41 & 0.49 \\
\hline $\begin{array}{c}\text { Collected from } 20 \\
\text { Holograms }\end{array}$ & $\mathrm{rad}$ & 0.0101 & 0.0104 & 0.0104 & 0.0130 \\
\cline { 2 - 6 } & $\mathrm{nm}$ & 0.40 & 0.41 & 0.41 & 0.52 \\
\hline $\begin{array}{c}\text { Collected from } 10 \\
\text { Holograms }\end{array}$ & $\mathrm{rad}$ & 0.0098 & 0.0107 & 0.0101 & 0.0114 \\
\cline { 2 - 6 } & $\mathrm{nm}$ & 0.39 & 0.43 & 0.40 & 0.45 \\
\hline $\begin{array}{c}\text { Collected from 5 } \\
\text { Holograms }\end{array}$ & $\mathrm{rad}$ & 0.0102 & 0.0109 & 0.0101 & 0.0112 \\
\cline { 2 - 6 } & $\mathrm{nm}$ & 0.41 & 0.43 & 0.40 & 0.45 \\
\hline
\end{tabular}

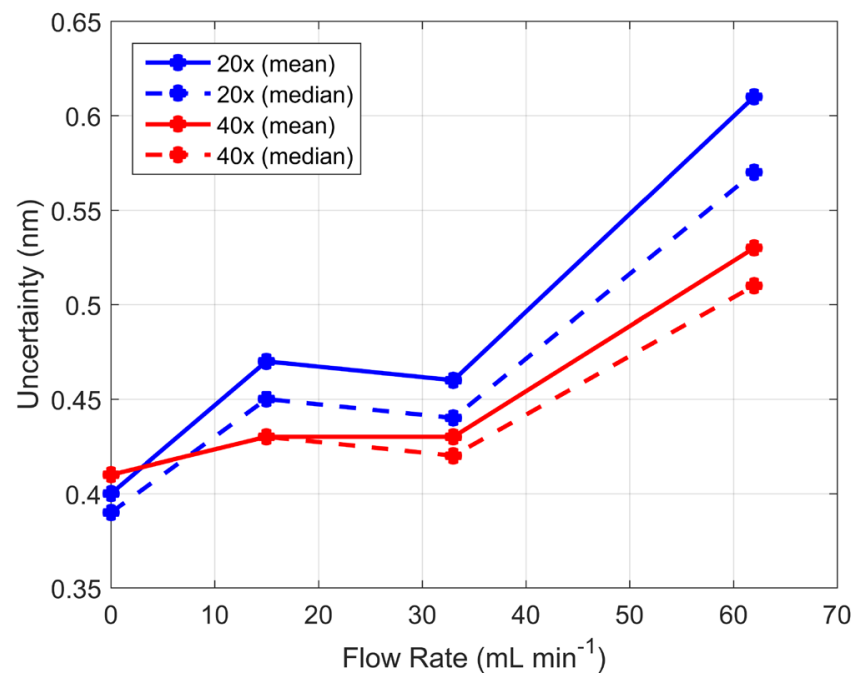

Fig. 13. Effect of flow rate on the mean and median uncertainty over 50 reconstructed phase maps for the $20 \times$ and $40 \times$ immersion lenses in water. 


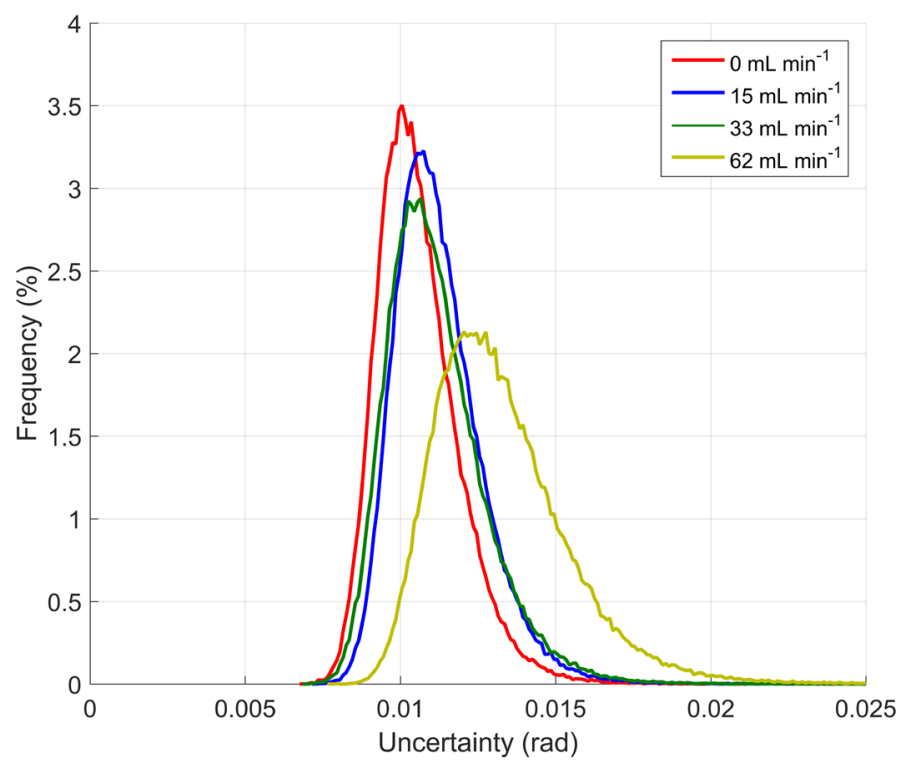

Fig. 14. Uncertainty over 100 reconstructed phase maps for a glass sample in water examined by a $40 \times$ immersion lens at various water flow rates and hologram acquisition rate at $25 \mathrm{~s}^{-1}$.

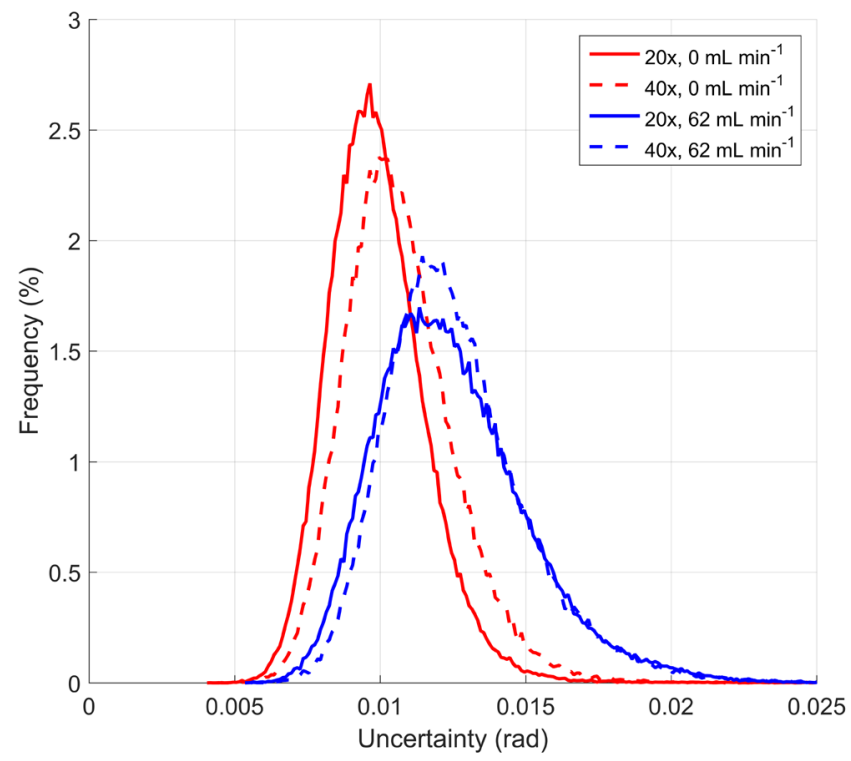

Fig. 15. Uncertainty over 30 reconstructed phase maps for a glass sample in water examined by $20 \times$ and $40 \times$ immersion lenses at two water flow rates and hologram acquisition rate at $25 \mathrm{~s}^{-1}$. 


\section{Journal of Research of the National Institute of Standards and Technology}

With regard to the normality of the data as evaluated by skewness and kurtosis, similar trends to Sec. 3.1 can be seen for the immersion lens data, namely, with regard to the distributions approaching normality with increasing magnification and decreasing sample size. With increasing flowing conditions, however, the skewness and kurtosis values both increase, indicating more positive skewness and a greater number of outliers (Table 15). Therefore, while the mean or median uncertainty value may not be greatly affected by slower flow rates (e.g., $15 \mathrm{~mL} \mathrm{~min}{ }^{-1}$ and $33 \mathrm{~mL} \mathrm{~min}$ ), the distribution skews to a greater number of outliers as the flow rate increases, particularly at high flow rates (e.g., $62 \mathrm{~mL} \mathrm{~min}^{-1}$ ), suggesting greater potential for uncertainty in the phase data as flow rate increases. The IQR also increases as the flow rate increases (Table 15), with the IQR from $62 \mathrm{~mL} \mathrm{~min}^{-1}$ potentially being twice the IQR value in static water. At $62 \mathrm{~mL} \mathrm{~min}^{-1}$, the IQR is $\leq 0.2 \mathrm{~nm}$, while the IQR is $\leq 0.15 \mathrm{~nm}$ for the $0 \mathrm{~mL} \mathrm{~min}^{-1}, 15 \mathrm{~mL} \mathrm{~min}^{-1}$, and 33 $\mathrm{mL} \min ^{-1}$ conditions. The magnitudes of the IQR values are comparable to the IQR for measurements in air from Sec. 3.1, although the IQR may be greater for the immersion lens data compared to measurements in air at a given number of holograms; for example, with 10 holograms at $20 \times$ magnification, the IQR is 0.15 $\mathrm{nm}$ for static conditions with the immersion lens, compared to $0.11 \mathrm{~nm}$ for measurements in air.

A quantile-quantile plot also demonstrates that the uncertainties at flow rates of $0 \mathrm{~mL} \mathrm{~min}{ }^{-1}$ and $62 \mathrm{~mL}$ $\min ^{-1}$ do not come from the same distribution (Fig. 16). Additionally, quantile-quantile plots comparing

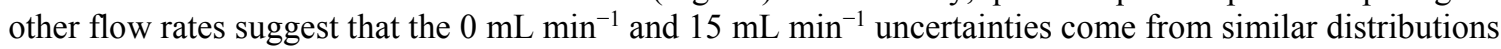
(Fig. 17a), while the $15 \mathrm{~mL} \mathrm{~min}^{-1}$ and $33 \mathrm{~mL} \mathrm{~min}^{-1}$ uncertainties may not (Fig. 17b). A plot of the empirical cumulative distribution function (ECDF) suggests similarities in the distributions for $0 \mathrm{~mL} \mathrm{~min}$, $15 \mathrm{~mL} \mathrm{~min}^{-1}$, and $33 \mathrm{~mL} \mathrm{~min}^{-1}$ (Fig. 18). To verify this, 1000 iterations of a two-sample KolmogorovSmirnov test were performed by randomly sampling 100 data points from each flow rate data set; results suggest that the $0 \mathrm{~mL} \mathrm{~min}{ }^{-1}, 15 \mathrm{~mL} \mathrm{~min}{ }^{-1}$, and $33 \mathrm{~mL} \mathrm{~min}^{-1}$ data sets were from the same distribution, while the $62 \mathrm{~mL} \mathrm{~min}^{-1}$ data set was not from the same distribution as any of the other flow rate data sets. ${ }^{4}$

\footnotetext{
${ }^{4}$ Of the 1000 iterations conducted, $82 \%$ of the Kolmogorov-Smirnov tests returned (with $95 \%$ confidence) that the $0 \mathrm{~mL} \mathrm{~min}^{-1}$ and $15 \mathrm{~mL} \mathrm{~min}^{-1}$ data sets were from the same distribution. Similarly, $84 \%, 94 \%, 0 \%$, and $0 \%$ of the tests returned that the $0 \mathrm{~mL} \mathrm{~min}^{-1}$ and $33 \mathrm{~mL} \mathrm{~min}{ }^{-1}$ data sets, $15 \mathrm{~mL} \mathrm{~min}^{-1}$ and $33 \mathrm{~mL} \mathrm{~min}^{-1}$ data sets, $0 \mathrm{~mL} \mathrm{~min}^{-1}$ and $62 \mathrm{~mL} \mathrm{~min}^{-1}$ data sets, and $33 \mathrm{~mL} \mathrm{~min}^{-1}$ and 62 $\mathrm{mL} \mathrm{min}^{-1}$ data sets were from the same distribution, respectively.
} 
Table 15. IQR, skewness, and kurtosis of data for flowing water with an immersion lens.

\begin{tabular}{|c|c|c|c|c|c|c|}
\hline \multirow{2}{*}{$\begin{array}{l}\text { Immersion } \\
\text { Lens }\end{array}$} & \multirow{2}{*}{$\begin{array}{l}\text { No. of } \\
\text { Holograms }\end{array}$} & \multirow{2}{*}{ Metric } & \multicolumn{4}{|c|}{ Water Flow Rate $\left(\mathrm{mL} \min ^{-1}\right)$} \\
\hline & & & 0 & 15 & 33 & 62 \\
\hline \multirow{24}{*}{$20 \times$} & \multirow{4}{*}{100} & IQR (rad) & 0.0017 & 0.0021 & 0.0026 & 0.0035 \\
\hline & & IQR (nm) & 0.07 & 0.08 & 0.10 & 0.14 \\
\hline & & Skewness & 7.8 & 8.2 & 9.8 & 4.2 \\
\hline & & Kurtosis & 176.6 & 213.5 & 270.1 & 66.1 \\
\hline & \multirow{4}{*}{50} & IQR (rad) & 0.0018 & 0.0025 & 0.0028 & 0.0038 \\
\hline & & IQR (nm) & 0.07 & 0.10 & 0.11 & 0.15 \\
\hline & & Skewness & 6.7 & 6.9 & 8.3 & 3.8 \\
\hline & & Kurtosis & 154.1 & 167.5 & 201.7 & 32.4 \\
\hline & \multirow{4}{*}{30} & IQR (rad) & 0.0021 & 0.0029 & 0.0028 & 0.0033 \\
\hline & & IQR (nm) & 0.08 & 0.12 & 0.11 & 0.13 \\
\hline & & Skewness & 5.7 & 6.8 & 7.5 & 5.5 \\
\hline & & Kurtosis & 127.9 & 174.3 & 162.3 & 162.8 \\
\hline & \multirow{4}{*}{20} & IQR (rad) & 0.0029 & 0.0030 & 0.0026 & 0.0047 \\
\hline & & IQR (nm) & 0.12 & 0.12 & 0.10 & 0.19 \\
\hline & & Skewness & 4.7 & 4.3 & 7.6 & 2.9 \\
\hline & & Kurtosis & 85.8 & 92.5 & 168.6 & 45.8 \\
\hline & \multirow{4}{*}{10} & IQR (rad) & 0.0038 & 0.0042 & 0.0034 & 0.0050 \\
\hline & & IQR (nm) & 0.15 & 0.17 & 0.14 & 0.20 \\
\hline & & Skewness & 2.4 & 2.1 & 2.7 & 3.8 \\
\hline & & Kurtosis & 31.2 & 28.9 & 35.4 & 98.7 \\
\hline & \multirow{4}{*}{5} & IQR (rad) & 0.0053 & 0.0060 & 0.0047 & 0.0063 \\
\hline & & IQR (nm) & 0.21 & 0.24 & 0.19 & 0.25 \\
\hline & & Skewness & 1.2 & 1.0 & 1.5 & 2.6 \\
\hline & & Kurtosis & 10.2 & 6.4 & 14.4 & 51.9 \\
\hline \multirow{24}{*}{$40 \times$} & \multirow{4}{*}{100} & IQR (rad) & 0.0017 & 0.0018 & 0.0020 & 0.0027 \\
\hline & & IQR (nm) & 0.07 & 0.07 & 0.08 & 0.11 \\
\hline & & Skewness & 3.1 & 6.4 & 17.9 & 18.4 \\
\hline & & Kurtosis & 46.7 & 175.7 & 1042 & 496.5 \\
\hline & \multirow{4}{*}{50} & IQR (rad) & 0.0018 & 0.0019 & 0.0020 & 0.0028 \\
\hline & & IQR (nm) & 0.07 & 0.08 & 0.08 & 0.11 \\
\hline & & Skewness & 2.5 & 4.3 & 19.8 & 18.3 \\
\hline & & Kurtosis & 36.6 & 109.8 & 1181 & 487.3 \\
\hline & \multirow{4}{*}{30} & IQR (rad) & 0.0024 & 0.0025 & 0.0024 & 0.0030 \\
\hline & & IQR (nm) & 0.10 & 0.10 & 0.10 & 0.12 \\
\hline & & Skewness & 1.8 & 2.7 & 11.3 & 14.4 \\
\hline & & Kurtosis & 20.7 & 47.6 & 553.8 & 381.4 \\
\hline & \multirow{4}{*}{20} & IQR (rad) & 0.0026 & 0.0026 & 0.0027 & 0.0036 \\
\hline & & IQR (nm) & 0.10 & 0.10 & 0.11 & 0.14 \\
\hline & & Skewness & 2.1 & 2.3 & 11.5 & 16.4 \\
\hline & & Kurtosis & 29.6 & 47.4 & 573.0 & 427.5 \\
\hline & \multirow{4}{*}{10} & IQR (rad) & 0.0033 & 0.0038 & 0.0035 & 0.0042 \\
\hline & & IQR (nm) & 0.13 & 0.15 & 0.14 & 0.17 \\
\hline & & Skewness & 0.5 & 0.9 & 7.8 & 12.8 \\
\hline & & Kurtosis & 4.6 & 9.2 & 355.1 & 331.1 \\
\hline & \multirow{4}{*}{5} & IQR (rad) & 0.0055 & 0.0056 & 0.0054 & 0.0060 \\
\hline & & IQR (nm) & 0.22 & 0.22 & 0.22 & 0.24 \\
\hline & & Skewness & 0.7 & 0.6 & 2.5 & 9.5 \\
\hline & & Kurtosis & 4.0 & 4.2 & 56.8 & 219.8 \\
\hline
\end{tabular}




\section{Journal of Research of the National Institute of Standards and Technology}

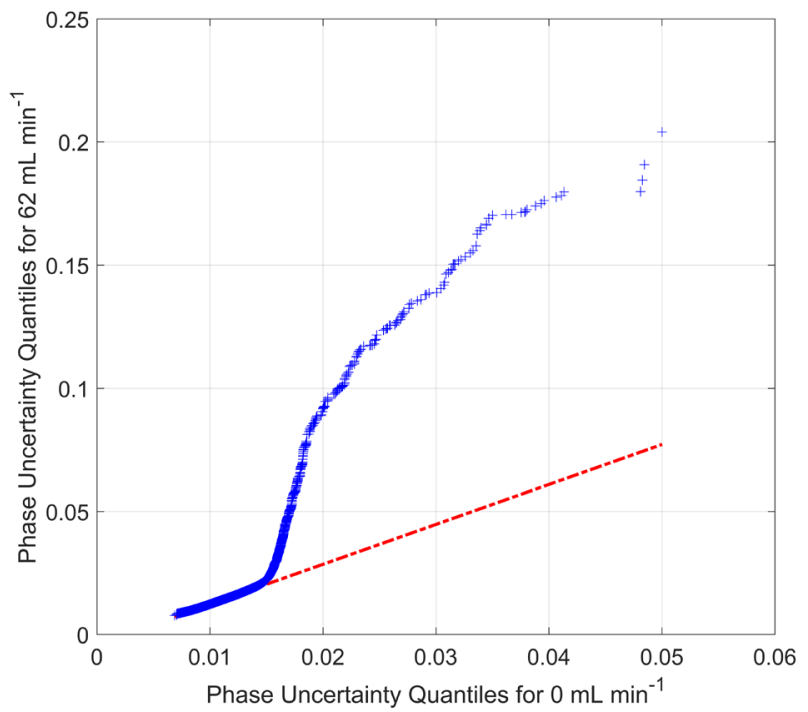

Fig. 16. Quantile-quantile plot of the phase uncertainty over 100 reconstructed phase maps for a glass sample in water examined by a $40 \times$ immersion lens, comparing uncertainty at flow rates of $0 \mathrm{~mL} \mathrm{~min}^{-1}$ and $62 \mathrm{~mL} \mathrm{~min}{ }^{-1}$. Hologram acquisition rate at $25 \mathrm{~s}^{-1}$. A reference line (linear fit of the second and third quantiles) is shown in red.

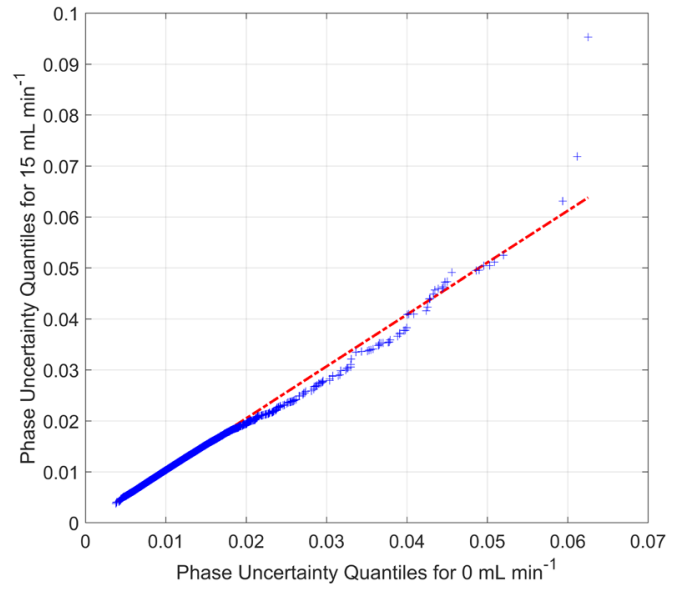

(a)

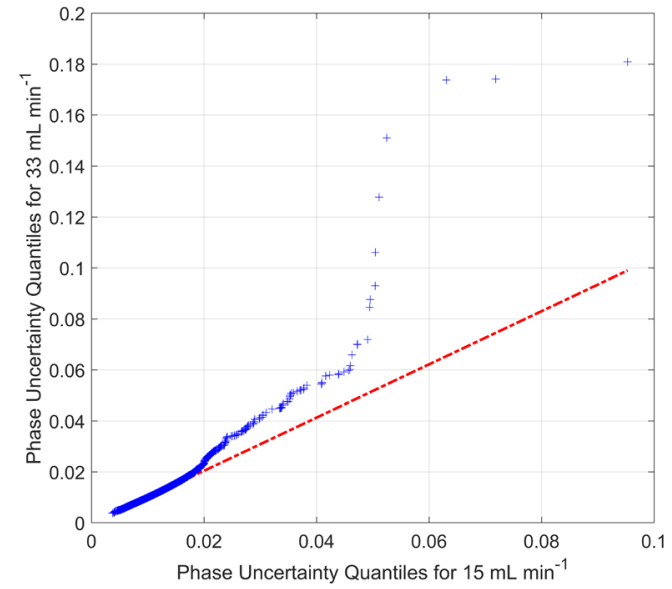

(b)

Fig. 17. Quantile-quantile plot of the phase uncertainty over 50 reconstructed phase maps for a glass sample in water examined by a $40 \times$ immersion lens, comparing uncertainty at flow rates of (a) $0 \mathrm{~mL} \mathrm{~min}^{-1}$ and $15 \mathrm{~mL} \mathrm{~min}^{-1}$ and (b) $15 \mathrm{~mL} \mathrm{~min}^{-1}$ and $33 \mathrm{~mL} \mathrm{~min}^{-1}$. A reference line (linear fit of the second and third quantiles) is shown in red. 


\section{Journal of Research of the National Institute of Standards and Technology}

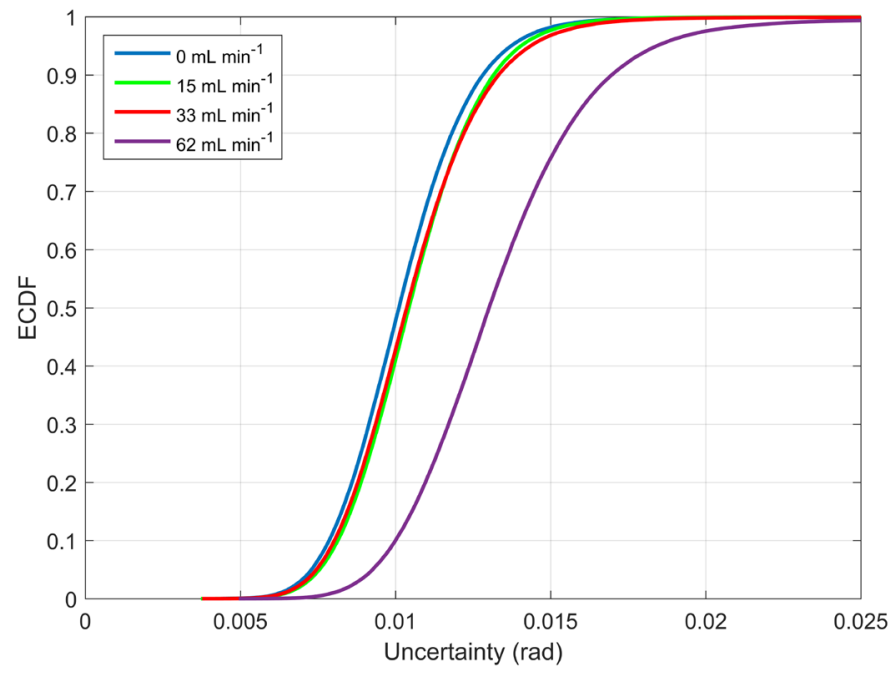

Fig. 18. ECDF plot of the phase uncertainty over 50 reconstructed phase maps for a glass sample in water examined by a $40 \times$ immersion lens for each flow rate.

In a comparison of the uncertainty from similar magnifications in air to the immersion lens data in water under static conditions (Table 16), the mean phase uncertainty (rad) is greater for the immersion lens data, but the mean height uncertainty $(\mathrm{nm})$ is comparable $(0.4 \mathrm{~nm}$ to $0.5 \mathrm{~nm})$. This is because the phase-toheight conversion, shown previously as Eq. (1), includes the index of refraction of the medium, so in air, the height is directly proportional to the phase, while in water, the height is directly proportional to the phase divided by 1.33. The two-sample Kolmogorov-Smirnov test suggested that the phase uncertainties are not from the same distribution when comparing the $20 \times$ objective lens in air to the $20 \times$ immersion objective lens in water and the $40 \times$ objective lens in air to the $40 \times$ immersion objective lens in water (i.e., all phase data comparison results rejected the null hypothesis with $95 \%$ confidence), although comparing the height uncertainty, the Kolmogorov-Smirnov test suggests that, at lower hologram sample sizes, the height uncertainty may be from similar continuous distributions, ${ }^{5}$ evidence of which can also be noted in a quantile-quantile plot of the $40 \times$ data (Fig. 19).

\footnotetext{
${ }^{5}$ Of the 1000 iterations conducted, $73 \%$ and $65 \%$ of the Kolmogorov-Smirnov tests returned (with $95 \%$ confidence) that the height data sets for the $20 \times$ objective lens in air and $20 \times$ immersion lens in water were from the same distribution for the 10 - and 5 hologram sample sizes, respectively, and $80 \%, 79 \%, 94 \%$, and $87 \%$ of the Kolmogorov-Smirnov tests returned (with $95 \%$ confidence) that the height data sets for the $40 \times$ objective lens in air and $40 \times$ immersion lens in water were from the same distribution for the 30-, 20-, $10-$, and 5-hologram sample sizes, respectively.
} 
Table 16. Mean uncertainty comparing $20 \times$ and $40 \times$ objective lenses in air and in water (static conditions).

\begin{tabular}{|c|c|c|c|c|c|}
\hline & \multirow{2}{*}{$\begin{array}{l}\text { Mean } \\
\text { Uncertainty }\end{array}$} & \multicolumn{4}{|c|}{ Objective Lens and Medium } \\
\hline & & $20 \times$ in Air & $20 \times$ in Water & $40 \times$ in Air & $40 \times$ in Water \\
\hline \multirow{2}{*}{$\begin{array}{c}\text { Collected from } 100 \\
\text { Holograms }\end{array}$} & $\mathrm{rad}$ & 0.0086 & 0.0104 & 0.0093 & 0.0102 \\
\hline & $\mathrm{nm}$ & 0.46 & 0.41 & 0.49 & 0.41 \\
\hline \multirow{2}{*}{$\begin{array}{c}\text { Collected from } 50 \\
\text { Holograms }\end{array}$} & $\mathrm{rad}$ & 0.0087 & 0.0100 & 0.0088 & 0.0104 \\
\hline & $\mathrm{nm}$ & 0.46 & 0.40 & 0.47 & 0.41 \\
\hline \multirow{2}{*}{$\begin{array}{c}\text { Collected from } 30 \\
\text { Holograms }\end{array}$} & $\mathrm{rad}$ & 0.0086 & 0.0099 & 0.0083 & 0.0107 \\
\hline & $\mathrm{nm}$ & 0.46 & 0.39 & 0.44 & 0.43 \\
\hline \multirow{2}{*}{$\begin{array}{c}\text { Collected from } 20 \\
\text { Holograms }\end{array}$} & $\mathrm{rad}$ & 0.0084 & 0.0106 & 0.0080 & 0.0103 \\
\hline & $\mathrm{nm}$ & 0.44 & 0.42 & 0.42 & 0.41 \\
\hline \multirow{2}{*}{$\begin{array}{c}\text { Collected from } 10 \\
\text { Holograms }\end{array}$} & $\mathrm{rad}$ & 0.0082 & 0.0105 & 0.0075 & 0.0099 \\
\hline & $\mathrm{nm}$ & 0.43 & 0.42 & 0.40 & 0.39 \\
\hline \multirow{2}{*}{$\begin{array}{c}\text { Collected from } 5 \\
\text { Holograms }\end{array}$} & $\mathrm{rad}$ & 0.0084 & 0.0102 & 0.0075 & 0.0106 \\
\hline & $\mathrm{nm}$ & 0.44 & 0.41 & 0.40 & 0.42 \\
\hline
\end{tabular}

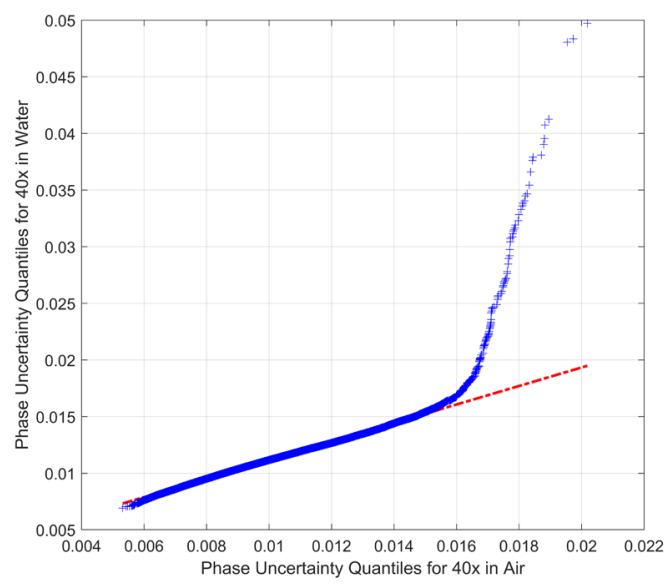

(a)

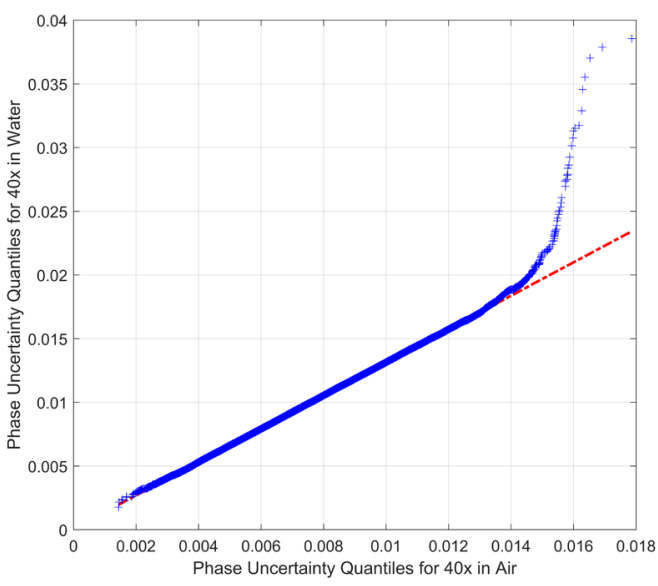

(b)

Fig. 19. Quantile-quantile plot of the phase uncertainty over (a) 100 and (b) 10 reconstructed phase maps for a glass sample examined by a $40 \times$ lens, comparing measurements in air and water. A reference line (linear fit of the second and third quantiles) is shown in red.

\subsection{Measurements in Flowing Water (through a Glass Window)}

For measurements through a window, only objective lenses up to $20 \times$ could be used, because of the limitations of shorter free working distances for the higher magnification objectives (see Table 1). The window used was float glass with a thickness of about $1.0 \mathrm{~mm}$, and it had an anti-reflective coating. Greater flow rates were possible in this configuration, since the water is forced through the outflow (with the immersion lens configuration, an "open-channel" condition permits the water to back up and spill over the

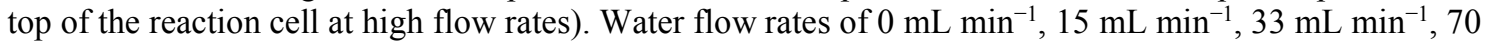

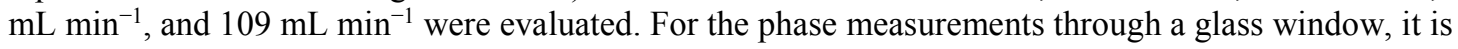
evident that the uncertainty increases from static to flowing water conditions (Table 17, Table 18, Table 19, and Fig. 20). In static water conditions, the uncertainty is on the order of $\leq 0.7 \mathrm{~nm}$ at $5 \times$ and $\leq 0.5 \mathrm{~nm}$ at $10 \times$ and $20 \times$ magnification. At slow flow conditions (up to $15 \mathrm{~mL} \mathrm{~min}^{-1}$ ), the uncertainty is less than $1 \mathrm{~nm}$ for all magnifications, but at faster flow conditions (up to $109 \mathrm{~mL} \mathrm{~min}^{-1}$ ), the uncertainty is as high as 1.8 $\mathrm{nm}$ at $5 \times, 1.0 \mathrm{~nm}$ at $10 \times$, and $2.4 \mathrm{~nm}$ at $20 \times$ magnification. The sudden increase in mean uncertainty at $20 \times$ from $70 \mathrm{~mL} \mathrm{~min}^{-1}$ to $109 \mathrm{~mL} \mathrm{~min}^{-1}$ is unexpected, considering that the mean uncertainty decreased at $5 \times$ and $10 \times$ with the same change in flow rate (Fig. 20); this is likely caused by some additional extrinsic factors (e.g., turbulence, vibration). 
Table 17. Phase measurement uncertainty characteristics with a $5 \times$ lens through a glass window.

\begin{tabular}{|c|c|c|c|c|c|c|c|}
\hline \multirow{2}{*}{$\begin{array}{l}\text { Flow Rate } \\
\left(\mathrm{mL} \min ^{-1}\right)\end{array}$} & \multirow{2}{*}{ Data Value } & \multicolumn{6}{|c|}{ No. of Holograms } \\
\hline & & 5 & 10 & 20 & 30 & 50 & 100 \\
\hline \multirow{8}{*}{0} & Mean (rad) & 0.0115 & 0.0108 & 0.0126 & 0.0126 & 0.0130 & 0.0184 \\
\hline & Mean (nm) & 0.46 & 0.43 & 0.50 & 0.50 & 0.52 & 0.73 \\
\hline & Median (rad) & 0.0111 & 0.0105 & 0.0123 & 0.0123 & 0.0126 & 0.0167 \\
\hline & Median (nm) & 0.44 & 0.42 & 0.49 & 0.49 & 0.50 & 0.66 \\
\hline & IQR (rad) & 0.0060 & 0.0040 & 0.0032 & 0.0032 & 0.0035 & 0.0080 \\
\hline & IQR (nm) & 0.24 & 0.16 & 0.13 & 0.13 & 0.14 & 0.32 \\
\hline & Skewness & 0.5 & 0.5 & 0.7 & 0.8 & 0.9 & 1.0 \\
\hline & Kurtosis & 3.3 & 3.4 & 3.7 & 3.9 & 3.9 & 3.3 \\
\hline \multirow{8}{*}{15} & Mean (rad) & 0.0214 & 0.0166 & 0.0213 & 0.0247 & 0.0245 & 0.0230 \\
\hline & Mean (nm) & 0.85 & 0.66 & 0.85 & 0.98 & 0.97 & 0.91 \\
\hline & Median (rad) & 0.0193 & 0.0150 & 0.0185 & 0.0214 & 0.0213 & 0.0200 \\
\hline & Median (nm) & 0.77 & 0.60 & 0.74 & 0.85 & 0.85 & 0.79 \\
\hline & IQR (rad) & 0.0157 & 0.0088 & 0.0152 & 0.0183 & 0.0183 & 0.0164 \\
\hline & IQR (nm) & 0.62 & 0.35 & 0.60 & 0.73 & 0.73 & 0.65 \\
\hline & Skewness & 0.7 & 2.5 & 0.9 & 0.8 & 0.8 & 0.8 \\
\hline & Kurtosis & 3.0 & 16.8 & 3.1 & 2.9 & 2.8 & 2.9 \\
\hline \multirow{8}{*}{33} & Mean (rad) & 0.0448 & 0.0555 & 0.0373 & 0.0417 & 0.0435 & 0.0446 \\
\hline & Mean (nm) & 1.78 & 2.21 & 1.48 & 1.66 & 1.73 & 1.77 \\
\hline & Median (rad) & 0.0386 & 0.0479 & 0.0330 & 0.0365 & 0.0379 & 0.0387 \\
\hline & Median (nm) & 1.53 & 1.90 & 1.31 & 1.45 & 1.51 & 1.54 \\
\hline & IQR (rad) & 0.0357 & 0.0454 & 0.0228 & 0.0277 & 0.0296 & 0.0309 \\
\hline & IQR (nm) & 1.42 & 1.80 & 0.91 & 1.10 & 1.18 & 1.23 \\
\hline & Skewness & 1.0 & 0.9 & 1.0 & 0.9 & 0.9 & 0.9 \\
\hline & Kurtosis & 3.8 & 3.1 & 4 & 3.3 & 3.3 & 3.3 \\
\hline \multirow{8}{*}{70} & Mean (rad) & 0.0248 & 0.0527 & 0.0407 & 0.0379 & 0.0357 & 0.0428 \\
\hline & Mean (nm) & 0.99 & 2.09 & 1.62 & 1.51 & 1.42 & 1.70 \\
\hline & Median (rad) & 0.0217 & 0.0433 & 0.0334 & 0.0311 & 0.0292 & 0.0349 \\
\hline & Median (nm) & 0.86 & 1.72 & 1.33 & 1.24 & 1.16 & 1.39 \\
\hline & IQR (rad) & 0.0208 & 0.0570 & 0.0420 & 0.0378 & 0.0350 & 0.0443 \\
\hline & IQR (nm) & 0.83 & 2.26 & 1.67 & 1.50 & 1.39 & 1.76 \\
\hline & Skewness & 0.6 & 0.5 & 0.5 & 0.6 & 0.6 & 0.5 \\
\hline & Kurtosis & 2.3 & 2.0 & 2.0 & 2.0 & 2.0 & 2.0 \\
\hline \multirow{8}{*}{109} & Mean (rad) & 0.0123 & 0.0244 & 0.0250 & 0.0313 & 0.0286 & 0.0312 \\
\hline & Mean (nm) & 0.49 & 0.97 & 0.99 & 1.24 & 1.14 & 1.24 \\
\hline & Median (rad) & 0.0113 & 0.0209 & 0.0211 & 0.0259 & 0.0238 & 0.0258 \\
\hline & Median (nm) & 0.45 & 0.83 & 0.84 & 1.03 & 0.95 & 1.03 \\
\hline & IQR (rad) & 0.0071 & 0.0204 & 0.0206 & 0.0294 & 0.0255 & 0.0289 \\
\hline & IQR (nm) & 0.28 & 0.81 & 0.82 & 1.17 & 1.01 & 1.15 \\
\hline & Skewness & 1.0 & 0.6 & 0.6 & 0.6 & 0.6 & 0.6 \\
\hline & Kurtosis & 4.2 & 2.3 & 2.2 & 2.1 & 2.1 & 2.1 \\
\hline
\end{tabular}


Table 18. Phase measurement uncertainty characteristics with a $10 \times$ lens through a glass window.

\begin{tabular}{|c|c|c|c|c|c|c|c|}
\hline \multirow{2}{*}{$\begin{array}{l}\text { Flow Rate } \\
\left(\mathrm{mL} \min ^{-1}\right)\end{array}$} & \multirow{2}{*}{ Data Value } & \multicolumn{6}{|c|}{ No. of Holograms } \\
\hline & & 5 & 10 & 20 & 30 & 50 & 100 \\
\hline \multirow{8}{*}{0} & Mean (rad) & 0.0103 & 0.0103 & 0.0110 & 0.0106 & 0.0111 & 0.0115 \\
\hline & Mean (nm) & 0.41 & 0.41 & 0.44 & 0.42 & 0.44 & 0.46 \\
\hline & Median (rad) & 0.0099 & 0.0101 & 0.0108 & 0.0104 & 0.0109 & 0.0112 \\
\hline & Median (nm) & 0.39 & 0.40 & 0.43 & 0.41 & 0.43 & 0.45 \\
\hline & IQR (rad) & 0.0053 & 0.0036 & 0.0030 & 0.0024 & 0.0024 & 0.0022 \\
\hline & IQR (nm) & 0.21 & 0.14 & 0.12 & 0.10 & 0.10 & 0.09 \\
\hline & Skewness & 0.6 & 0.5 & 0.6 & 0.6 & 1.0 & 1.2 \\
\hline & Kurtosis & 3.6 & 3.4 & 3.8 & 3.7 & 5.1 & 6.1 \\
\hline \multirow{8}{*}{15} & Mean (rad) & 0.0108 & 0.0165 & 0.0180 & 0.0172 & 0.0186 & 0.0196 \\
\hline & Mean (nm) & 0.43 & 0.66 & 0.72 & 0.68 & 0.74 & 0.78 \\
\hline & Median (rad) & 0.0103 & 0.0152 & 0.0168 & 0.0160 & 0.0173 & 0.0179 \\
\hline & Median (nm) & 0.41 & 0.60 & 0.67 & 0.64 & 0.69 & 0.71 \\
\hline & IQR (rad) & 0.0057 & 0.0080 & 0.0083 & 0.0077 & 0.0087 & 0.0095 \\
\hline & IQR (nm) & 0.23 & 0.32 & 0.33 & 0.31 & 0.35 & 0.38 \\
\hline & Skewness & 0.9 & 1.1 & 0.9 & 1.1 & 1.0 & 1.0 \\
\hline & Kurtosis & 5.8 & 6.1 & 4.5 & 5.5 & 4.6 & 4.2 \\
\hline \multirow{8}{*}{33} & Mean (rad) & 0.0267 & 0.0250 & 0.0221 & 0.0233 & 0.0227 & 0.0233 \\
\hline & Mean (nm) & 1.06 & 0.99 & 0.88 & 0.93 & 0.90 & 0.93 \\
\hline & Median (rad) & 0.0232 & 0.0221 & 0.0200 & 0.0210 & 0.0205 & 0.0210 \\
\hline & Median (nm) & 0.92 & 0.88 & 0.79 & 0.83 & 0.81 & 0.83 \\
\hline & IQR (rad) & 0.0216 & 0.0171 & 0.0128 & 0.0138 & 0.0130 & 0.0138 \\
\hline & IQR (nm) & 0.86 & 0.68 & 0.51 & 0.55 & 0.52 & 0.55 \\
\hline & Skewness & 0.9 & 0.9 & 0.9 & 0.9 & 0.9 & 0.9 \\
\hline & Kurtosis & 3.2 & 3.4 & 3.5 & 3.4 & 3.4 & 3.4 \\
\hline \multirow{8}{*}{70} & Mean (rad) & 0.0197 & 0.0223 & 0.0219 & 0.0237 & 0.0245 & 0.0233 \\
\hline & Mean (nm) & 0.78 & 0.89 & 0.87 & 0.94 & 0.97 & 0.93 \\
\hline & Median (rad) & 0.0184 & 0.0212 & 0.0209 & 0.0227 & 0.0235 & 0.0223 \\
\hline & Median (nm) & 0.73 & 0.84 & 0.83 & 0.90 & 0.93 & 0.89 \\
\hline & IQR (rad) & 0.0121 & 0.0132 & 0.0123 & 0.0143 & 0.0153 & 0.0138 \\
\hline & IQR (nm) & 0.48 & 0.52 & 0.49 & 0.57 & 0.61 & 0.55 \\
\hline & Skewness & 0.9 & 0.5 & 0.6 & 0.4 & 0.4 & 0.4 \\
\hline & Kurtosis & 4.5 & 3 & 3.3 & 2.7 & 2.5 & 2.7 \\
\hline \multirow{8}{*}{109} & Mean (rad) & 0.0131 & 0.0135 & 0.0132 & 0.0134 & 0.0133 & 0.0132 \\
\hline & Mean (nm) & 0.52 & 0.54 & 0.52 & 0.53 & 0.53 & 0.52 \\
\hline & Median (rad) & 0.0122 & 0.0128 & 0.0127 & 0.0128 & 0.0126 & 0.0126 \\
\hline & Median (nm) & 0.48 & 0.51 & 0.50 & 0.51 & 0.50 & 0.50 \\
\hline & IQR (rad) & 0.0075 & 0.0056 & 0.0045 & 0.0043 & 0.0040 & 0.0038 \\
\hline & IQR (nm) & 0.30 & 0.22 & 0.18 & 0.17 & 0.16 & 0.15 \\
\hline & Skewness & 1.2 & 1.6 & 1.9 & 2.2 & 2.4 & 2.5 \\
\hline & Kurtosis & 7.7 & 13.9 & 19.8 & 22.2 & 25.0 & 27.6 \\
\hline
\end{tabular}


Table 19. Phase measurement uncertainty characteristics with a $20 \times$ lens through a glass window.

\begin{tabular}{|c|c|c|c|c|c|c|c|}
\hline \multirow{2}{*}{ 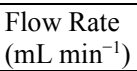 } & \multirow{2}{*}{ Data Value } & \multicolumn{6}{|c|}{ No. of Holograms } \\
\hline & & 5 & 10 & 20 & 30 & 50 & 100 \\
\hline \multirow{8}{*}{0} & Mean (rad) & 0.0112 & 0.0108 & 0.0112 & 0.0112 & 0.0115 & 0.0118 \\
\hline & Mean (nm) & 0.45 & 0.43 & 0.45 & 0.45 & 0.46 & 0.47 \\
\hline & Median (rad) & 0.0108 & 0.0105 & 0.0110 & 0.0111 & 0.0112 & 0.0115 \\
\hline & Median (nm) & 0.43 & 0.42 & 0.44 & 0.44 & 0.45 & 0.46 \\
\hline & IQR (rad) & 0.0058 & 0.0038 & 0.0030 & 0.0025 & 0.0023 & 0.0021 \\
\hline & IQR (nm) & 0.23 & 0.15 & 0.12 & 0.10 & 0.09 & 0.08 \\
\hline & Skewness & 0.6 & 0.5 & 0.8 & 0.7 & 1.3 & 1.3 \\
\hline & Kurtosis & 3.4 & 3.4 & 4.9 & 4.2 & 8.2 & 6.2 \\
\hline \multirow{8}{*}{15} & Mean (rad) & 0.0193 & 0.0204 & 0.0201 & 0.0190 & 0.0200 & 0.0206 \\
\hline & Mean (nm) & 0.77 & 0.81 & 0.80 & 0.75 & 0.79 & 0.82 \\
\hline & Median (rad) & 0.0188 & 0.0196 & 0.0195 & 0.0184 & 0.0194 & 0.0200 \\
\hline & Median (nm) & 0.75 & 0.78 & 0.77 & 0.73 & 0.77 & 0.79 \\
\hline & IQR (rad) & 0.0098 & 0.0099 & 0.0082 & 0.0072 & 0.0076 & 0.0080 \\
\hline & IQR (nm) & 0.39 & 0.39 & 0.33 & 0.29 & 0.30 & 0.32 \\
\hline & Skewness & 0.3 & 0.6 & 0.5 & 0.5 & 0.4 & 0.4 \\
\hline & Kurtosis & 2.9 & 3.0 & 2.9 & 2.8 & 2.5 & 2.4 \\
\hline \multirow{8}{*}{33} & Mean (rad) & 0.0216 & 0.0265 & 0.028 & 0.0259 & 0.0259 & 0.0276 \\
\hline & Mean (nm) & 0.86 & 1.05 & 1.11 & 1.03 & 1.03 & 1.10 \\
\hline & Median (rad) & 0.0208 & 0.0261 & 0.0274 & 0.0253 & 0.0253 & 0.0268 \\
\hline & Median (nm) & 0.83 & 1.04 & 1.09 & 1.01 & 1.01 & 1.06 \\
\hline & IQR (rad) & 0.0120 & 0.0121 & 0.0132 & 0.0114 & 0.0112 & 0.0133 \\
\hline & IQR (nm) & 0.48 & 0.48 & 0.52 & 0.45 & 0.45 & 0.53 \\
\hline & Skewness & 0.5 & 0.2 & 0.3 & 0.3 & 0.3 & 0.3 \\
\hline & Kurtosis & 3.0 & 2.5 & 2.3 & 2.3 & 2.3 & 2.2 \\
\hline \multirow{8}{*}{70} & Mean (rad) & 0.0224 & 0.0179 & 0.0245 & 0.0199 & 0.0202 & 0.0232 \\
\hline & Mean $(\mathrm{nm})$ & 0.89 & 0.71 & 0.97 & 0.79 & 0.80 & 0.92 \\
\hline & Median (rad) & 0.0214 & 0.0175 & 0.0238 & 0.0194 & 0.0197 & 0.0224 \\
\hline & Median (nm) & 0.85 & 0.70 & 0.95 & 0.77 & 0.78 & 0.89 \\
\hline & IQR (rad) & 0.0128 & 0.0070 & 0.0119 & 0.0075 & 0.0076 & 0.0102 \\
\hline & IQR (nm) & 0.51 & 0.28 & 0.47 & 0.30 & 0.30 & 0.41 \\
\hline & Skewness & 0.5 & 0.4 & 0.3 & 0.4 & 0.4 & 0.3 \\
\hline & Kurtosis & 3.1 & 3.0 & 2.4 & 2.6 & 2.6 & 2.3 \\
\hline \multirow{8}{*}{109} & Mean (rad) & 0.0493 & 0.0347 & 0.0595 & 0.0520 & 0.0551 & 0.0557 \\
\hline & Mean (nm) & 1.96 & 1.38 & 2.36 & 2.07 & 2.19 & 2.21 \\
\hline & Median (rad) & 0.0488 & 0.0337 & 0.0583 & 0.0510 & 0.0539 & 0.0544 \\
\hline & Median (nm) & 1.94 & 1.34 & 2.32 & 2.03 & 2.14 & 2.16 \\
\hline & IQR (rad) & 0.0343 & 0.0237 & 0.0465 & 0.0382 & 0.0415 & 0.0419 \\
\hline & IQR (nm) & 1.36 & 0.94 & 1.85 & 1.52 & 1.65 & 1.66 \\
\hline & Skewness & 0.1 & 0.2 & 0.1 & 0.1 & 0.1 & 0.3 \\
\hline & Kurtosis & 2.1 & 2.1 & 1.9 & 1.9 & 1.9 & 1.9 \\
\hline
\end{tabular}




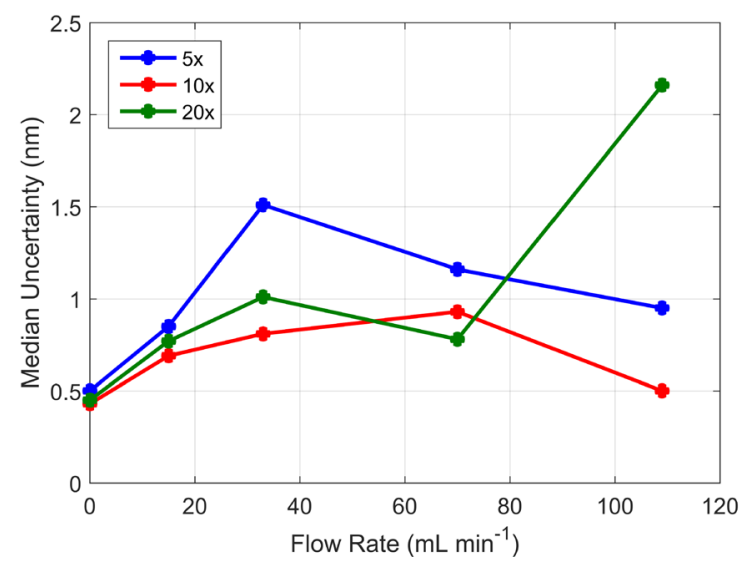

Fig. 20. Effect of water flow rate on the median uncertainty over 50 reconstructed phase maps for the $5 \times, 10 \times$, and $20 \times$ objective lenses through a glass window.

For this enclosed configuration, the uncertainty distributions for the $5 \times$ (Fig. 21) and 10× (Fig. 22) objective lenses suggest that uncertainty increases from $0 \mathrm{~mL} \mathrm{~min}^{-1}$ to $33 \mathrm{~mL} \mathrm{~min}^{-1}$ and decreases from 33

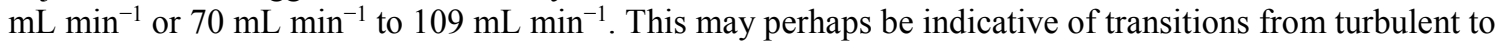
more laminar flow conditions within the fluid cell. Turbulence in the water will affect interferometric measurements, with greater magnitudes of turbulence inducing more noise in the phase measurement [51]. This explains why there is more noise in the phase measurement when flowing conditions are present, and this suggests that, at least for the through-window configuration, the most turbulent conditions in the fluid cell occur at the $33 \mathrm{~mL} \mathrm{~min}^{-1}$ and $70 \mathrm{~mL} \mathrm{~min}^{-1}$ flow rates. As seen in the Table 20 comparison, there is more noise at a given flow rate for the through-window configuration, and the noise does not change substantially from $0 \mathrm{~mL} \mathrm{~min}{ }^{-1}$ to $33 \mathrm{~mL} \mathrm{~min}$ for the immersion lens configuration, which suggests that these turbulent conditions occur in the through-window configuration and are not as prevalent in the immersion lens configuration.

In a comparison of measurements in flowing conditions by an immersion lens to those through a glass window (Fig. 23 and Table 20), the glass window measurements yield greater uncertainty. In static conditions, the uncertainty is comparable: $0.4 \mathrm{~nm}$ for the immersion lens compared to $0.5 \mathrm{~nm}$ for the through-window measurements. With flowing conditions, the uncertainties are on the order of $0.5 \mathrm{~nm}$ and $0.8 \mathrm{~nm}$ at $15 \mathrm{~mL} \mathrm{~min}^{-1}$ for the immersion lens and through-window measurements, respectively, and 0.5 $\mathrm{nm}$ and $1.1 \mathrm{~nm}$ at $33 \mathrm{~mL} \mathrm{~min}{ }^{-1}$ for the immersion lens and through-window measurements, respectively. A quantile-quantile plot comparing the immersion lens and through-window measurements suggests that the uncertainties are from dissimilar distributions (Fig. 24), which was confirmed by a two sample Kolmogorov-Smirnov test. ${ }^{6}$

\footnotetext{
${ }^{6}$ Over 1000 iterations, comparing the 20x immersion lens to the $20 \mathrm{x}$ objective lens through a window, $50 \%$ of the KolmogorovSmirnov tests returned (with $95 \%$ confidence) that the static flow $\left(0 \mathrm{~mL} \mathrm{~min}^{-1}\right)$ datasets were from the same distribution when data from 20 holograms were considered. Similarly, when data from 10 and 5 holograms were used, $88 \%$ and $67 \%$ of the KolmogorovSmirnov tests returned (with $95 \%$ confidence), respectively, that the static flow $\left(0 \mathrm{~mL} \mathrm{~min}^{-1}\right)$ datasets were from the same distribution. This suggests that, for the 10-hologram dataset, the uncertainties under static flow conditions may be from the same distribution. For the same comparison under flow conditions $\left(15 \mathrm{~mL} \mathrm{~min}^{-1}\right.$ and $\left.33 \mathrm{~mL} \mathrm{~min}^{-1}\right)$, the Kolmogorov-Smirnov test results suggest that the datasets are not from the same distribution, regardless of the number of holograms considered.
} 


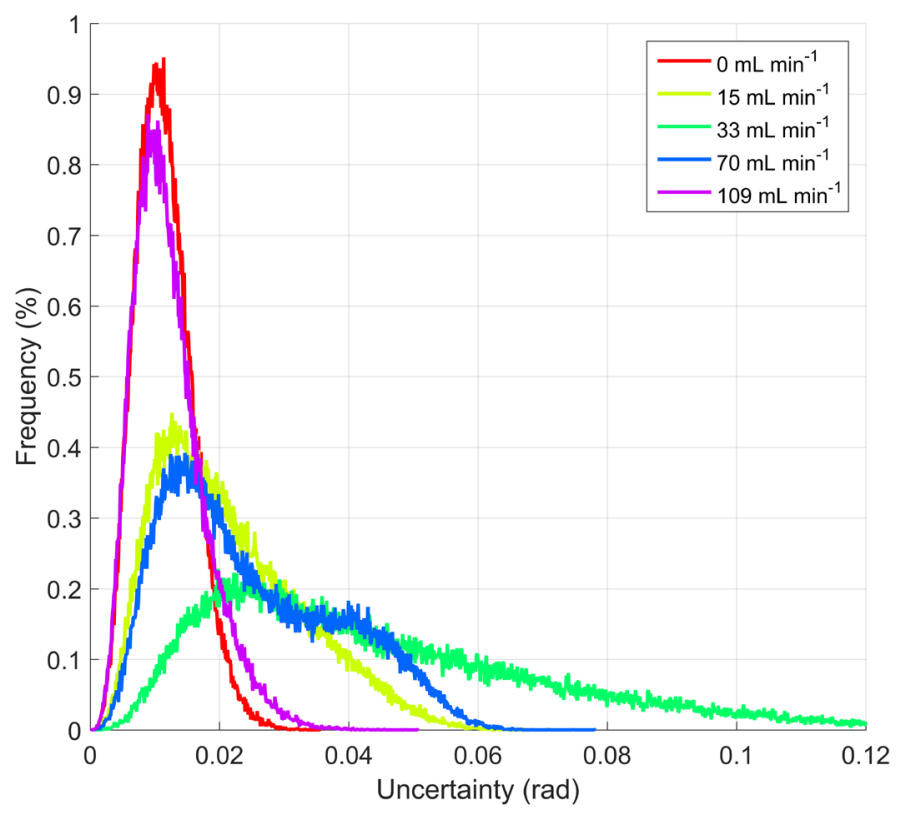

Fig. 21. Uncertainty over 5 reconstructed phase maps for a glass sample in water at various water flow rates examined by $5 \times$ objective lens through a glass window.

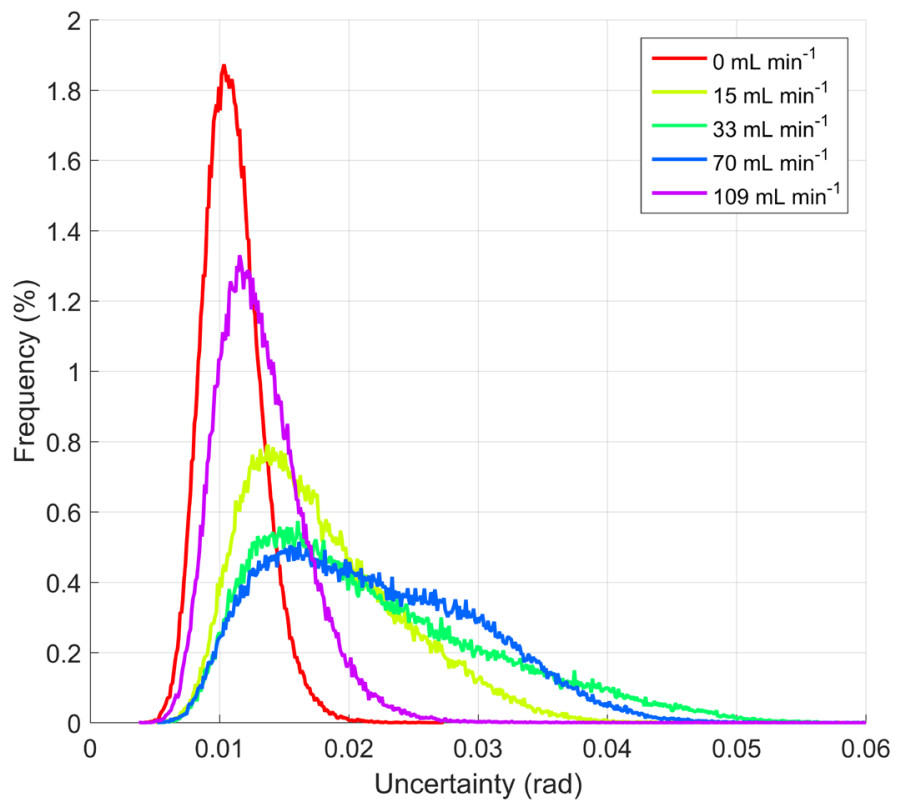

Fig. 22. Uncertainty over 20 reconstructed phase maps for a glass sample in water at various water flow rates examined by $10 \times$ objective lens through a glass window. 


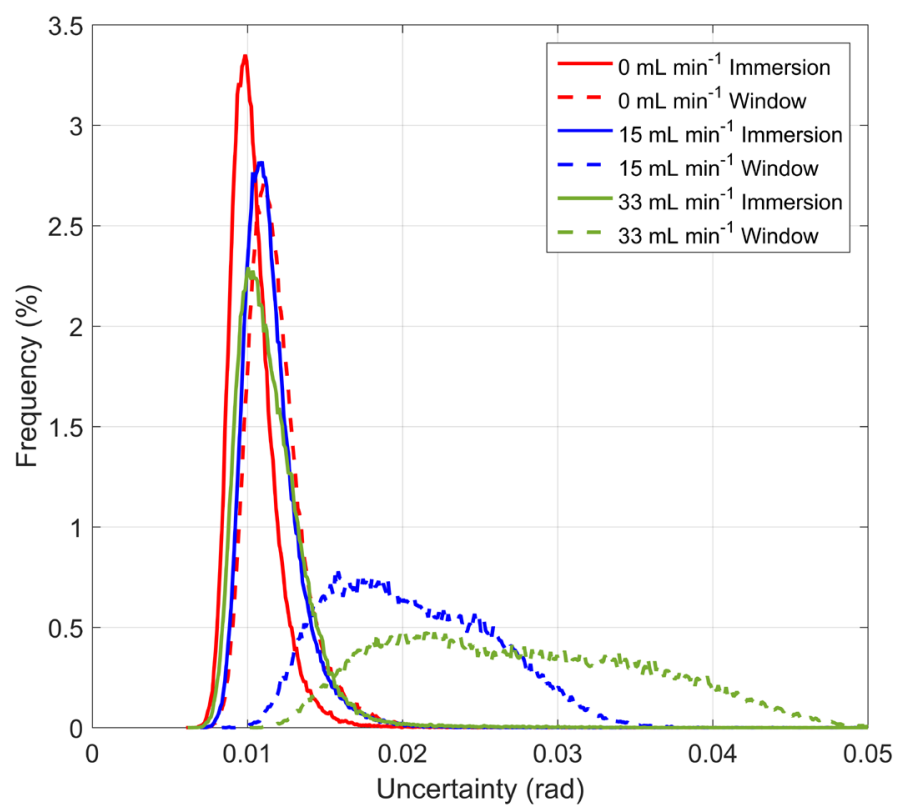

Fig. 23. Uncertainty over 100 reconstructed phase maps for a glass sample in water examined by $20 \times$ lenses comparing immersion lens data (solid lines) to an air objective lens through a glass window (dashed lines) at flow rates of $0 \mathrm{~mL} \mathrm{~min}^{-1}, 15 \mathrm{~mL} \mathrm{~min}^{-1}$, and 33 $\mathrm{mL} \min ^{-1}$.

Table 20. Uncertainty in water comparing $20 \times$ immersion lens and through-window measurements.

\begin{tabular}{|l|l|c|c|c|c|c|c|}
\hline \multirow{2}{*}{$\begin{array}{l}\text { No. of } \\
\text { Holograms }\end{array}$} & \multirow{2}{*}{$\begin{array}{l}\text { Mean } \\
\text { Uncertainty }\end{array}$} & \multicolumn{9}{|c|}{ Water Flow Rate $\left(\mathrm{mL} \mathrm{min}^{-1}\right)$} \\
\cline { 3 - 8 } & & \multicolumn{2}{|c|}{0} & \multicolumn{2}{|c|}{15} & \multicolumn{2}{c|}{33} \\
\cline { 3 - 8 } & & Immersion & Window & Immersion & Window & Immersion & Window \\
\hline \multirow{2}{*}{100} & $\mathrm{rad}$ & 0.0104 & 0.0112 & 0.0116 & 0.0193 & 0.0115 & 0.0216 \\
\cline { 2 - 8 } & $\mathrm{nm}$ & 0.41 & 0.45 & 0.46 & 0.77 & 0.46 & 0.86 \\
\hline \multirow{2}{*}{50} & $\mathrm{rad}$ & 0.0100 & 0.0108 & 0.0117 & 0.0204 & 0.0116 & 0.0265 \\
\cline { 2 - 8 } & $\mathrm{nm}$ & 0.40 & 0.43 & 0.47 & 0.81 & 0.46 & 1.05 \\
\hline \multirow{2}{*}{30} & $\mathrm{rad}$ & 0.0099 & 0.0112 & 0.0116 & 0.0201 & 0.0111 & 0.0280 \\
\cline { 2 - 8 } & $\mathrm{nm}$ & 0.39 & 0.45 & 0.46 & 0.80 & 0.44 & 1.11 \\
\hline \multirow{2}{*}{20} & $\mathrm{rad}$ & 0.0106 & 0.0112 & 0.0115 & 0.0190 & 0.0102 & 0.0259 \\
\cline { 2 - 8 } & $\mathrm{nm}$ & 0.42 & 0.45 & 0.46 & 0.75 & 0.41 & 1.03 \\
\hline \multirow{2}{*}{10} & $\mathrm{rad}$ & 0.0105 & 0.0015 & 0.0123 & 0.0200 & 0.0099 & 0.0259 \\
\cline { 2 - 8 } & $\mathrm{nm}$ & 0.42 & 0.46 & 0.49 & 0.79 & 0.39 & 1.03 \\
\hline \multirow{2}{*}{5} & $\mathrm{rad}$ & 0.0102 & 0.0118 & 0.0114 & 0.206 & 0.0093 & 0.0276 \\
\cline { 2 - 8 } & $\mathrm{nm}$ & 0.41 & 0.47 & 0.45 & 0.82 & 0.37 & 1.10 \\
\hline
\end{tabular}




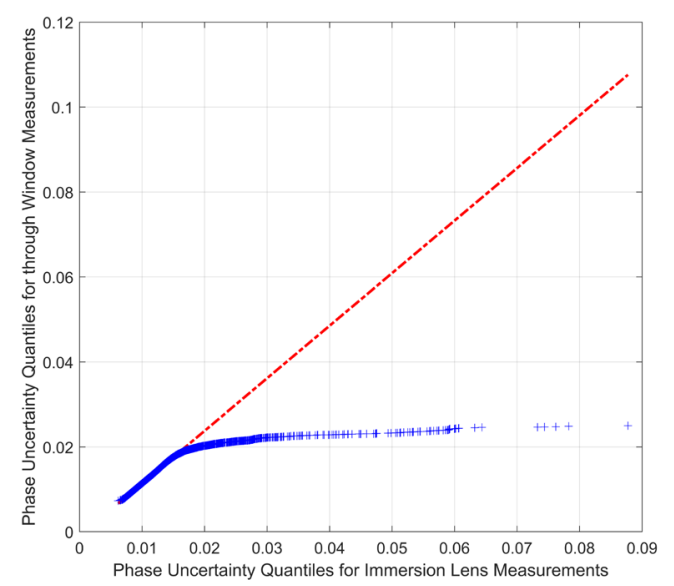

(a)

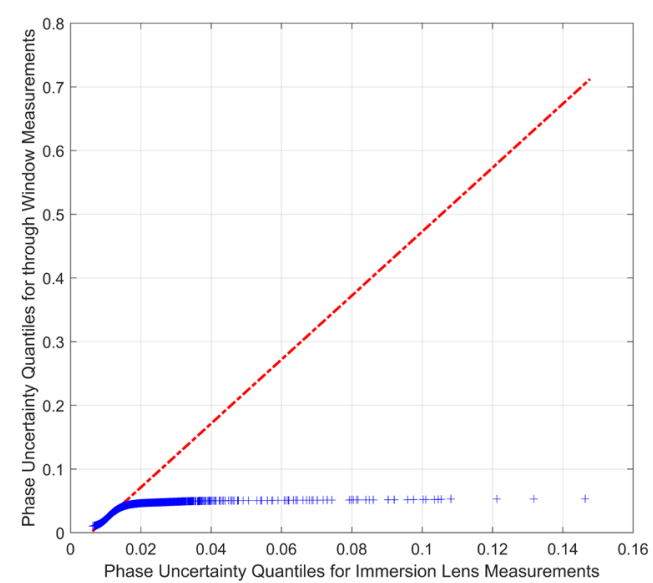

(b)

Fig. 24. Quantile-quantile plot of the phase uncertainty from 100 reconstructed phase maps examined by a $20 \times$ objective lens, comparing the immersion lens and through-window measurements for the (a) static $\left(0 \mathrm{~mL} \mathrm{~min}^{-1}\right)$ and (b) $33 \mathrm{~mL} \mathrm{~min}^{-1}$ flow conditions. A reference line (linear fit of the second and third quantiles) is shown in red.

One possibility in the flowing condition is that the flow could affect the spatial distribution of uncertainty per pixel. That is to say, if the "downstream" pixels represent a greater uncertainty than the "upstream" pixels, such as by some effect of water-induced vibration, turbulence of the water, etc. Ultimately, no evidence of such a flow direction bias was found. Plotting uncertainty values per pixel as a 3D surface (Fig. 25), it can be seen that, aside from a few scattered peaks, the spatial distribution of values is relatively uniform at $0 \mathrm{~mL} \mathrm{~min} \mathrm{~min}^{-1}, 15 \mathrm{~mL} \mathrm{~min}^{-1}$, and $109 \mathrm{~mL} \mathrm{~min}{ }^{-1}$, with a slightly greater spatial distribution for the data at $70 \mathrm{~mL} \mathrm{~min}^{-1}$. This agrees with Fig. 22, where the distribution of uncertainty is greater at $70 \mathrm{~mL} \mathrm{~min}^{-1}$, and it further suggests that perhaps the flow is more turbulent at $70 \mathrm{~mL} \mathrm{~min}{ }^{-1}$ compared to $0 \mathrm{~mL} \mathrm{~min}^{-1}, 15 \mathrm{~mL} \mathrm{~min}^{-1}$, and $109 \mathrm{~mL} \mathrm{~min}^{-1}$.
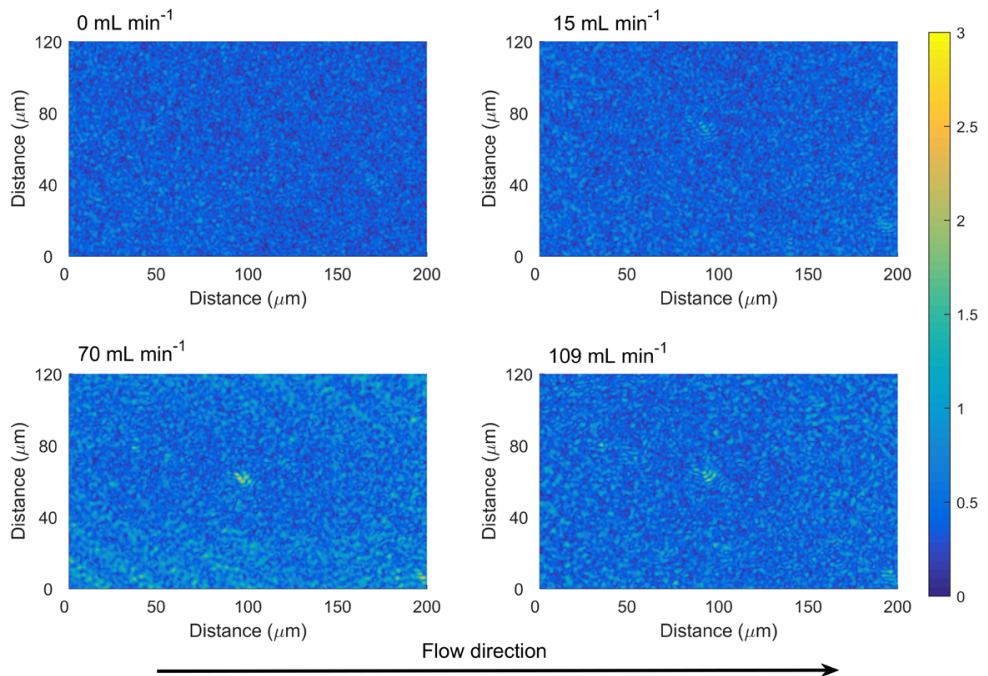

Fig. 25. Phase uncertainty from 5 holograms plotted as a function of spatial distribution for measurements through a glass window with $10 \times$ magnification and a water flow rates of $0 \mathrm{~mL} \mathrm{~min}^{-1}, 15 \mathrm{~mL} \mathrm{~min}^{-1}, 70 \mathrm{~mL} \mathrm{~min}^{-1}$, and $109 \mathrm{~mL} \mathrm{~min}^{-1}$. The scale on the color bar represents height uncertainty $(\mathrm{nm})$. 


\section{Discussion}

\subsection{How Many Holograms are Needed?}

Kühn et al. [22] argued that temporal averaging over a 25-hologram sequence (with an acquisition rate of $25 \mathrm{~s}^{-1}$ ) can reduce the effects of shot noise in the DHM. However, the findings from this study suggest that the number of holograms required for a given measurement is dependent on the experimental configuration, the sensitivity of the value to be measured, and the user-defined allowable uncertainty tolerance in the measurement. For measurements in air (Sec. 3.1), the mean and median uncertainties were minimally affected by the number of holograms, where the values were around $0.4 \mathrm{~nm}$ to $0.5 \mathrm{~nm}$ at magnifications from $2.5 \times$ to $40 \times$. The skewness and kurtosis increased while the IQR decreased with increasing sample size. The IQR was $\leq 0.1 \mathrm{~nm}$ for sample sizes of 10 holograms or more and $\leq 0.2 \mathrm{~nm}$ for 5 holograms, which suggests that a minimum of 10 holograms may be sufficient when a $25 \mathrm{~s}^{-1}$ acquisition rate is used, depending on the allowable desired measurement tolerance. Similar behavior was noted at a lower acquisition rate of $12.5 \mathrm{~s}^{-1}$, which suggests that 10 holograms may also be sufficient at that acquisition rate. With an immersion lens, the IQR is slightly greater compared to measurements in air, suggesting that sample sizes greater than 10 holograms may be beneficial, and similar arguments can be made for measurements through a glass window. Additionally, with flowing water conditions, it may be advisable to collect additional holograms to further reduce the effects of noise and uncertainty in the measurement. The effects of the number of holograms and allowable sensitivity are further discussed through hypothetical measurements in Sec. 5.

\subsection{Sources of Noise}

As discussed in Sec. 2, the primary sources of noise in the DHM are shot noise, which is related to the intrinsic variability in photons incident on the CCD camera, and Gaussian noise, which is the combined effects from numerous intrinsic and extrinsic sources [23-29]. Given that the findings in this study evaluated the global uncertainty in measurements, it is not possible to reliably state which source (or sources) of noise is the primary cause of the quantified uncertainty. However, for a given experimental configuration, certain noise sources may be more likely to be present, which will be the main discussion of this section.

\subsubsection{Effect of Acquisition Rate}

As was demonstrated in Sec. 3.1.1, there was not a significant effect of acquisition rate $\left(25 \mathrm{~s}^{-1}\right.$ compared to $12.5 \mathrm{~s}^{-1}$ ) on the uncertainty, and results from the Kolmogorov-Smirnov test suggested that the uncertainties were from similar distributions. The effects of shot noise should be identical at these two acquisition rates, since the CCD camera settings remained unchanged. Therefore, any change in the uncertainty at different acquisition rates would be attributable to extrinsic factors, such as if there were some drifting or vibrations, but that was not evident in the experiments conducted in this study.

\subsubsection{Dual-Wavelength Mode}

The additive nature of noise in multiple-wavelength configurations relative to a single-wavelength configuration has been discussed in the literature [32, 34, 48-50], particularly with regard to how $2 \pi$ phase ambiguities can be removed. While the additive nature of noise in this configuration is known, additional potential sources of noise will be discussed in this section.

In dual-wavelength mode, there is the possibility of crosstalk between the signals for two wavelengths, which results in additional uncertainty. One experiment with a dual-wavelength DHM configuration 
(wavelengths of $632.8 \mathrm{~nm}$ and $532.8 \mathrm{~nm}$ ) predicted a $5 \%$ crosstalk [52]. ${ }^{7}$ It is therefore possible that crosstalk is occurring in the $\lambda_{1}-\lambda_{2}$ and $\lambda_{1}-\lambda_{3}$ dual-wavelength modes, which could be one source of increased noise when comparing the single- to the dual-wavelength modes.

The CCD camera settings are different between the single- and dual-wavelength modes, and this affects the shot noise contribution. In dual-wavelength mode, the camera shutter speed is reduced relative to the single-wavelength mode to account for the additional photons from the second wavelength. Because of the longer exposure for the single-wavelength mode, it can be expected that the shot noise is greater. However, the longer exposure for single-wavelength mode also results in a higher signal-to-noise ratio (SNR), therefore reducing the relative effect of shot noise and yielding less uncertainty for $\lambda_{1}$ phase data collected from single-wavelength mode compared to the $\lambda_{1}$ phase data collected from dual-wavelength mode.

To further evaluate the effects of noise in the single- and dual-wavelength modes, a brief experiment was conducted. For the $\lambda_{1}-\lambda_{2}$ dual-wavelength mode, using the $10 \times$ objective lens in air and an acquisition rate of $25 \mathrm{~s}^{-1}$ to collect 100 holograms, an optimized hologram was generated, and the $\lambda_{1}$ phase data were extracted (Test D1 in Table 21). Then, using the same optimized camera settings, the $\lambda_{2}$ laser source was switched off, and 100 holograms were collected to extract the $\lambda_{1}$ phase data (Test D2). These two data sets from the dual-wavelength mode were then compared to two configurations for the $\lambda_{1}$ single-wavelength mode: one with an optimized hologram and optimized camera settings (Test S1), and another with the camera settings set to the dual-wavelength mode optimized hologram (Test S2). The same ROI was evaluated across all experiments. The results are summarized in Table 21, which demonstrates that once the possible crosstalk and fluctuations from $\lambda_{2}$ are removed, the uncertainty is reduced, and the uncertainty characteristics are similar to those obtained in the single-wavelength mode with reduced camera settings (i.e., compare Test D2 to Test S2). To compare the distributions, a quantile-quantile plot (Fig. 26) confirms, along with the two-sample Kolmogorov-Smirnov test, that Test D2 and Test S2 come from similar distributions. Of the 1000 iterations, $94 \%$ of the Kolmogorov-Smirnov tests returned (with $95 \%$ confidence) that Test D2 and Test S2 were from the same distribution. The results also demonstrate that the reduced shutter speed yields an increase in the uncertainty because of the reduction in SNR (e.g., compare Test S2 to Test S1). This confirms that that main causes of increased uncertainty in the dual-wavelength mode are attributable to: crosstalk and fluctuations from the second wavelength and the reduced shutter speed.

Table 21. Comparison of noise in different configurations of single- and dual-wavelength mode.

\begin{tabular}{|c|c|c|c|c|c|}
\hline & \multicolumn{2}{|c|}{$\lambda_{1}-\lambda_{2}$ Dual-Wavelength Mode } & \multicolumn{2}{|c|}{$\lambda_{1}$ Single-Wavelength Mode } \\
\hline & & Test D1 & Test D2 & Test S1 & Test S2 \\
\hline \multicolumn{2}{|c|}{ Experiment Description } & $\begin{array}{l}\lambda_{1} \text { and } \lambda_{2} \text { sources } \\
\text { turned on }\end{array}$ & $\begin{array}{l}\lambda_{2} \text { source } \\
\text { turned off }\end{array}$ & $\begin{array}{l}\text { Optimized } \\
\text { hologram }\end{array}$ & $\begin{array}{l}\text { Camera settings set to } \\
\text { optimized hologram in dual- } \\
\text { wavelength mode }\end{array}$ \\
\hline \multicolumn{2}{|c|}{ Shutter Speed $(\mu \mathrm{s})$} & 492 & 492 & 872 & 492 \\
\hline \multirow{8}{*}{ 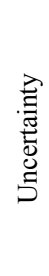 } & Mean (rad) & 0.0148 & 0.0116 & 0.0084 & 0.0115 \\
\hline & Mean (nm) & 0.78 & 0.61 & 0.44 & 0.61 \\
\hline & Median (rad) & 0.0148 & 0.0115 & 0.0084 & 0.0114 \\
\hline & Median (nm) & 0.78 & 0.61 & 0.44 & 0.60 \\
\hline & IQR (rad) & 0.0017 & 0.0014 & 0.0011 & 0.0013 \\
\hline & IQR (nm) & 0.09 & 0.07 & 0.06 & 0.07 \\
\hline & Skewness & 0.5 & 1.8 & 2.3 & 1.3 \\
\hline & Kurtosis & 4.3 & 23.5 & 29.2 & 13.4 \\
\hline
\end{tabular}

\footnotetext{
${ }^{7}$ Note that the DHM configuration and sensor in Ref. [52] is different than that of the present study. Therefore, the $5 \%$ crosstalk estimated by Ref. [52] is not representative of the potential crosstalk in this study and is included here only as an illustrative discussion point.
} 


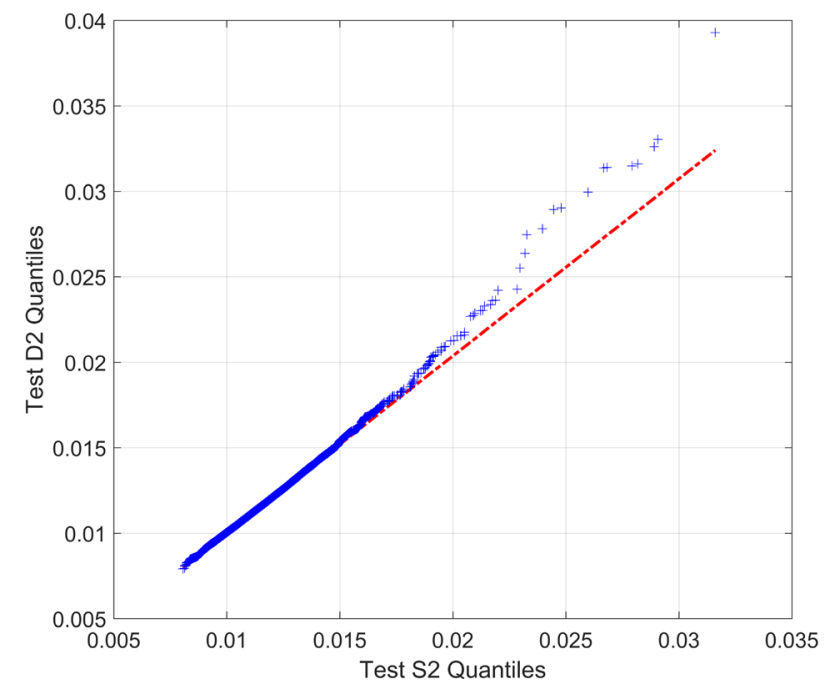

Fig. 26. A quantile-quantile plot comparing the uncertainty results from a dual-wavelength configuration with the second wavelength turned off (Test D2) to the uncertainty results from a single-wavelength configuration with the same shutter speed as the dualwavelength configuration (Test S2). A reference line (linear fit of the second and third quantiles) is shown in red.

\subsubsection{Flowing Solution}

Relative to static conditions $\left(0 \mathrm{~mL} \mathrm{~min}{ }^{-1}\right)$, the presence of flowing water in either the immersion lens or the through-window experimental configuration was shown to increase the uncertainty. This can primarily be attributed to the greater noise induced by turbulent flow conditions [51], which is therefore an extrinsic noise contribution that can only be minimized as a function of the flow rate magnitude.

The through-window configuration was found to yield greater uncertainties relative to the immersion lens configuration. This is likely attributable to changes in the SNR. In the hologram, the maximum SNR of a given pixel is a function of the object and reference wave intensities, $I_{\mathrm{O}}$ and $I_{\mathrm{R}}$, respectively, where the numerator represents the maximum signal that could be obtained, while the denominator represents the shot noise [23]:

$$
S N R_{\text {max }}=\frac{2 \sqrt{I_{O} I_{R}}}{\sqrt{I_{O}+I_{R}}} .
$$

In the through-window configuration, some of the signal is lost due to reflections at the window, and multiple reflections inside the window can affect the reflected signal [53]. For perpendicularly incident light, the Fresnel reflection coefficient was previously defined in Eq. (4). Considering the index of refraction for various media, $n_{\text {air }}=1.0, n_{\text {water }}=1.33$, and $n_{\text {glass }} \approx 1.5$, the Fresnel reflection coefficient for incident light perpendicular to the surface is $4 \%$ for the air-glass interface and $0.4 \%$ for the glass-water interface. In the through-window configuration, the signal lost from reflection at interfaces occurs at the air-glass interface of the objective lens, air-glass interface of the window, and the water-glass interface of the window, thus diminishing $I_{\mathrm{O}}$ and resulting in a potential decrease in the hologram SNR. There is less uncertainty in the immersion lens configuration, because signal lost from these reflections only occurs at the water-glass interface of the immersion lens, and therefore the immersion lens configuration has potentially greater SNR than the through-window configuration. However, it is theoretically possible that, for a constant $I_{\mathrm{R}}$, a decrease in $I_{\mathrm{O}}$ may yield an increase in the phase image SNR, at least when considering SNR relative to shot noise only [23]. Considering that the present study considered the global intrinsic and extrinsic noise effects (and not just shot noise), it is likely that this argument is still feasible considering SNR relative to all noise factors. 
Another loss in signal can occur at the interface of the sample surface. As was shown in Sec. 3.2 (Table 16), the phase uncertainty in static water is greater than the phase uncertainty in static air at the same magnification. Consider measurements of the surface of the glass without a chromium film. The Fresnel reflection coefficient is lower in water $(0.4 \%)$ compared to in air $(4 \%)$, so there is less reflected signal when measurements are conducted in water. Because of the relationship in Eq. (4), measurements of a given sample in water will likely have greater phase uncertainty than measurements in air when considering the combined effects of all intrinsic and extrinsic factors.

\subsubsection{Sample Surface}

As a general comment, the sample type, condition, and preparation are all critical to the phase uncertainty. As already established, because of Eq. (4), measurements in any media where $n>1.0$ will likely yield greater phase uncertainty than measurements in air as a result of the reduction in SNR.

Similarly, considering any measurement in any given medium, the index of refraction of the sample surface is also important. For example, measurements of a selenite (gypsum) surface $(n \approx 1.52)$ will contain more uncertainty than measurements of a calcite surface $(n \approx 1.66)$. The opaqueness of the sample as well as the intensity of incident light (e.g., single wavelength vs. dual wavelength) are also important factors when considering the experimental configuration and potential magnitude of uncertainty.

\section{Effect of Measurement Uncertainty on Measured Dissolution Fluxes}

Recent research at NIST is utilizing the DHM to quantify mineral dissolution fluxes by observing in situ changes in surface topography over time [13,14], similar to what is performed in geochemical studies by measurements with vertical scanning interferometry (e.g., [54-56]). Through these measurements, the surface-normal dissolution flux, $k_{\mathrm{s}}$, is computed based on the surface-normal dissolution velocity, $v_{\mathrm{s}}$, which is simply the change in height over time of a pixel or set of pixels, $\Delta h / \Delta t$, and the molar volume, $V_{m}$ [54]:

$$
\mathrm{k}_{\mathrm{s}}=\frac{v_{\mathrm{s}}}{V_{m}}=\frac{\Delta h}{\Delta t} \frac{1}{V_{m}} .
$$

Though discussed for dissolution (i.e., when $v_{\mathrm{s}}<0$ and $k_{\mathrm{s}}<0$ ), since that was the primary focus of the recent studies [13, 14], Eq. (7) applies equally to precipitation or growth studies (i.e., when $v_{\mathrm{s}}>0$ and $k_{\mathrm{s}}>$ $0)$. Note that in these experiments, an inert reference mask was partially applied to the surface to serve as a reference height offset, so that relative measurements were determined. In experiments where only one reaction is occurring (i.e., only dissolution, precipitation, or growth), spatial averaging can be performed, which can provide details on the spatial variability of fluxes $[13,14]$ and can also reduce the effects of noise [22, 32]. Spatial averaging is conducted by averaging over an ROI and evaluating the mean change in height over time, so $v_{\mathrm{s}}$ essentially becomes a mean height change over time rather than a height change per pixel over time.

To evaluate the effect of uncertainty, assume, for example, a hypothetical perfectly flat mineral surface with known values $V_{m}=3.7 \times 10^{-5} \mathrm{~m}^{3} \mathrm{~mol}^{-1}$ and $k_{\mathrm{s}}=-0.1 \mu \mathrm{mol} \mathrm{m} \mathrm{m}^{-2}$, which are approximate values for calcite [13]. Consider an experiment in which DHM is used with a $20 \times$ immersion lens and $\lambda_{1}$ singlewavelength mode with a flow rate of $15 \mathrm{~mL} \mathrm{~min}^{-1}$. Holograms are collected at an acquisition rate of $25 \mathrm{~s}^{-1}$, and a set of 10 holograms is collected every minute for an experiment duration of $1 \mathrm{~h}$. The phase map is 300 pixels by 300 pixels. The data for a perfectly dissolving surface with these values are shown in Fig. 27, which indicates a dissolution flux of exactly $-0.1 \mu \mathrm{mol} \mathrm{m} \mathrm{m}^{-2} \mathrm{~s}^{-1}$. Using the uncertainty from Sec. 3.2 for this experimental configuration, for each pixel in the phase map at each time step, a randomly ${ }^{8}$ selected value from the uncertainty distribution is added or subtracted at random from the given pixel value, yielding the hypothetically "measured" dissolution data in Fig. 27, which indicate a flux of $(-0.100 \pm 0.001) \mu \mathrm{mol} \mathrm{m}{ }^{-2}$ $\mathrm{s}^{-1}$. The data in Fig. 27 are a representation of the spatially averaged mean height over the entire phase map

${ }^{8}$ By "random selection," a uniform sampling was used. Values from the uncertainty data set in Sec. 3.2 were sampled uniformly at random. The decision to add or subtract the uncertainty value to or from the given pixel height value was also determined by a uniform random distribution. 
per time step. Therefore, it can be concluded that, at least for calcite, the dissolution flux is large enough (i.e., $\Delta h$ is large enough per $\Delta t$ time step in this experiment) such that the effect of phase measurement uncertainty is relatively negligible (i.e., the difference is $0.4 \%$ ). ${ }^{9}$

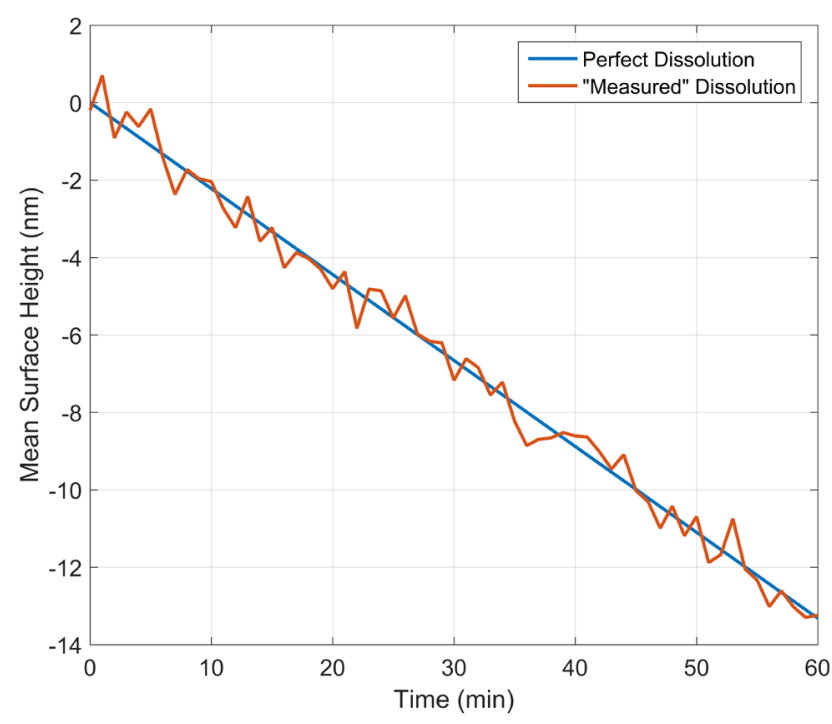

Fig. 27. Surface-normal dissolution velocity data for a perfectly linear dissolving surface and considering the uncertainty in the phase measurement. Linear regression through the data suggests surface-normal dissolution velocities of exactly $-0.2220 \mathrm{~nm} \mathrm{~min}^{-1}$ (dissolution flux of exactly $-0.1 \mu \mathrm{mol} \mathrm{m}{ }^{-2} \mathrm{~s}^{-1}$ ) for perfect dissolution and $(-0.2230 \pm 0.0032) \mathrm{nm} \mathrm{min}{ }^{-1}$, which is a dissolution flux of $(-0.1004 \pm 0.0014) \mu \mathrm{mol} \mathrm{m}^{-2} \mathrm{~s}^{-1}$, when uncertainty is added.

If the computed calcite dissolution flux is relatively unaffected by DHM phase measurement uncertainty, what is the limiting dissolution flux such that the measured changes in height are indistinguishable from the uncertainty? Since minerals can have the same $k_{\mathrm{s}}$ but different $V_{m}$, the product of these parameters (i.e., dissolution velocity, $v_{\mathrm{s}}$ ) will be the independent variable. Assuming the same experiment configuration as for calcite, the perfect linear dissolving mineral surface is compared to the "measured" height changes per pixel with added uncertainty, as shown in Table 22. Some of the "known" $v_{\mathrm{s}}$ values are hypothetical, while others are derived from the literature. Table 22 shows that any mineral with a surface-normal dissolution velocity greater than about $-10^{-12} \mathrm{~m} \mathrm{~s}^{-1}$ can be safely measured with the DHM (for the assumed experimental configuration) without significant detriment to the measurement from phase uncertainty. All "measured" $v_{\mathrm{s}}$ values in Table 22 had a standard error of regression on the order of $10^{-13.3} \mathrm{~m} \mathrm{~s}^{-1}$, which also appears to be the threshold where the known and "measured" $v_{\mathrm{s}}$ values begin to differ by $\geq 100 \%$. Also, at very low dissolution $v_{\mathrm{s}}$, such as $-10^{-15} \mathrm{~m} \mathrm{~s}^{-1}$, uncertainty in the measurement may even result in a measured precipitation or growth velocity because the uncertainty is greater than the actual dissolution rate.

Considering a different experimental configuration (and therefore different uncertainty), Table 23 demonstrates that a configuration with greater uncertainty (such as using a glass window and a faster flow rate) results in a larger difference between the known and "measured" $v_{\mathrm{s}}$, as expected. While the dissolution of gypsum and calcite, as measured by the DHM, were still fast enough to not be affected by the uncertainty, the limit appears to be around $-10^{-11.8} \mathrm{~m} \mathrm{~s}^{-1}$ for the lowest dissolution velocity measured by DHM in this configuration before uncertainty significantly affects the measurement. As with the immersion lens configuration, at low dissolution velocities (e.g., $\leq-10^{-13.7} \mathrm{~m} \mathrm{~s}^{-1}$ ), the uncertainty is significant enough for a precipitation or growth to be measured rather than dissolution. As expected, since the uncertainty is

${ }^{9}$ This is the result of one simulated experiment. In 10 replicate simulated experiments, the mean percent difference was found to be $1.4 \%$, with values ranging from $0.3 \%$ to $3.4 \%$ difference. 
greater for the configuration in Table 23, the error of regression is greater than the immersion lens configuration in Table 22, and the typical error of regression also appears to be related to the velocity at which the difference between known and measured values is $\geq 100 \%$.

Table 22. Effect of uncertainty on hypothetical dissolving mineral surfaces of known $v_{\mathrm{s}}$ (Experiment 1 ). ${ }^{\mathrm{a}}$

\begin{tabular}{|c|c|c|c|}
\hline Known $v_{\mathrm{s}}\left(\mathrm{m} \mathrm{s}^{-1}\right)$ & "Measured" $v_{\mathrm{s}}\left(\mathrm{m} \mathrm{s}^{-1}\right)$ & $\begin{array}{c}\text { Percent } \\
\text { Difference }\end{array}$ & Example Mineral Dissolution \\
\hline$-10^{-9.65}$ & $-10^{-9.65} \pm 10^{-13.29}$ & Negligible & $\begin{array}{l}\text { Gypsum in water }\left(k_{\mathrm{s}}=-3.0 \mu \mathrm{mol} \mathrm{m}^{-2} \mathrm{~s}^{-1} ; V_{m}\right. \\
\left.=7.45 \times 10^{-5} \mathrm{~m}^{3} \mathrm{~mol}^{-1}\right)\end{array}$ \\
\hline$-10^{-11.43}$ & $-10^{-11.43} \pm 10^{-13.27}$ & Negligible & $\begin{array}{l}\text { Calcite in water }\left(k_{\mathrm{s}}=-0.1 \mu \mathrm{mol} \mathrm{m}{ }^{-2}\right. \\
\left.\mathrm{s}^{-1} ; V_{m}=3.7 \times 10^{-5} \mathrm{~m}^{3} \mathrm{~mol}^{-1}\right)[13]\end{array}$ \\
\hline$-10^{-12.0}$ & $-10^{-12.01} \pm 10^{-13.29}$ & $1.6 \%$ & \\
\hline$-10^{-12.2}$ & $-10^{-12.27} \pm 10^{-13.26}$ & $14.9 \%$ & $\begin{array}{l}\text { Anorthite dissolution at } \mathrm{pH} 3.0\left(k_{\mathrm{s}}=\right. \\
\left.-5.7 \times 10^{-9} \mathrm{~mol} \mathrm{~m}^{-2} \mathrm{~s}^{-1}\right)[54] ; V_{m} \text { assumed } \\
1.05 \times 10^{-4} \mathrm{~m}^{3} \mathrm{~mol}^{-1}\end{array}$ \\
\hline$-10^{-13.0}$ & $-10^{-13.59} \pm 10^{-13.17}$ & $74.3 \%$ & \\
\hline$-10^{-13.2}$ & $-10^{-14.17} \pm 10^{-13.21}$ & $89.3 \%$ & $\begin{array}{l}\text { Pyrite dissolution at } \mathrm{pH} 1.0\left(k_{\mathrm{s}}=\right. \\
-2.8 \times 10^{-9} \mathrm{~mol} \mathrm{~m}^{-2} \mathrm{~s}^{-1} ; V_{m}=2.4 \times 10^{-5} \mathrm{~m}^{3} \\
\left.\mathrm{~mol}^{-1}\right)[57]\end{array}$ \\
\hline$-10^{-13.3}$ & $-10^{-14.95} \pm 10^{-13.23}$ & $97.8 \%$ & \\
\hline$-10^{-13.7}$ & $-10^{-13.29} \pm 10^{-13.22}$ & $157 \%$ & $\begin{array}{l}\text { Muscovite dissolution at } \mathrm{pH} 9.4 \text { and } 155^{\circ} \mathrm{C} \\
\left(k_{\mathrm{s}}=-1.4 \times 10^{-10} \mathrm{~mol} \mathrm{~m}^{-2} \mathrm{~s}^{-1}\right)[58] ; V_{m} \\
\text { assumed } 1.4 \times 10^{-4} \mathrm{~m}^{3} \mathrm{~mol}^{-1}\end{array}$ \\
\hline$-10^{-14.0}$ & $-10^{-13.31} \pm 10^{-13.21}$ & $390 \%$ & \\
\hline$-10^{-15.0}$ & $10^{-13.18} \pm 10^{-13.18}$ & $6510 \%$ & \\
\hline
\end{tabular}

${ }^{a}$ Assuming $20 \times$ immersion lens, 10 -hologram collection, $\lambda_{1}$ single-wavelength mode, $25 \mathrm{~s}^{-1}$ acquisition rate, and $15 \mathrm{~mL}$ $\min ^{-1}$ water flow rate

Table 23. Effect of uncertainty on hypothetical dissolving mineral surfaces of known $v_{\mathrm{s}}$ (Experiment 2). ${ }^{\mathrm{a}}$

\begin{tabular}{|l|l|l|l|}
\hline \multicolumn{1}{|c|}{ Known $v_{\mathrm{s}}\left(\mathrm{m} \mathrm{s}^{-1}\right)$} & \multicolumn{1}{|c|}{ "Measured" $v_{\mathrm{s}}\left(\mathrm{m} \mathrm{s}^{-1}\right)$} & \multicolumn{1}{c|}{$\begin{array}{c}\text { Percent } \\
\text { Difference }\end{array}$} & \multicolumn{1}{c|}{ Example Mineral Dissolution } \\
\hline$-10^{-9.65}$ & $-10^{-9.65} \pm 10^{-12.91}$ & Negligible & $\begin{array}{l}\text { Gypsum in water }\left(k_{\mathrm{s}}=-3.0 \mu \mathrm{mol} \mathrm{m}^{-2} \mathrm{~s}^{-1} ; V_{m}=\right. \\
\left.7.45 \times 10^{-5} \mathrm{~m}^{3} \mathrm{~mol}^{-1}\right)[14]\end{array}$ \\
\hline$-10^{-11.43}$ & $-10^{-11.43} \pm 10^{-12.92}$ & Negligible & $\begin{array}{l}\text { Calcite in water }\left(k_{\mathrm{s}}=-0.1 \mu \mathrm{mol} \mathrm{m}^{-2}\right. \\
\left.\mathrm{s}^{-1} ; V_{m}=3.7 \times 10^{-5} \mathrm{~m}^{3} \mathrm{~mol}^{-1}\right)[13]\end{array}$ \\
\hline$-10^{-11.7}$ & $-10^{-11.70} \pm 10^{-12.94}$ & Negligible & \\
\hline$-10^{-11.8}$ & $-10^{-11.79} \pm 10^{-12.90}$ & $2.2 \%$ & \\
\hline$-10^{-12.0}$ & $-10^{-11.95} \pm 10^{-12.84}$ & $12.2 \%$ & \\
\hline$-10^{-12.2}$ & $-10^{-12.15} \pm 10^{-12.92}$ & $12.2 \%$ & $\begin{array}{l}\text { Anorthite dissolution at } \mathrm{pH} 3.0\left(k_{\mathrm{s}}=\right. \\
\left.-5.7 \times 10^{-9} \mathrm{~mol} \mathrm{~m}^{-2} \mathrm{~s}^{-1}\right)[54] ; V_{m} \text { assumed } 1.05 \\
\times 10^{-4} \mathrm{~m}^{3} \mathrm{~mol}^{-1}\end{array}$ \\
\hline$-10^{-12.9}$ & $-10^{-12.67} \pm 10^{-12.92}$ & $68.1 \%$ & \\
\hline$-10^{-13.0}$ & $-10^{-12.64} \pm 10^{-13.01}$ & $129 \%$ & $\begin{array}{l}\text { Pyrite dissolution at } \mathrm{pH} 1.0\left(k_{\mathrm{s}}=\right. \\
-2.8 \times 10^{-9} \mathrm{~mol} \mathrm{~m}^{-2} \mathrm{~s}^{-1} ; V_{m}=2.4 \times 10^{-5} \mathrm{~m}^{3} \\
\left.\text { mol }{ }^{-1}\right)[57]\end{array}$ \\
\hline$-10^{-13.2}$ & $-10^{-12.56} \pm 10^{-12.87}$ & $337 \%$ & $\begin{array}{l}\text { Muscovite dissolution at } \mathrm{pH} 9.4 \text { and } 155^{\circ} \mathrm{C}\left(k_{\mathrm{s}}\right. \\
\left.=-1.4 \times 10^{-10} \mathrm{~mol} \mathrm{~m}^{-2} \mathrm{~s}^{-1}\right)[58] ; V_{m} \text { assumed } \\
1.4 \times 10^{-4} \mathrm{~m}^{3} \mathrm{~mol}^{-1}\end{array}$ \\
\hline$-10^{-13.7}$ & $10^{-13.05} \pm 10^{-12.99}$ & $547 \%$ & \\
\hline$-10^{-14.0}$ & $10^{-12.45} \pm 10^{-12.83}$ & $3650 \%$ & \\
\hline$-10^{-15.0}$ & $10^{-12.96} \pm 10^{-12.84}$ & $11100 \%$ & \\
\hline
\end{tabular}

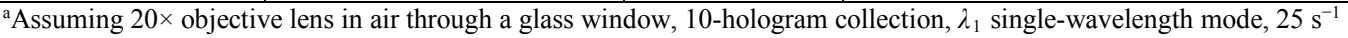
acquisition rate, and $33 \mathrm{~mL} \mathrm{~min}{ }^{-1}$ water flow rate

Based on the results in Table 22 and Table 23, the limiting dissolution velocity for a number of experimental configurations with water using an immersion lens and through-window measurements is summarized in Table 24. The limiting velocity was selected based on a percent difference threshold of $5 \%$. This limiting velocity is applicable to dissolution or precipitation measurements by accounting for a change in sign (e.g., dissolution would be a negative velocity). In general, the number of holograms did not greatly impact the limiting surface-normal velocity, so for each experiment configuration and flow rate in Table 
24 , a recommended limit is suggested based on the most conservative case. When using a $20 \times$ or $40 \times$ immersion lens, regardless of the flow rate, a surface-normal velocity limit of $10^{-11.7} \mathrm{~m} \mathrm{~s}^{-1}$ can be assumed. When using a glass window, there is greater uncertainty, especially when flowing water is used, so a surface-normal velocity limit of $10^{-11.7} \mathrm{~m} \mathrm{~s}^{-1}$ can be assumed with static water $\left(0 \mathrm{~mL} \mathrm{~min}{ }^{-1}\right)$, a surfacenormal velocity limit of $10^{-11.4} \mathrm{~m} \mathrm{~s}^{-1}$ can be assumed with slow flow $\left(15 \mathrm{~mL} \mathrm{~min}{ }^{-1}\right)$, and a surface-normal velocity limit of $10^{-11.0} \mathrm{~m} \mathrm{~s}^{-1}$ can be assumed with fast flow (up to $109 \mathrm{~mL} \mathrm{~min}^{-1}$ ). Based on these recommended limits, it is evident that the dissolution fluxes measured for calcite [13] and gypsum [14] are valid. These findings also demonstrate that, in general, the extrinsic noise factors with a flowing solution (e.g., turbulence, vibration), as a direct result of increasing the uncertainty, reduce the reliable confidence with which dissolution fluxes can be measured (i.e., a velocity as low as $10^{-11.7} \mathrm{~m} \mathrm{~s}^{-1}$ could be reliably measured in static water through a glass window, but such a low velocity cannot be reliably measured at higher flow rates, since the velocity limits are $10^{-11.4} \mathrm{~m} \mathrm{~s}^{-1}$ and $10^{-11.0} \mathrm{~m} \mathrm{~s}^{-1}$ at flow rates of $15 \mathrm{~mL} \mathrm{~min}{ }^{-1}$ and $109 \mathrm{~mL} \mathrm{~min}^{-1}$, respectively).

Table 24. Limiting surface-normal velocity $\left(\mathrm{m} \mathrm{s}^{-1}\right)$ for conditions with flowing water.

\begin{tabular}{|c|c|c|c|c|c|c|c|c|}
\hline \multirow{2}{*}{$\begin{array}{l}\text { Objective } \\
\text { Lens }\end{array}$} & \multirow{2}{*}{ 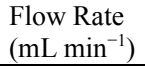 } & \multicolumn{6}{|c|}{ No. of Holograms } & \multirow{2}{*}{$\begin{array}{l}\text { Recommended } \\
\text { Limit }^{\mathrm{a}}\end{array}$} \\
\hline & & 5 & 10 & 20 & 30 & 50 & 100 & \\
\hline \multirow{3}{*}{$\begin{array}{l}20 \times \\
\text { Immersion }\end{array}$} & 0 & $10^{-11.9}$ & $10^{-11.8}$ & $10^{-11.9}$ & $10^{-12.1}$ & $10^{-11.7}$ & $10^{-11.9}$ & $10^{-11.7}$ \\
\hline & 15 & $10^{-12.0}$ & $10^{-12.0}$ & $10^{-12.1}$ & $10^{-12.1}$ & $10^{-11.9}$ & $10^{-11.9}$ & $10^{-11.9}$ \\
\hline & 62 & $10^{-11.9}$ & $10^{-12.1}$ & $10^{-12.1}$ & $10^{-11.8}$ & $10^{-11.7}$ & $10^{-11.8}$ & $10^{-11.7}$ \\
\hline \multirow{2}{*}{$\begin{array}{l}40 \times \\
\text { Immersion }\end{array}$} & 0 & $10^{-12.0}$ & $10^{-12.3}$ & $10^{-11.9}$ & $10^{-12.1}$ & $10^{-11.8}$ & $10^{-12.3}$ & $10^{-11.8}$ \\
\hline & 62 & $10^{-11.9}$ & $10^{-12.1}$ & $10^{-11.9}$ & $10^{-12.2}$ & $10^{-12.0}$ & $10^{-12.2}$ & $10^{-11.9}$ \\
\hline \multirow{4}{*}{$\begin{array}{l}5 \times \\
\text { Window }\end{array}$} & 0 & $10^{-12.0}$ & $10^{-12.1}$ & $10^{-11.8}$ & $10^{-11.7}$ & $10^{-11.7}$ & $10^{-11.7}$ & $10^{-11.7}$ \\
\hline & 15 & $10^{-11.5}$ & $10^{-12.1}$ & $10^{-11.5}$ & $10^{-11.4}$ & $10^{-11.9}$ & $10^{-11.5}$ & $10^{-11.4}$ \\
\hline & 33 & $10^{-11.2}$ & $10^{-11.2}$ & $10^{-11.1}$ & $10^{-11.3}$ & $10^{-11.5}$ & $10^{-11.1}$ & $10^{-11.1}$ \\
\hline & 70 & $10^{-11.5}$ & $10^{-11.4}$ & $10^{-11.4}$ & $10^{-11.5}$ & $10^{-11.6}$ & $10^{-11.4}$ & $10^{-11.4}$ \\
\hline \multirow{3}{*}{$\begin{array}{l}10 \times \\
\text { Window }\end{array}$} & 33 & $10^{-11.5}$ & $10^{-11.6}$ & $10^{-11.5}$ & $10^{-11.6}$ & $10^{-11.8}$ & $10^{-11.8}$ & $10^{-11.5}$ \\
\hline & 70 & $10^{-11.5}$ & $10^{-11.5}$ & $10^{-11.7}$ & $10^{-11.6}$ & $10^{-11.8}$ & $10^{-11.7}$ & $10^{-11.5}$ \\
\hline & 109 & $10^{-11.8}$ & $10^{-11.5}$ & $10^{-11.7}$ & $10^{-11.8}$ & $10^{-11.7}$ & $10^{-11.9}$ & $10^{-11.5}$ \\
\hline \multirow{5}{*}{$\begin{array}{l}20 \times \\
\text { Window }\end{array}$} & 0 & $10^{-11.9}$ & $10^{-12.0}$ & $10^{-12.1}$ & $10^{-12.0}$ & $10^{-12.2}$ & $10^{-11.9}$ & $10^{-11.9}$ \\
\hline & 15 & $10^{-11.6}$ & $10^{-11.7}$ & $10^{-11.6}$ & $10^{-11.6}$ & $10^{-11.6}$ & $10^{-11.7}$ & $10^{-11.6}$ \\
\hline & 33 & $10^{-11.5}$ & $10^{-11.8}$ & $10^{-11.7}$ & $10^{-11.7}$ & $10^{-11.7}$ & $10^{-11.2}$ & $10^{-11.2}$ \\
\hline & 70 & $10^{-11.6}$ & $10^{-11.6}$ & $10^{-11.5}$ & $10^{-11.8}$ & $10^{-11.4}$ & $10^{-11.5}$ & $10^{-11.4}$ \\
\hline & 109 & $10^{-11.3}$ & $10^{-11.1}$ & $10^{-11.4}$ & $10^{-11.0}$ & $10^{-11.2}$ & $10^{-11.2}$ & $10^{-11.0}$ \\
\hline
\end{tabular}

${ }^{\mathrm{a}}$ Based on a $5 \%$ difference

The discussion of these simulated data has so far been concerned with temporally and spatially averaged data. The temporal averaging was the result of the assumed averaging of 10 holograms, and the spatial averaging occurred as the mean surface height per time step (e.g., Fig. 27). However, these analyses are only applicable to experiments with only one reaction occurring (e.g., only dissolution, precipitation, or growth). Some mineralogical systems react through a coupled dissolution-precipitation reaction [59], which means that the temporal phase data from the DHM would indicate that certain pixels or local groups of pixels would have a negative $v_{\mathrm{s}}$ (i.e., dissolution), while others would have a positive $v_{\mathrm{s}}$ (i.e., precipitation). For an example, consider an experiment on a mineral surface experiencing coupled precipitation (known $v_{\mathrm{s}, \text { precipitation }}=10^{-11.9}$ ) and dissolution (known $v_{\mathrm{s}, \text { dissolution }}$ is 1.5 times the precipitation velocity), where a $20 \times$ immersion lens is used with a $15 \mathrm{~mL} \mathrm{~min}^{-1}$ flow rate, and 10 holograms are collected every minute. Applying the uncertainty as before, the "measured" $v_{\mathrm{s}}$ values are determined on a per pixel basis (i.e., for every pixel, the slope of height over time is determined), which actually yields a distribution of values, as shown in Fig. 28. The mean surface-normal precipitation and dissolution velocities are $\left(10^{-11.91} \pm 10^{-14.64}\right)$ $\mathrm{m} \mathrm{s}^{-1}$ and $\left(-10^{-10.73} \pm 10^{-14.46}\right) \mathrm{m} \mathrm{s}^{-1}$, respectively, both of which are $2.3 \%$ different from the known 
velocity. Therefore, the mean values are comparable ${ }^{10}$ between the simulated minerals experiencing pure dissolution, precipitation, or growth and those experiencing coupled dissolution-precipitation, so the surface-normal velocity limits in Table 24 are valid for coupled dissolution-precipitation experiments as well.

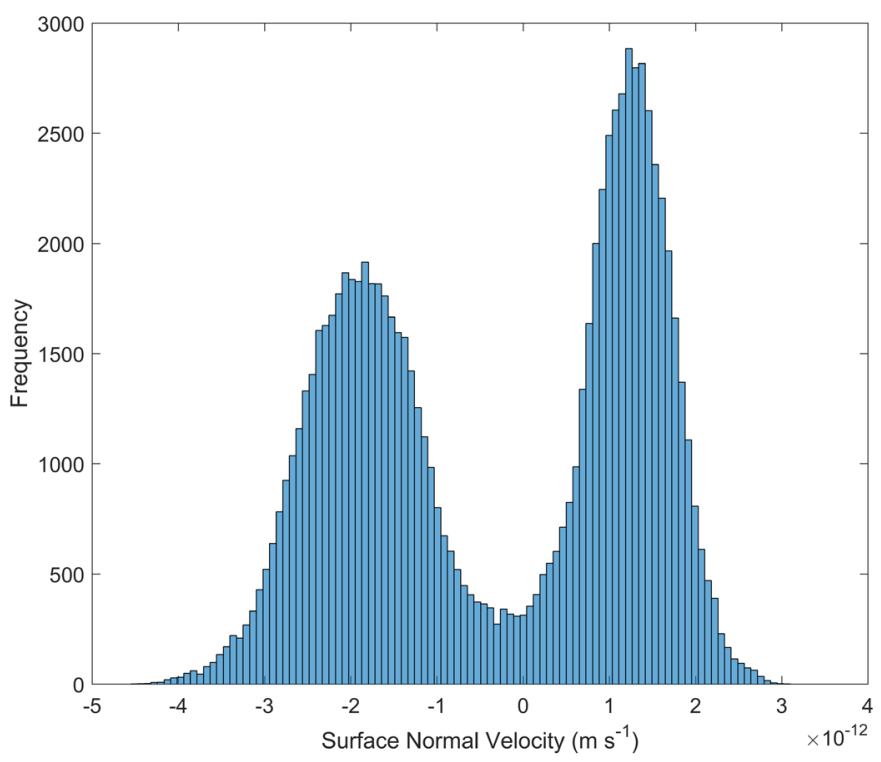

Fig. 28. Simulated surface-normal velocity results for a mineral experiencing a coupled dissolution-precipitation reaction. Note: all values are nonzero, despite the histogram bins overlapping zero.

\section{Summary and Conclusions}

Type A uncertainty was quantified in this study for measurements conducted with a digital holographic microscope considering various experimental configurations, including objective lens magnification, objective lens type (air objective and immersion objective), measurement medium (air and water), and flowing water conditions. The findings suggest that the uncertainty has a non-normal distribution of values, with mean values of $\leq 0.5 \mathrm{~nm}$ up to $40 \times$ magnification for measurements in air and in static water (immersion lens). With increasing water flow rates, the mean uncertainty was found to be $\leq 0.6 \mathrm{~nm}$ up to $40 \times$ magnification with an immersion lens. For measurements conducted through a glass window up to $20 \times$ magnification, the mean uncertainty was $\leq 0.7 \mathrm{~nm}$ in static water conditions, $\leq 1.0 \mathrm{~nm}$ in slow-flowing water, and $\leq 2.4 \mathrm{~nm}$ in fast-flowing water. The acquisition rate did not significantly impact the uncertainty when varied from $25 \mathrm{~s}^{-1}$ to $12.5 \mathrm{~s}^{-1}$. Collecting holograms in single-wavelength versus dual-wavelength modes did impact the uncertainty, where mean uncertainty at $10 \times$ magnification was $\leq 0.5 \mathrm{~nm}$ from the single-wavelength mode compared to $\leq 1.5 \mathrm{~nm}$ from the dual-wavelength mode.

Based on the uncertainties quantified in this study, limitations are posited for allowable average changes in surface topography in a given time step that can be confidently measured. For example, for a hypothetical dissolving (or growing) mineral surface examined with an immersion lens in flowing water conditions, surface topography changes need to be $\geq 10^{-11.7} \mathrm{~m} \mathrm{~s}^{-1}$ in order to be confident that the measured height changes are not significantly (i.e., differ by more than $5 \%$ ) affected by the inherent uncertainty. Similarly, in a configuration with a glass window, the surface topography changes need to be

${ }^{10}$ It can also be noted that the standard error is lower for these data compared to Table 22, which is expected given the larger number of samples examined in this simulation. 
$\geq 10^{-11.7} \mathrm{~m} \mathrm{~s}^{-1}, \geq 10^{-11.4} \mathrm{~m} \mathrm{~s}^{-1}$, and $\geq 10^{-11.0} \mathrm{~m} \mathrm{~s}^{-1}$ for conditions with static $\left(0 \mathrm{~mL} \mathrm{~min}{ }^{-1}\right)$, slow $(\leq 15 \mathrm{~mL}$ $\left.\min ^{-1}\right)$, and fast $\left(\leq 109 \mathrm{~mL} \mathrm{~min}^{-1}\right)$ water flow conditions, respectively.

The uncertainty characterized in this study can be used to further develop experimental designs and methodologies. For example, based on the expected dissolution rate of a given mineral, the experimental conditions of the DHM can be modified such that the effects of uncertainty in the measurement are minimized. In addition, these uncertainty data are needed in order to have confidence in the phase output provided by the DHM and in the data produced (such as computed dissolution fluxes) in the postprocessing analyses.

\section{Acknowledgments}

The author would like to acknowledge Adam Pintar (NIST) for his helpful discussion of the applicability of various statistical tests, Jeffrey W. Bullard (NIST) and Pan Feng (Southeast University) for their helpful discussions, Tristan Colomb (Lyncée Tec) and additional anonymous reviewers for their helpful comments and recommendations, and Jay Brandenburg (NIST) for fabrication of the reaction cell. The author would like to acknowledge the National Research Council for support through the NRC Postdoctoral Research Associateship Program at NIST.

\section{References}

[1] Yu X, Hong J, Liu C, Kim MK (2014) Review of digital holographic microscopy for three-dimensional profiling and tracking. Optical Engineering 53(11):112306. https://doi.org/10.1117/1.OE.53.11.112306

[2] Charrière F, Kühn J, Colomb T, Montfort F, Cuche E, Emery Y, Weible K, Marquet P, Depeursinge C (2006) Characterization of microlenses by digital holographic microscopy. Applied Optics 45(5):829-835. https://doi.org/10.1364/AO.45.000829

[3] Kemper B, von Bally G (2008) Digital holographic microscopy for live cell applications and technical inspection. Applied Optics 47(4):A52-A61. https://doi.org/10.1364/AO.47.000A52

[4] De Nicola S, Ferraro P, Finizio A, Coppola G, Iodice M, De Natale P, Chiarini M (2004) Surface topography of microstructures in lithium niobate by digital holographic microscopy. Measurement Science and Technology 15(5):961-968. https://doi.org/10.1088/0957-0233/15/5/026

[5] Coppola G, Ferraro P, Iodice M, De Nicola S, Finizio A, Grilli S (2004) A digital holographic microscope for complete characterization of microelectromechanical systems. Measurement Science and Technology 15(3):529-539. https://doi.org/10.1088/0957-0233/15/3/005

[6] Shi H, Fu Y, Quan C, Tay CJ, He X (2009) Vibration measurement of a micro-structure by digital holographic microscopy. Measurement Science and Technology 20(6):65301. https://doi.org/10.1088/0957-0233/20/6/065301

[7] Emery Y, Aspert N, Marquet F (2012) Dynamical topography measurements of MEMS up to $25 \mathrm{MHz}$, through transparent window, and in liquid by digital holographic microscope (DHM). AIP Conference Proceedings 1457:71-77. https://doi.org/10.1063/1.4730544

[8] Dubois F, Callens N, Yourassowsky C, Hoyos M, Kurowski P, Monnom O (2006) Digital holographic microscopy with reduced spatial coherence for three-dimensional particle flow analysis. Applied Optics 45(5):864-871. https://doi.org/10.1364/AO.45.000864

[9] Verrier N, Fournier C, Fournel T (2015) 3D tracking the Brownian motion of colloidal particles using digital holographic microscopy and joint reconstruction. Applied Optics 54(16):4996-5002. https://doi.org/10.1364/AO.54.004996

[10] Langehanenberg P, Ivanova L, Bernhardt I, Ketelhut S, Vollmer A, Dirksen D, Georgiev G, von Bally G, Kemper B (2015) Automated three-dimensional tracking of living cells by digital holographic microscopy. Journal of Biomedical Optics 14(1):14018. https://doi.org/10.1117/1.3080133

[11] Rappaz B, Cano E, Colomb T, Kühn J, Depeursinge C, Simanis V, Magistretti PJ, Marquet P (2014) Noninvasive characterization of the fission yeast cell cycle by monitoring dry mass with digital holographic microscopy. Journal of Biomedical Optics 14(3):34049. https://doi.org/10.1117/1.3147385

[12] Boss D, Kühn J, Jourdain P, Depeursinge C, Magistretti PJ, Marquet P (2013) Measurement of absolute cell volume, osmotic membrane water permeability, and refractive index of transmembrane water and solute flux by digital holographic microscopy. Journal of Biomedical Optics 18(3):36007. https://doi.org/10.1117/1.JBO.18.3.036007

[13] Brand AS, Feng P, Bullard JW (2017) Calcite dissolution rate spectra measured by in situ digital holographic microscopy. Geochimica et Cosmochimica Acta in review.

[14] Feng P, Brand AS, Chen L, Bullard JW (2017) In situ nanoscale observations of gypsum dissolution by digital holographic microscopy. Chemical Geology in review.

[15] Abbott AP, Azam M, Ryder KS, Saleem S (2013) In situ electrochemical digital holographic microscopy; a study of metal electrodeposition in deep eutectic solvents. Analytical Chemistry 85(14):6653-6660. https://doi.org/10.1021/ac400262c

[16] Mir M, Bhaduri B, Wang R, Zhu R, Popescu G (2012) Quantitative Phase imaging. Progress in Optics, Vol. 57, ed Wolf E (Elsevier, Amsterdam), pp 133-217. https://doi.org/10.1016/B978-0-44-459422-8.00003-5 
[17] Marquet P, Depeursinge C, Magistretti PJ (2013) Exploring neural cell dynamics with digital holographic microscopy. Annual Review of Biomedical Engineering 15:407-431. https://doi.org/10.1146/annurev-bioeng-071812-152356

[18] Kim MK (2010) Applications of digital holography in biomedical microscopy. Journal of the Optical Society of Korea 14(2):77-89. https://doi.org/10.3807/JOSK.2010.14.2.077

[19] Cuche E, Marquet P, Depeursinge C (1999) Simultaneous amplitude-contrast and quantitative phase-contrast microscopy by numerical reconstruction of Fresnel off-axis holograms. Applied Optics 38(34):6994-7001. https://doi.org/10.1364/AO.38.006994

[20] Schnars U, Jüptner WPO (2002) Digital recording and numerical reconstruction of holograms. Measurement Science and Technology 13(9):R85-R101. https://doi.org/10.1088/0957-0233/13/9/201

[21] Kim MK (2010) Principles and techniques of digital holographic microscopy. SPIE Reviews 1:18005. https://doi.org/10.1117/6.0000006

[22] Kühn J, Charrière F, Colomb T, Cuche E, Montfort F, Emery Y, Marquet P, Depeursinge C (2008) Axial sub-nanometer accuracy in digital holographic microscopy. Measurement Science and Technology 19(7):74007. https://doi.org/10.1088/0957-0233/19/7/074007

[23] Charrière F, Colomb T, Montfort F, Cuche E, Marquet P, Depeursinge C (2006) Shot-noise influence on the reconstructed phase image signal-to-noise ratio in digital holographic microscopy. Applied Optics 45(29):7667-7673. https://doi.org/10.1364/AO.45.007667

[24] Charrière F, Rappaz B, Kühn J, Colomb T, Marquet P, Depeursinge C (2007) Influence of shot noise on phase measurement accuracy in digital holographic microscopy. Optics Express 15(14):8818-8831. https://doi.org/10.1364/OE.15.008818 Pandey N, Hennelly B (2011) Effect of additive noise on phase measurement in digital holographic microscopy. $3 D$ Research 2(1):1-6. https://doi.org/10.1007/3DRes.01(2011)6

[26] León-Rodríguez M, Rodríguez-Vera R, Rayas JA, Calixto S (2012) High topographical accuracy by optical shot noise reduction in digital holographic microscopy. Journal of the Optical Society of America A 29(4):498-506. https://doi.org/10.1364/JOSAA.29.000498

[27] Pan F, Xiao W, Liu S, Rong L (2013) Application of three-dimensional spatial correlation properties of coherent noise in phase noise suppression for digital holographic microscopy. Optics and Laser Technology 51:67-71. https://doi.org/10.1016/j.optlastec.2013.03.022

[28] Hosseini P, Zhou R, Kim Y-H, Peres C, Diaspro A, Kuang C, Yaqoob Z, So PTC (2016) Pushing phase and amplitude sensitivity limits in interferometric microscopy. Optics Letters 41(7):1656-1659. https://doi.org/10.1364/OL.41.001656 Poittevin J, Picart P, Gautier F, Pezerat C (2015) Quality assessment of combined quantization-shot-noise-induced decorrelation noise in high-speed digital holographic metrology. Optics Express 23(24):30917-30932. https://doi.org/10.1364/OE.23.030917

[30] Colomb T, Cuche E, Charrière F, Kühn J, Aspert N, Montfort F, Marquet P, Depeursinge C (2006) Automatic procedure for aberration compensation in digital holographic microscopy and applications to specimen shape compensation. Applied Optics 45(5):851-863. https://doi.org/10.1364/AO.45.000851

[31] Colomb T, Kühn J, Charrière F, Depeursinge C, Marquet P, Aspert N (2006) Total aberrations compensation in digital holographic microscopy with a reference conjugated hologram. Optics Express 14(10):4300-4306. https://doi.org/10.1364/OE.14.004300

[32] Kühn J, Colomb T, Montfort F, Charrière F, Emery Y, Cuche E, Marquet P, Depeursinge C (2007) Real-time dualwavelength digital holographic microscopy with a single hologram acquisition. Optics Express 15(12):7231-7242. https://doi.org/10.1364/OE.15.007231

[33] de Groot P, Kishner S (1991) Synthetic wavelength stabilization for two-color laser-diode interferometry. Applied Optics 30(28):4026-4033. https://doi.org/10.1364/AO.30.004026

[34] Gass J, Dakoff A, Kim MK (2003) Phase imaging without $2 \pi$ ambiguity by multiwavelength digital holography. Optics Letters 28(13):1141-1143. https://doi.org/10.1364/ol.28.001141

[35] Vaseghi SV (2008) Advanced Digital Signal Processing and Noise Reduction (John Wiley and Sons, West Sussex), 4th Ed.

[36] Nomura T, Okamura M, Nitanai E, Numata T (2008) Image quality improvement of digital holography by superposition of reconstructed images obtained by multiple wavelengths. Applied Optics 47(19):D38-D43. https://doi.org/10.1364/AO.47.000D38

[37] Quan C, Kang X, Tay CJ (2007) Speckle noise reduction in digital holography by multiple holograms. Optical Engineering 46(11):115801. https://doi.org/10.1117/1.2802060

[38] Lyncée Tec (2017) Reflection DHM: R2200 Series. https://www.lynceetec.com/reflection-dhm/ [Accessed February 14, 2017].

[39] Colomb T, Krivec S, Hutter H, Akatay AA, Pavillon N, Montfort F, Cuche E, Kühn J, Depeursinge C, Emery Y (2010) Digital holographic reflectometry. Optics Express 18(4):3719-3731. https://doi.org/10.1364/OE.18.003719

[40] Debnath SK, Kothiyal MP, Schmit J, Hariharan P (2006) Spectrally resolved phase-shifting interferometry of transparent thin films: sensitivity of thickness measurements. Applied Optics 45(34):8636-8640. https://doi.org/10.1364/AO.45.008636 Rakić AD, Djurišić AB, Elazar JM, Majewski ML (1998) Optical properties of metallic films for vertical-cavity optoelectronic devices. Applied Optics 37(22):5271-5283. https://doi.org/10.1364/AO.37.005271

[42] Lozanova V, Lalova A, Soserov L, Todorov R (2014) Optical and electrical properties of very thin chromium films for optoelectronic devices. Journal of Physics: Conference Series 514:12003. https://doi.org/10.1088/1742-6596/514/1/012003 Rauf A, Ahmed K, Nasim F, Khan AN, Gul A (2016) Optical and structural properties of Cr and Ag thin films deposited on glass substrate. IOP Conference Series: Materials Science and Engineering 146:12013. https://doi.org/10.1088/1757$899 X / 146 / 1 / 012013$

[44] Wang S, Lin H, Bor H, Tsai Y, Wei C (2011) Characterization of chromium thin films by sputter deposition. Journal of Alloys and Compounds 509(41):10110-10114. https://doi.org/10.1016/j.jallcom.2011.08.052

[45] JCGM 100 (2008) Evaluation of measurement data-Guide to the expression of uncertainty in measurement (Joint 
Committee for Guides in Metrology, Bureau International des Poids et Mesures, Sèvres, France). Available at: http://www.bipm.org/ [Accessed November 29, 2016].

[46] NIST/SEMATECH (2013) NIST/SEMATECH e-Handbook of Statistical Methods (National Institute of Standards and Technology, Gaithersburg, Maryland). http://www.itl.nist.gov/div898/handbook [Accessed February 14, 2017].

[47] Bartoszyński R, Niewiadomska-Bugaj M (1996) Probability and Statistical Inference (Wiley, New York).

[48] Parshall D, Kim MK (2006) Digital holographic microscopy with dual-wavelength phase unwrapping. Applied Optics 45(3):451-459. https://doi.org/10.1364/AO.45.000451

[49] Clark DC, Kim MK (2016) Extended synthetic wavelength phase imaging by multiwavelength digital holography. Proceedings of the SPIE 9718:9718Q. https://doi.org/10.1117/12.2216880

[50] Mann CJ, Bingham PR, Paquit VC, Tobin KW (2008) Quantitative phase imaging by three-wavelength digital holography. Optics Express 16(13):9753-9764. https://doi.org/10.1364/OE.16.009753

[51] Redding B, Davis A, Kirkendall C, Dandridge A (2016) The influence of underwater turbulence on optical phase measurements. Proceedings of the SPIE 9827:982707. https://doi.org/10.1117/12.2230203

[52] León-Rodríguez M, Rodríguez-Vera R, Rayas JA, Flores-Moreno JM (2013) One-shot dual-wavelength in-line digital holographic microscopy. Optics and Lasers in Engineering 51(7):883-889. https://doi.org/10.1016/j.optlaseng.2013.02.005

[53] Kosmeier S, Langehanenberg P, von Bally G, Kemper B (2012) Reduction of parasitic interferences in digital holographic microscopy by numerically decreased coherence length. Applied Physics B 106(1):107-115. https://doi.org/10.1007/s00340011-4667-0

[54] Lüttge A, Bolton EW, Lasaga AC (1999) An interferometric study of the dissolution kinetics of anorthite: The role of reactive surface area. American Journal of Science 299:652-678. https://doi.org/10.2475/ajs.299.7-9.652

[55] Luttge A, Arvidson RS (2010) Reactions at surfaces: A new approach integrating interferometry and kinetic simulations. Journal of the American Ceramic Society 93(11):3519-3530. https://doi.org/10.1111/j.1551-2916.2010.04141.x

[56] Arvidson RS, Ertan IE, Amonette JE, Luttge A (2003) Variation in calcite dissolution rates: A fundamental problem? Geochimica et Cosmochimica Acta 67(9):1623-1634. https://doi.org/10.1016/S0016-7037(02)01177-8

[57] Asta MP, Cama J, Soler JM, Arvidson RS, Lüttge A (2008) Interferometric study of pyrite surface reactivity in acidic conditions. American Mineralogist 93(4):508-519. https://doi.org/10.2138/am.2008.2685

[58] Kurganskaya I, Arvidson RS, Fischer C, Luttge A (2012) Does the stepwave model predict mica dissolution kinetics? Geochimica et Cosmochimica Acta 97:120-130. https://doi.org/10.1016/j.gca.2012.08.033

[59] Ruiz-Agudo E, Putnis C V, Putnis A (2014) Coupled dissolution and precipitation at mineral-fluid interfaces. Chemical Geology 383:132-146. https://doi.org/10.1016/j.chemgeo.2014.06.007

[60] Sung Y, Lue N, Hamza B, Martel J, Irimia D, Dasari RR, Choi W, Yaqoob Z, So P (2014) Three-dimensional holographic refractive-index measurement of continuously flowing cells in a microfluidic channel. Physical Review Applied 1:14002. https://doi.org/10.1103/PhysRevApplied.1.014002

[61] Paturzo M, Finizio A, Memmolo P, Puglisi R, Balduzzi D, Galli A, Ferraro P (2012) Microscopy imaging and quantitative phase contrast mapping in turbid microfluidic channels by digital holography. Lab on a Chip 12:3073-3076. https://doi.org/10.1039/C2LC40114B

[62] Bianco V, Paturzo M, Finizio A, Calabuig A, Javidi B, Ferraro P (2014) Clear microfluidics imaging through flowing blood by digital holography. IEEE Journal of Selected Topics in Quantum Electronics 20(3):6801507. https://doi.org/10.1109/JSTQE.2013.2286075

[63] Pandiyan VP, John R (2016) Optofluidic bioimaging platform for quantitative phase imaging of lab on a chip devices using digital holographic microscopy. Applied Optics 55(3):A54-A59. https://doi.org/10.1364/AO.55.000A54

[64] Roitshtain D, Turko NA, Javidi B, Shaked NT (2016) Flipping interferometry and its application for quantitative phase microscopy in a micro-channel. Optics Letters 41(10):2354-2357. https://doi.org/10.1364/OL.41.002354

About the author: Alexander S. Brand, Ph.D., is in the Materials and Structural Systems Division of the Engineering Laboratory at NIST, where he started in January 2016 as a National Research Council Postdoctoral Research Associate. He received his Ph.D. in civil engineering from the University of Illinois at Urbana-Champaign in December 2015. His research interests focus on the materials science, microstructure development, and reaction kinetics of cementitious materials.

The National Institute of Standards and Technology is an agency of the U.S. Department of Commerce. 